\title{
THE DAIRY ORACLE: A CULTURAL AND DESIGN EXPLORATION OF NEW ZEALAND DAIRY
}

\author{
LILY NICHOLS
}

\begin{abstract}
A 90 point thesis submitted to the Victoria University of Wellington in fulfilment of the requirements for the degree of Master of Design Innovation
\end{abstract}

Victoria University of Wellington

2021 


\section{ACKNOWLEDGMENTS}

I would like to express my deepest appreciation to my inspiring supervisor, Dr. Anne Galloway. This research portfolio would not have been possible without her constant encouragement, guidance and feedback. I am grateful for the knowledge she was shared with me, and the time she has taken to help me achieve my goals.

A special thanks to my research participants, Glen Herud and Chris Falconer for sharing their knowledge and stories with me. Their participation was invaluable to the development of this research. I would also like to extend my thanks to Madi Mañetto Quick for her assistance as my note-taker.

Lastly, I would like to thank my family and friends for their constant encouragement. Their advice, kind words and reassurance helped me reach the finish line. 


\section{ABSTRACT}

The intensification and expansion of New Zealand's dairy industry has caused animal welfare and environmental sustainability issues to arise. Animal welfare issues directly impact the physical and mental wellbeing of cattle, and environmental sustainability issues contribute to climate change, impact human and animal health and cause biodiversity loss. As the first step to creating a better world for dairy cattle and sustaining the environment for future generations, this research investigates how cultural and design research can be used to understand what New Zealand dairy is today and imagine what it could become in the future. Semi-structured interviews and an observational site visit were conducted with the Happy Cow Milk Company founder and one of their dairy farmers. The interviews and site visit focused on developing an understanding of the participant's values, their relationships with their cows and the land, and how they address their dairy farming concerns through their farming practices. This cultural research provided insight into what the participants considered the most significant animal welfare and environmental sustainability issues in New Zealand and how these issues could be addressed through alternative dairy farming practices and farmer, cattle, and environmental relationships. The cultural research then inspired the development of the experimental discursive prototype, The Dairy Oracle. This prototype aims to prompt discussion around existing understandings of New Zealand dairy farming and spark imagination around the future possibilities of dairy farming. It was tested at a local farmers' market to investigate its potential. The findings from the event reflect and discuss how The Dairy Oracle was engaged with by shoppers at the farmers' market, its potential to address the design objectives, and how it could be developed in future research. 
1.0. Introduction

1.1. Portfolio Layout

Chapter 2: Background

2.0. Cultural Research: Literature Review 9

2.1. Cultural Research: Case Study 13

2.2. Design Research: Literature Review 15

2.3. Design Research: Research-through-design

Chapter 3: The Happy Cow Milk Company

3.0. Case Study: Research Process

3.1. Happy Cow Milk: Making a Difference to Dairy

3.2. Discussion

Chapter 4: The Dairy Oracle

4.0. Designing the Dairy Oracle

4.1. Testing the Dairy Oracle

4.2. Dicussion

Chapter 5: Conclusions

5.0 Conclusions

References

Reference List 
CHAPTER 1.

INTRODUCTION

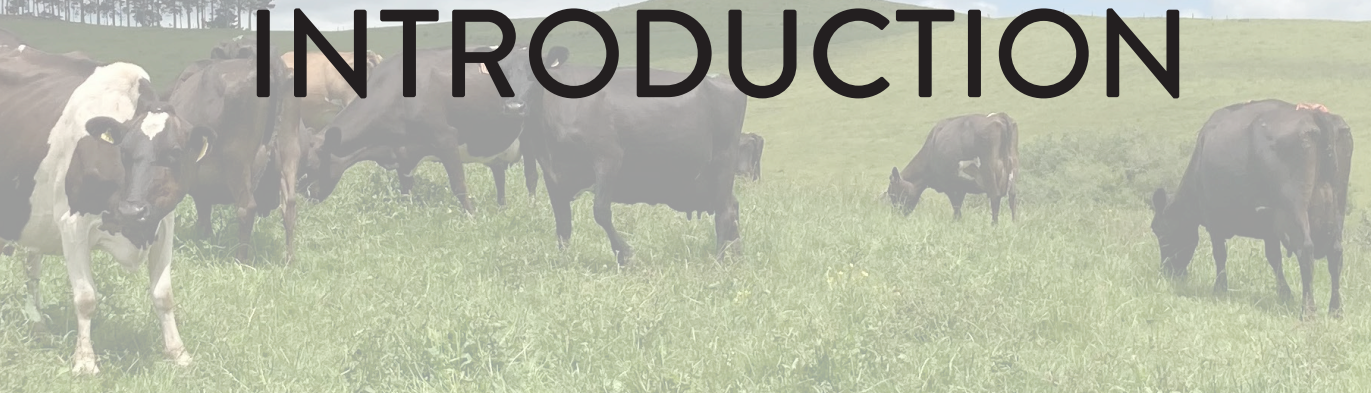


Like many people who live in urban areas, my only interaction with dairy cattle has been through the consumption of their milk, or when I pass them as I drive through rural areas. On road trips, I enjoy watching the cows graze, rest, socialise and walk to or from their afternoon milking. I grew up with the assumption that dairy cattle lived happy lives, however, as I grew older I learnt that was not always true. The impact intensive dairy farming has on animal welfare and environmental sustainability was introduced to me through discourse on social media. The discourse was confronting and overwhelming. The relationships that humans have with nonhuman animals and the environment influences how we perceive and treat them. As I engaged with the discourse around welfare and sustainability, I began to question the relationships we, as an industrialised society, had formed with farmed animals and the environment. It was distant and exploitative, and I did not support it.

New Zealand is the world's largest exporter of dairy products. The industry is a significant part of the country's economy as dairy exports bring in billions of dollars each year (Statistics NZ, 2020). Over the past two decades, New Zealand's dairy industry has expanded and intensified to increase production rates. Intensive farming provides individuals with livelihoods and brings income into the local economy. However, this can come at the expense of animal welfare and environmental sustainability. Industry organisation, DairyNZ, works with dairy farmers to ensure they are incorporating animal welfare and environmental sustainability into their farm management; however, issues still arise. Breeding practices, calving problems, illness such as lameness and mastitis, and cow and calf separation are among the animal welfare issues. They have a direct impact on the mental and physical wellbeing of dairy cattle. Increased stocking rates, vegetation removal, nitrate leaching and the release of methane from cattle are among the environmental sustainability issues. These issues contribute to climate change, threaten human and animal health and cause biodiversity loss. Due to the complexity of the problem, there is no definite solution to how we might fix it. However, it is still important to generate possible solutions to gain a better understanding of the problem and aim to improve the world of those affected by the issue. (Rittel \& Webber, 1973).
It was clear to me that the issues within intensive dairy farming needed to be addressed - for the animals and the environment. However, I was finding that the only way to confront these issues was to stop consuming dairy or to stop farming. Although this is still a possible solution, I was interested in exploring alternative ways to address these issues while still supporting the continuation of ethical and sustainable dairy farming practices. Dairy is an important food source and way of life for many people. I believe when practiced ethically and sustainably, farming can open up beautiful and unique relationships between humans, farmed animals and the environment. Relationships centred around care and respect.

As my first step towards creating a better world for dairy cattle and sustaining the environment for future generations, this research aims to answer the question: how can cultural and design research be used to understand what NZ dairy is today and imagine what it could become in the future?

The two main aims of this project are to 1) investigate the cultural values, practices and relationships that impact animal welfare and environmental sustainability in dairy farming, and 2) use this cultural analysis to design and test a speculative event for public engagement.

The first part of the cultural research involves a review of relevant literature, such as farmer memoirs and interdisciplinary research. The literature review outlines the intensification of farming, investigates the impacts of intensification on cattle and the environment, and explores possible approaches to address animal welfare and environmental sustainability issues. The second part of the cultural research is a case study of New Zealand-based dairy company, the Happy Cow Milk Company. The case study involved the analysis of qualitative interviews and an observational site visit. The design research begins with another literature review where connections between political activism, and design theory and practice are explored. Research- through-design was then used to develop an experimental discursive design and event, The Dairy Oracle. Detailed findings from The Dairy Oracle event are then reflected on and discussed. 
Chapter 2: Background explores both the cultural and design literature reviews, as well as the research methods used to conduct this research. The chapter is split into two sections - cultural research and design research. The cultural research starts with the literature review which investigates dairy farming in the industrialised world. It discusses the disconnection between humans and farmed animals and how this led to the normalisation of intensive agriculture. The impacts intensive dairy farming has on cattle and the environment is discussed, followed by how scholars suggest we address animal welfare and environmental sustainability issues. A review of Happy Cow Milk's business model, and the data collection methods used in the case study are also explained in this chapter. These research methods include qualitative interviews and an observational site visit. The method used to the analyse the case study is discussed in Chapter 3: The Happy Cow Milk Company.

The second section of chapter 2 explores the design research. It begins with a literature review which first investigates the need for public engagement when addressing issues associated with dairy farming. Followed by a broad outline of the different approaches to design, the focus is then narrowed down to discursive and experimental design. Relevant design precedents are also discussed as examples of the different design approaches. Following the design literature review, the research method used to conduct the design research, researchthrough-design, is outlined. This research method is supported by descriptions of speculative and activist design, and eventful speculative design.

Chapter 3: The Happy Cow Milk Company explores the research process and findings from the case study. The first section of the chapter introduces the participants, the process of getting in contact with them, and the ethics application. The method of thematic analysis is outlined and used to analyse the interview transcripts and notes from the observational site visit. The second section of this chapter discusses the findings from the thematic analysis, this explores the participant's concerns for New Zealand dairy farming and how they are addressing these concerns through their approach to dairy. A Venn diagram is used to map the participant's values, practices and relationships in relation to farmer, cow and environmental wellbeing. Each subtheme depicted in the Venn diagram is then discussed indepth. Following this, the findings are discussed; this includes their relevance to supporting the research question, how they relate to existing literature, and how they have informed and inspired the design research.

Chapter 4: The Dairy Oracle describes the research-through-design process and critically reflects on the experimental discursive design, The Dairy Oracle. The first section of this chapter introduces the design objectives, the final prototype and how the oracle cards are used and interacted with. This is followed by an exploration of the design process, including the initial concepts and the development of the card content, imagery and layout. The second section of the chapter explores the process of setting up the design event at the local farmers' market, this includes the preparation of the reading and the discussion prompts. This is followed by a critical reflection of the event. The reflection describes the event as well as discussing how participants interacted with and responded to The Dairy Oracle. The chapter is concluded with a discussion of The Dairy Oracle prototype and event; this includes how existing knowledge supported the design process, and how The Dairy Oracle met the design objectives.

The full project is summarised and assessed in Chapter 5: Conclusions. Special attention is given to how the research question was addressed, how the research could be taken further into a PhD project and a reflection on the most rewarding and challenging aspects of the research. 


\section{CHAPTER 2.}

\section{BACKGROUND}




\subsubsection{DAIRY FARMING IN THE INDUSTRIALISED WORLD}

Urban societies in the industrialised world have grown distant from the nonhuman animals we are dependent on for food, but it has not always been this way. For tens of thousands of years, human and nonhuman animal lives have been deeply entangled. Novelist and poet Le Guin (2009) reflects on humanity's time as hunter-gathers and reminds us we were a part of the food chain - we hunted and were hunted by nonhuman animals. We also formed spiritual kinships with nonhuman animals; they were our ancestors, and we belonged with them. As humans began to settle down in villages and practice agriculture, our relationship with nonhuman animals changed into one of breeding for utility. We relied on nonhuman animals for food, drink, transport and sport. In exchange for what the animals provided, we were supposed to care for them. The give-and-take relationship formed a sense of community between humans and nonhuman animals. As humans moved into industrialisation, our relationship with nonhuman animals changed again. Some people believed we were dominant to nonhuman species and separated ourselves from them as we moved into cities. This separation made it easier to assert dominance and deny kinship with these animals. Today, the animals valuable to us for food and other needs are bred to produce as much as possible, which has led to animal welfare and environmental concerns. We remain highly dependent on these animals but may fail to recognise this because "we have made a world for ourselves alone, in which nothing matters, nothing has meaningful existence, but us." (Le Guin, 2009, p. 47).

\subsubsection{DISCONNECTION}

Two types of disconnected relationships, physical and emotional, are described in the literature. Physical disconnection is the geographical distance people in industrialised societies have from farmed animals. Velten (2007) is a researcher who has worked on British dairy farms and Australian cattle stations. Velten states that most cows are hidden away on distant farms, and most production, transport and slaughter happens behind 'closed doors'. As a result, those of us that have a physical disconnection become ignorant to cow's lives because we do not have the opportunity to interact with them, build relationships with them or understand what goes into producing milk, meat and leather. Multispecies ethnographer Gillespie (2018) acknowledges that people who live in urban areas are limited in their engagement with farmed animals. Therefore, they are unable to gain an understanding of these animals or form relationships with them. Furthermore, Gillespie brings attention to the disconnected relationship between farmers and cows, who interact daily.

Throughout Gillespie's research, she noticed that despite farmers recognising their cows as individuals with different qualities and characteristics, they still viewed the cow as a commodity and valued how efficiently they could produce more than who they were as an individual. Gillespie reflects on the way humans create hierarchies to separate themselves from other nonhuman species. Hierarchies create another barrier that restricts us from forming meaningful relationships with them. According to Gillespie, humans categorise other species depending on cultural norms. In industrialised societies, cows are categorised as 'food', which further enforces the idea that they are products for consumption. By creating this hierarchy, we are normalising the idea that cows are something that we consume. This emotional disconnection causes us to view cows as 'objects' (Velten 2007). As a result, we demand a constant supply of good quality yet reasonably priced milk, meat and leather without thinking about the consequences our consumption habits have on the lives of cows and their emotional and physical welfare.

\subsubsection{INTENSIFICATION}

Intensive farming can be defined as a farming system that requires a high input of labour and capital relative to land size (Britannica, 2017). The main objective of intensive farming is to maximise the productivity of an area of land for profitable gain. In animal agriculture, this generally means having high stocking rates which means more animals grazing on smaller areas of land. Unfortunately, when the main objective is productivity and profit, animal welfare and environmental sustainability tend to be less of a priority. 


\section{Impact on cattle:}

Velten (2007) claims that intensification and "mass production has demeaned cattle to objects" (p.156). Cows are bred and raised as cheaply as possible to get the most, economically, from what they produce. This is a consequence of the commodification of cows. Gillespie (2018) states that the commodification process has caused us to "treat animals as things to be brought, transformed into new things, and sold" (p. 15). Cows are both producers of commodities (milk) and commodities themselves (can be sold alive as producers or dead as meat and leather). The mass production of cow's bodies and extraction of their milk has become normalised in the industrialised world. As a result, intensive dairy farms became prominent to keep up with the high demand for products produced by cows. Intensive dairy farms are a significant concern, as the farming practices and living conditions on intensive farms can negatively impact animal welfare. Farmer Young (2018) claims that cows on intensive farms live in unnatural, boring and crowded conditions. This takes away their identities as individuals and causes them to become stressed and prone to disease.

Veterinarian Stafford (2013), studies the welfare of dairy cattle in New Zealand. Stafford claims that poor stockmanship and farm management can lead to animal welfare issues that cause pain and distress. These issues include lameness, disease, inadequate shelter and cow and calf separation. Stockmanship is a combination of knowledge and attitude which influences how a person treats a farmed animal. Stafford claims that dairy cattle welfare depends on good stockmanship because there is a close interaction between people and dairy cattle. The intensification of dairy in New Zealand caused an increase in herd size and dairy farm employees. Inadequate staff training, poor attitudes towards cattle and long work hours resulted in a higher chance of poor stockmanship and farm management.

Lameness is a common issue linked to intensification and poor stockmanship. It is a painful injury or disease to the sole of a cow's foot (Stafford, 2013). Intensification caused herd sizes to increase. To accommodate this, cows now walk longer distances to the milking shed and spend more time on the concrete holding yards. This can make a cow's feet prone to injury. Walking on poorly designed or managed tracks, wet and stony areas, rushing cattle to and from the milking shed, and poorly managing them in the holding yards can all increase the risk of lameness. The condition is painful for dairy cattle and can lead to reduced production, lower reproduction rates, and ultimately the affected cow could be culled (Stafford, 2013).

Inadequate shelter is also considered an animal welfare issue (Stafford, 2013). Dairy cattle in New Zealand spend most of their lives outdoors; depending on the weather, they will often seek shelter or shade.

However, intensive farming systems often lack trees, hedges and housing for shade and shelter. Cows need to have options to seek shelter from the heat of summer or the wet and cold of winter. Without these options, they can become prone to physical and mental distress. Housing cows in barns is not always the best option either, as it can lead to lameness, digital dermatitis, sole ulcers, and mastitis.

Finally, Stafford touches on the separation of cow and calf, which typically happens within 12 hours of birth. Cows bond very quickly with their calf, but when separated, individual cows respond differently some show distress, whereas others are uninterested. Young (2018) argues that separating cows from their family groups and grouping them by age and size can impacts the cow's ability to learn from other cows, particularly older generations; this suppresses the cow's natural animal instincts. Dairy cattle welfare is a sign of the standards of farming in the industry. The industry are aware of the animal welfare issues that are occurring and are putting in effort to force improvements on farms with poor animal welfare (Stafford, 2013).

\section{Impact on environment:}

Intensive dairy farming not only impacts animal welfare but also impacts environmental sustainability. Scientific literature explores the impact of intensive dairy farming on New Zealand's environment. Water, soil and air quality are among the biggest environmental concerns in New Zealand.

Freshwater ecologist Joy (2015), claims that the intensification of agriculture in New Zealand has had the greatest impact on freshwater quality, and dairying has contributed to the decline in water quality more than other agricultural practices (Foote et al., 2015; Statistics, NZ, 2019). Intensive dairy farming practices that have an impact on freshwater 
quality include increased stocking rates, grazing livestock by waterways, fertiliser application, vegetation removal, wetland damage, discharging waste from the milking sheds directly into rivers, and nitrate leaching from cow urine (Foote et al., 2015; Joy, 2015). Joy argues that nitrate leaching from cow urine has the most severe impact on freshwater health. Nitrogen is essential for plant growth. However, fertilisers and cow urine provide more nitrates than the plants and microorganisms need (Statistics, NZ, 2019). The excess nitrate leaches through the soil and eventually makes its way into the groundwater, streams, lakes and estuaries. Increased nitrate levels in waterways impact the health of the animals residing within the water, contaminates groundwater that is used as drinking water by $40 \%$ of New Zealand's population and causes toxic algae to grow, which can impact human health (Foote et al., 2015; Joy, 2015).

Intensive dairy farming also impacts soil quality - a vital aspect of farming (Joy, 2015). The application of fertilisers on pastures contaminates the soil with a heavy metal called cadmium. High levels of cadmium in the soil can impact human and animal health and threaten food security (Foote et al., 2015; Joy, 2015). Overstocking cows can also have an impact on soil quality. On intensive dairy farms, there are more cows in a smaller area, which increases the pressure in the soil, which causes it to compact. Compaction damages the soil structure and restricts root growth, negatively impacting plant productivity and reducing the number of air pockets used for water storage. This leads to soil erosion, flooding and run-off into surface waters (Foote et al., 2015). In winter, pasture growth slows down so, winter crops of kale, swedes, turnips and fodder beets are planted for cows to graze on. If winter grazing is poorly managed or overstocking occurs, the risk of soil damage increases significantly (Dairy NZ, 2019) and adds to animal welfare concerns (Stafford, 2013).

Intensive dairy farming significantly impacts air quality in New Zealand. Agriculture makes up nearly half of New Zealand's total greenhouse gas emissions (GHG), and about a quarter of that is from dairy farming (Foote et al., 2015; Ministry of the Environment, 2021). A cow's digestive process, known as enteric fermentation, produces methane, which is released into the atmosphere when a cow burps. (Baskaran et al., 2009; Ministry of the Environment, 2021). Nitrous oxide also contributes to GHG emissions; this is produced by livestock waste and excessive nitrogen fertiliser use (Baskaran et al., 2009; Foote et al., 2015).
Ultimately, importing animal feed into New Zealand is what made the intensification of the industry possible (Joy, 2015). This rapid increase in production and demand for imported animal feed has led to farther-reaching environmental issues. Imported feed is used by most dairy farms in New Zealand, mainly for grazing cows off the milking area, extending lactation periods and increasing stocking rates (Foote et al., 2015). Palm kernel extract (PKE) is an imported feed supplement that is causing environmental concerns. New Zealand is the world's largest importer of PKE (Foote et al., 2015; Joy, 2015). All of it used as cow feed in the dairy industry. PKE is the biproduct of palm oil; palm oil production causes deforestation, loss of biodiversity, and greenhouse gas emissions (Foote et al., 2015). Since PKE is a waste product, farmers rely on the heavy consumption of palm oil to maintain access to this feed.

\subsubsection{ADDRESSING ANIMAL WELFARE AND ENVIRONMENTAL SUSTAINABILITY ISSUES}

\section{Animal Welfare}

Author and farmer Young (2018), runs a small-scale beef and lamb farm in the United Kingdom. Young was introduced to farming at a young age, in 1953 her parents began a farm that consisted of 5 cows and an old tractor. At the time, financial incentives from the government pressured farmers into expanding and intensifying, but Young's parents were determined to continue farming at a smallscale "to make the lives of the animals in their care dignified and comfortable" (p.2). Through written narrative, Young shares stories involving the beef and dairy cows on her own farm, Kite's Nest Farm. Animal welfare is one of Young's top priorities. Although the cows are being raised for human consumption, they are respected as individual beings and provided space to live a dignified and comfortable life. The cows on Young's farm are given the space and freedom to succeed as cows, they are not restricted to exist only to fulfil human need. The cows are provided with an environment where they can choose what they eat, where they sleep, what they do with their day, and who they communicate or dissociate from.

Young is respectful towards the mental experiences of the animals who reside on her farm. The way Young evaluates animal welfare aligns with Mellor's (2017) Five Domain's framework. The 
framework is an assessment and management of animal welfare. It reformulates the Five Freedoms - freedom from hunger and thirst, from discomfort, from pain, injury and disease, to express natural behaviours, and from fear and distress - into the Five Domains of nutrition, environment, health, behaviour, and mental state. In New Zealand, the Five Freedoms are protected under the Animal Welfare Act and constitute the legal minimum, not the best practice. The Five Freedoms assess if an animal's basic needs have been met, whereas, the Five Domains goes a step further to assess the subjective mental experiences of an animal (Mellor, 2017).

External conditions, such as animal's living environment, can have a significant impact on their mental experiences. The person in charge of a domesticated animal dictates their external conditions, so, to create positive mental experiences for the animal the person must provide a spacious, stimulating and safe environment. This gives the animal agency and provides opportunities for the animal to engage in behaviours they find rewarding. In doing so, the animal is more likely to experience comfort, pleasure, interest and confidence, and experience feelings of being joyful, energised, sociable, secure and nurtured (Mellor, 2017).

Alongside providing animals with safe and enriching environments and respecting their mental experiences, forming meaningful humananimal relations might also play a role in addressing animal welfare issues. Feminist scholar Haraway (2018) states that "there can be no environmental justice of ecological reworlding without multispecies environmental justice and that means nurturing and inventing enduring multispecies - human and nonhuman - kindreds" (p. 102). In order to form these relations, Haraway explains that we must cultivate 'response-ability' for one another. The way I understand 'response-ability' is that we have the ability to choose how we respond to each other. Ideally this should be carried out with good intentions, kindness and care. Haraway's work also encapsulates ideas that will contribute to addressing environmental sustainability issues. Similarly, Gillespie (2018) suggests that forming humananimal relationships centred around care will be an important step towards addressing animal welfare issues. Gillespie hopes for a future of farming where humans learn from animals, and these stories are used to re-imagine what human-animal relations can be. The quality of the relationship should not be fully determined by the human, instead humans should learn from animals and hear their stories to build a relationship that is positive for both.

\section{Environmental sustainability}

When it comes to addressing environmental issues related to dairy farming, Joy (2015) states that "there is a growing awareness of the crisis we are facing and interest in how we address it. However, changing the direction of farming will not be easy" (p. 54). Joy suggests that we need to put a cost on pollution, enforce stronger legislation and raise public awareness and discussion on the issue.

Paying for the cost of environmental mitigation and repair could be an important step in addressing environmental sustainability issues Joy proposes that businesses need to pay, through taxes or levies, for their pollution, while those who are farming in a sustainable way are financially rewarded. By providing financial incentives, it is more likely that we can mitigate the impacts of dairy farming on the environment. However, covering the costs of environmental repair is going to be difficult, not least because, as Foote et al (2015) claim, the cost of cleaning up the environmental damage that dairy farming has caused is going to be more costly than not polluting in the first place.

It is important that both government and industry accept the reality of environmental degradation. If we hope to succeed in protecting biodiversity, strong legislation and the resources to support it need to be enforced (Joy, 2015). This is not an issue that only concerns the government and the industry. It is important to include the public in the discussion. Foote et al state that "there needs to be a more holistic conversation in New Zealand about whether the [dairy] industry is actually beneficial for the country: economically, environmentally, and socially" (p. 717). However, many New Zealander's are unaware of the true extent of the environmental issues due to inaccuracy of knowledge shared by the media and dairy industry (Joy, 2015). There needs to be an increase in public awareness about these issues, so the public are able to engage in well-informed conversations. To achieve this, Joy believes the government needs to release honest reports on the environmental impacts of dairy farming. 
Farming practices, human values, and the relationships between humans, dairy cattle, and the environment have a significant impact on animal welfare and environmental sustainability. To investigate this further a case study was conducted with the Happy Cow Milk Company, a New Zealand based dairy company. The case study involved reviewing the company's business model, conducting indepth qualitative interviews with Glen Herud and Chris Falconer from Happy Cow Milk Company, and visiting Chris' farm for a day.

Case studies are useful in qualitative research to gain an in-depth understanding of a single case, or to explore a specific problem or issue (Crewell, 2013). The case study with the Happy Cow Milk Company provided insight into the relationships, values, and practices of both the company and individuals within the company. It also allowed a deeper understanding of the issues surrounding intensive dairy farming in New Zealand and how the participants are addressing these issues through their farming practices.

\subsubsection{LITERATURE REVIEW: HAPPY COW MILK COMPANY}

Determined to do dairy more ethically and sustainably, thirdgeneration dairy farmer, Glen Herud, founded the Happy Cow Milk company in 2014 (Herud, 2018). Happy Cow Milk is a small New Zealand based dairy company that is $100 \%$ crowd-funded and owned. In order to bring "kindness, caring and fairness to every litre of milk" (Happy Cow Milk, n.d1), they redesigned dairy farming, processing, and distribution.

Happy Cow Milk strives to be transparent with their customers about where their milk is produced and what practices are used, so all Happy Cow farmers are encouraged to farm the 'Happy Cow Way' (Happy Cow Milk, n.d2). The 'Happy Cow Way' (Happy Cow Milk, n.d2) gives an overview of the company's values and practices. Regarding animal welfare, their policy starts with the legal requirement to meet the 'five freedoms', which ensure an animal is free from hunger, thirst, discomfort, pain, injury or disease, fear and distress, and are free to express normal behaviours. To ensure cows are free from fear and distress and can express natural behaviours, Happy Cow Milk has implemented the 'Cow and Calf policy'. They believe all calves, regardless if they are male or female, should stay with their mothers until they reach an appropriate size and no longer need milk. At around 8-10 weeks, a plastic flap clips onto the calves' nose; this encourages them to eat grass as the flap makes it difficult for them to suckle milk. After the calves become independent and no longer need milk, they are moved to a neighbouring paddock, where they can still socialise with their mother through the fence if needed. Finally, to ensure that cows are free from discomfort or distress, responsible winter grazing is practised. Cows graze on crops, but stand-off pads, sacrificed paddocks and covered barns are also available as precautions.

Regarding the environment, Happy Cow Milk works according to a simple rule: "cows put nutrients into the ground and plants take nutrients out of the ground" (Happy Cow Milk, n.d2). Farming practices that allow cows, plants, and crops to work together are supported. These practices include planting diverse pastures with herbs, legumes, and grasses and rotating crops and cows around the farm. To lower nitrate leaching and methane emissions, the 'Happy Cow Way' supports farmers having lower stocking rates, normally two cows per hectare, by paying them more per litre of milk than other dairy companies.

When it comes to processing and disruption, Happy Cow Milk designed a small-scale milk processor so that anyone can farm, sell or buy Happy Cow milk in an economical way (Happy Cow Milk, n.d3). Once the dishwasher-size machine has pasteurised the milk (figure 1), the whole machine is transported to a Happy Cow Milk vending location where customers can fill up their reusable glass bottles. A litre of Happy Cow Milk costs around \$2.50, and farmers get \$1.20 of that.

Herud has worked hard to develop an ethical, sustainable, and affordable model. There were plenty of challenges along the way, but with the moral and financial support of people who believed that dairy 


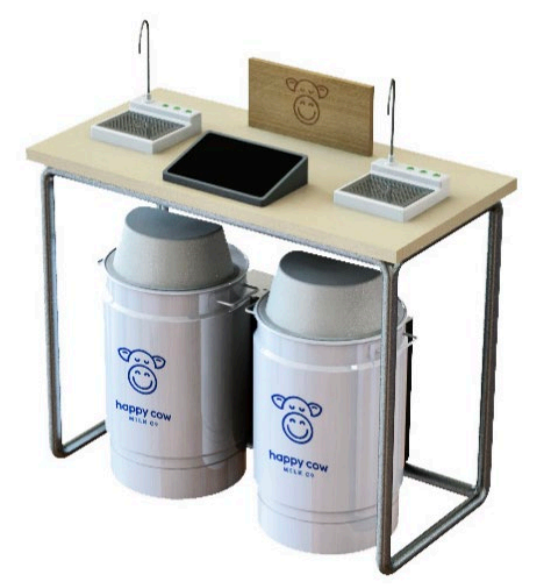

Figure 1. The Happy Cow Milk processing system (Happy Cow Milk, n.d4)

could be done differently, the model could be developed. In order to trial and refine the model, Happy Cow Milk was joined by their first farmer, Chris Falconer. It was anticipated that Falconer would start a trial with Happy Cow Milk in March 2020 (Happy Cow Milk, 2019). Falconer milks dairy cows on 250 hectares of land in North Waikato (Happy Cow Milk, 2019). He is focused on improving animal welfare, water quality, soil health, and strengthening habitats. So far, this has been achieved by once-a-day milking, calving twice-a-year, managing effluent storage and spreading, fencing waterways and damp, low-lying areas of land, and planting over 10,000 native plants (NZ Herald, 2020).

Happy Cow Milk can be seen as a response to intensive dairy farming within New Zealand. Through re-inventing the farming, processing, and distribution of dairy they are working to address the animal welfare and environmental sustainability issues that arise in intensive dairy farming. The Happy Cow Milk concept has been able to develop into a viable business model because of the moral and financial support from the public. This shows that New Zealanders want more choices than simply maintaining the status quo or abolishing dairy entirely, and many support the idea that dairy can be done differently. I was interested in investigating Happy Cow Milk further to learn more about the ways in which they address intensive dairy farming at a small-scale. Happy Cow Milk has given me hope that we can find possible solutions that are beneficial for the cows, environment, and people.

\subsubsection{QUALITATIVE INTERVIEWS}

In order to gain an understanding of the participants' lived experience, opinions, attitudes and perspectives (Hanington \& Martin 2012), in-depth qualitative interviews were conducted. Due to the uncertainty of the COVID-19 situation and the geographical distance from the participants, the interviews were held over Zoom, an online video conference platform. Individual interviews were conducted with each participant and went for approximately 1 hour each. The audio from the interviews was recorded through Zoom and later transcribed.

The interviews were semi-structured; I went in with a set of openended questions that would create space for the participants to share their knowledge and narrate their experiences (Galletta \& Cross, 2013). The questions varied slightly between the two participants, but overall, they focused on developing an understanding of what types of practices, values and relationships supported them in creating an ethical and sustainable dairy farming model (see Appendix A for interview questions).

\subsubsection{OBSERVATIONAL SITE VISIT}

A week after the interviews, I visited Chris' farm for the day; I arrived at the farm at around 10am and left around $3 \mathrm{pm}$. The intent of the visit was to observe the relationship Chris had with his cows and the land he farms on, gain a better understanding of the concepts and terms discussed throughout the interview, and talk further with Chris.

During the visit, I wrote down quick notes of things I noticed or heard from Chris that I found interesting and took photos. After the farm visit, I wrote in-depth fieldnotes of my observations, thoughts, and emotions during my time there. The time I spent at Chris' farm was brief, but it allowed me to develop a richer understanding of what life was like on Chris' farm, for the people, animals and the environment. 


\subsection{DESIGN RESEARCH: LITERATURE REVIEW}

\subsubsection{NEED FOR PUBLIC ENGAGEMENT}

Listening to public concerns and understanding their values will be an essential step in developing sustainable dairy futures. The public is becoming more interested in where their milk comes from and is often educated through undercover video documentation filmed and shared by animal rights organisations (Weary \& von Keyserlingk, 2017; Cardoso et al., 2016). These videos often depict the distressing life of cows on some intensive dairy farms around the industrialised world. The imagery in the videos causes public concerns and influences the public's opinion on dairy farming (Cardoso et al., 2016). Boogaard et al. (2011) conducted a national survey with Dutch citizens not affiliated with the dairy industry to investigate and understand their acceptance of modern dairy farming practices. They found that the public had contradicting opinions and values towards dairy farming. However, two factors of modern dairy farming were heavily scrutinised - the way sentient beings are being used for production and how a dairy farm functions as a business. With the increased public scrutiny towards dairy farming, Weary and von Keyserlingk (2017) suggest that the dairy industry needs to foster sustained engagement with consumers and the general public, this means having a two-way conversation where the dairy industry can explain farming practices and the public can voice their concerns "engaging in the substantive conversations will allow individuals within the dairy industry to better understand public concerns, and to develop practices on their farms that begin to address these concerns" (p. 1204). This conversation will only be possible if the public is open to hearing the farmer's perspective and being able to consider solutions that take this perspective into account. Furthermore, for people working within the dairy industry to consider the public's perspective, some people within the industry deem the public opinions as not legitimate (Weary \& von Keyserlingk, 2017). Weary and von Keyserlingk do not fully address how this conversation will be facilitated. However, they are confident that if people within and outside of the dairy industry communicate and consider each other's values, opinions and experiences, we can collectively find solutions to address animal welfare and environmental sustainability concerns. 


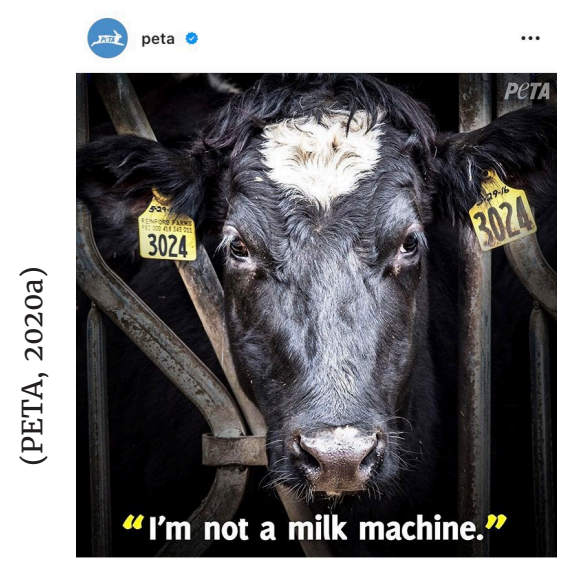

$\bigcirc \bigcirc \nabla$

$\varpi$ peta Their life is an endless cycle. They're impregnated,
their babies are taken, and they're milked over and over until
they're killed. Just so humans can steal their milk.

$$
\text { View all } 975 \text { comments }
$$

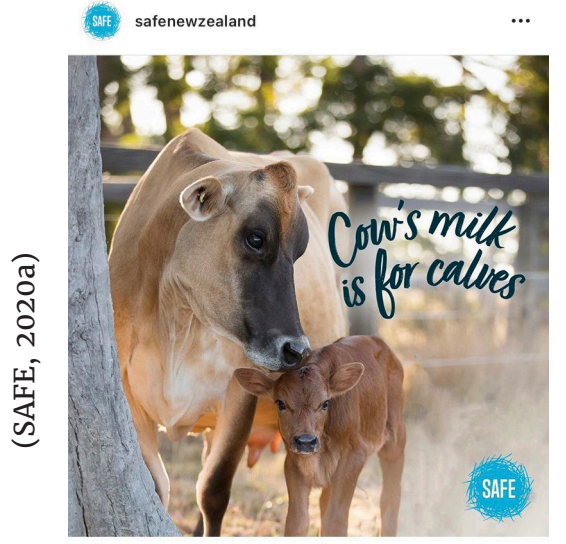

$\bigcirc \bigcirc \vee$

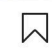

ఐ

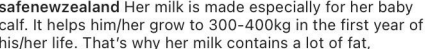

lis/her life. That's why her milk contains a lot of fat,
ormones and proteins. Just right for a calf, less suited - and

Figure 2. Instagram posts by animal rights organisations.

\subsubsection{ANIMAL RIGHTS ACTIVISM}

Political activism is a widely known form of activism, but in recent years the field of design has been engaging in activism in new ways to bring about social change. When advocating a change to agricultural farming, many animal rights organisations design graphics for social media in order to share their discourse and engage with the public. According to DeMello (2018), animal rights activists have used pictures and film to advocate for better animal treatment for a long time. They often accompany this imagery with text to express animal suffering and trigger empathetic audience responses.

Figure 2 is a collection of posts from SAFE and PETA's public Instagram accounts advocating for a change to dairy farming. Both organisation's use a similar method to what DeMello describes. PETA has a more aggressive approach to their activism than SAFE do.

PETA uses distressing imagery of cows in intensive farms to make a statement about the poor living conditions many cows have to endure. In contrast, SAFE's imagery focuses on cows with a good quality of life and are less confrontational. Although the organisations use text and imagery differently, they both advocate for a change to dairy farming. They suggest that if humans stop consuming dairy, this change can happen.

Animal rights organisations engage in political activism, which generally focuses on preventing or stopping things from happening or raising awareness about an issue. However, they generally do not discuss how this could be approached or solved beyond veganism (Thorpe, n.d)

\subsubsection{APPROACHES TO DESIGN: FOUR-FIELD FRAMEWORK}

Design educators and industrial designers Tharp and Tharp (2018) created the four-field framework to better understand the practice and intentions of product design. Tharp and Tharp saw the practice of product design as 'a bit of a mess' (p. 43) and thought it could benefit from an organisational framework. From this, the fourfield framework was developed. The framework is an approach that explores why designers design and should be seen as a practical device that assists in design decisions and communication. Based 
on the designer's intention or how their objects are understood, it attempts to make sense of reality through categorisation. The fourfield framework consists of the following agendas:

Commercial design is considered the most prevalent agenda. It is motivated by profit. The design work produced through commercial design is oriented toward and driven by the market.

Responsible design is understood as socially responsible design as it aims to help those in need. It is motivated by serving the underserved. Responsible design works to create functional and desirable products for those that the market ignores.

Experimental design is motivated by curiosity or a question. The design is used to explore, experiment and discover. Through this agenda, the process is more important than the outcome.

Discursive design encourages audience reflection through objects that carry ideas. Artifacts are embedded with or positioned as discourse and designed with the primary purpose of communication. The aim is to encourage audience reflection and initiate discussion and debate about the artifact's portrayed discourse.

This design framework is useful as it allows designers to understand and focus their project efforts and allows others to see design in new ways that stray from design's typical commercial agenda. It is important to note that designers are not confined to follow a single agenda. There are blurry boundaries between the four agendas, which allows them to be combined.

Tharp \& Tharp imagine that the four-field framework approach could be a "helpful starting point to encourage the designer's self-reflection on her intentions for the work" (p. 64) and to communicate how the design should be understood. As I reflect on the intentions of this design research, the agendas of experimental and discursive design stand out. I am curious about how design might be used for public engagement and opening up discussions about the possible ways we might address the animal welfare and environmental sustainability issues within dairy farming. The design should be understood as an object that carries ideas about dairy farming and encourages selfreflection and discussion rather than an object that has been produced for the market.

\subsubsection{DISCURSIVE AND EXPERIMENTAL DESIGN}

Tharp and Tharp (2018) focus heavily on the theory of discursive design, which underpins my research-through-design process. Discursive artifacts are tools for thinking as they raise awareness and understanding of important and debatable social issues. Communication is the primary purpose of these artifacts, and the discourse that they are embedded with is the most critical part of their being. Audience reflection is also an important aspect of discursive design. Therefore, discursive design projects, which are often presented through exhibitions, film, websites and print, are frequently designed for social engagement with the general public. Social engagement aims to inform others, bring awareness, and invite others to engage with the discourse embedded in the design.

An example of discursive design created for audience reflection is Pollution Popsicles (figure 3). Designed by Hung I-chen, Guo Yi-hui and Cheng Yu-ti, students from National Taiwan University of Arts (Tharp \& Tharp, 2018), the artifact brings attention to the impacts of water pollution in Taiwan. The collection of 100 popsicles each contain a sample from Taiwan's lakes, rivers and beaches (Neira, 2017). The materials included in the samples are plastic, metal and mercury. They are preserved in resin. This project draws attention to water pollution issues through an object that looks beautiful, even appetising, but would be deadly if consumed, much like polluted water. Through social engagement, this design works to inform the audience and raise awareness.

Discursive design can also be a tool for research. Typically in design, it is used as a form of user research. Tharp \& Tharp claim that this approach provides people with the space to talk about issues in new ways, either seriously or playfully. Discursive design's intention of getting people to reflect and respond works well to get insight into people's attitudes, beliefs and values. These insights can help progress a design process or find possible solutions to the issue addressed through the design.

When creating a discursive design for social engagement or as a research tool, it is essential that the design is well informed and framed correctly. Tharp and Tharp state that "poorly informed and framed discursive work is a waste of the audience's time and energy 


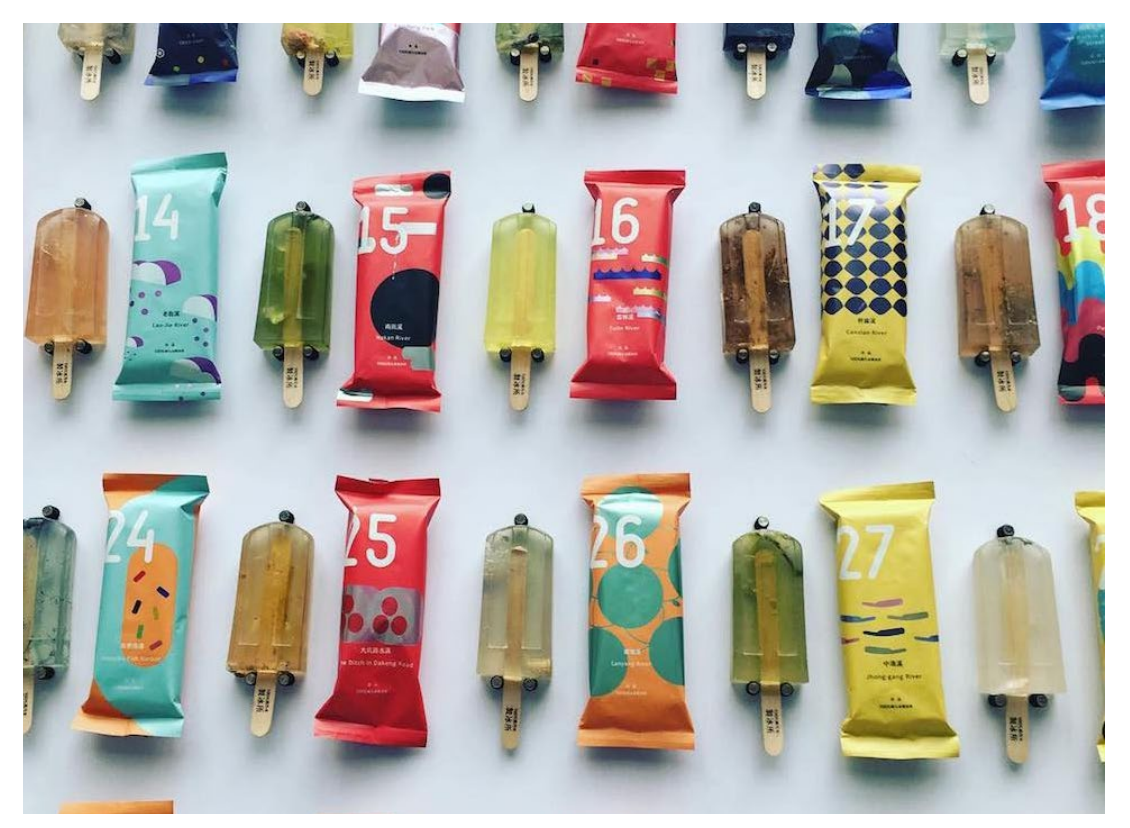

Figure 3. Pollution Popsicles (Sierzputowski, 2017)

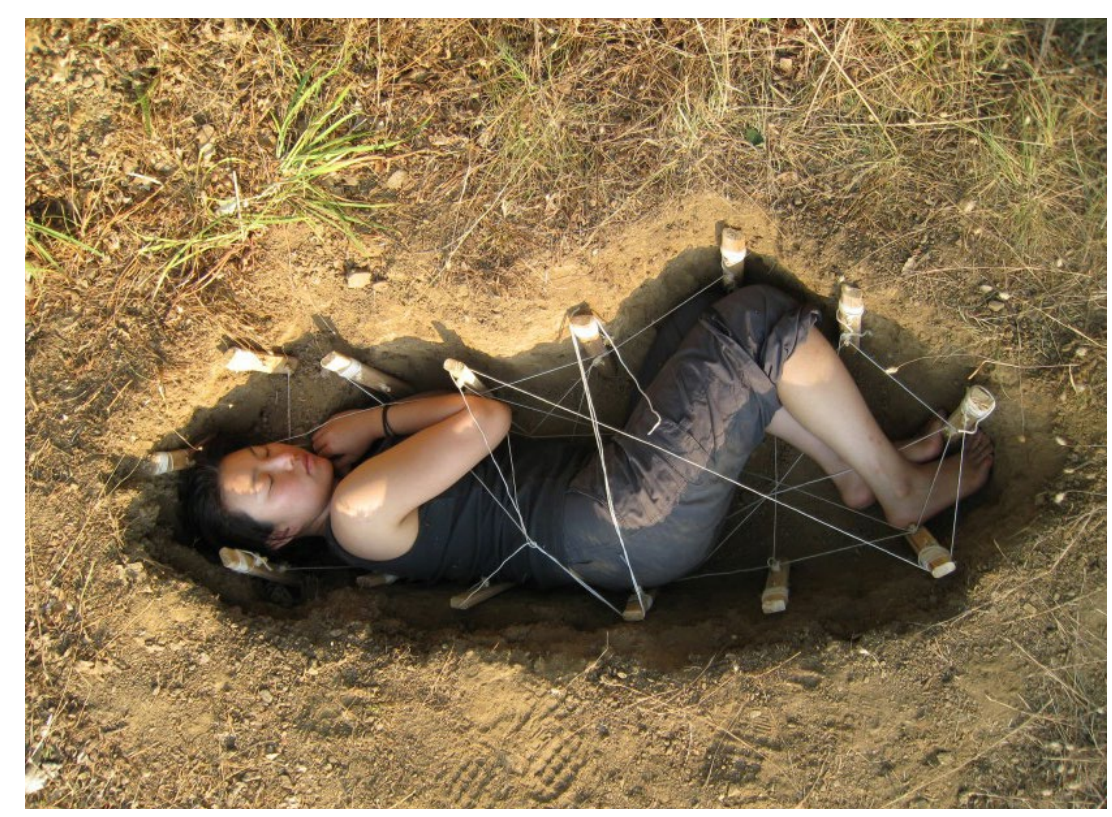

Figure 4. The Mushroom Burial Suit (Coeio, n.d) 
and ultimately the designer's as well" (p. 159). To gain an informed and in-depth understanding of the discourse shared through a design, designers are encouraged to research relevant literature and conduct primary research. Primary research can be valuable to designers, especially when creating particular messages for particular audiences. When working with an external, non-design topic, designers should engage with relevant literature and collaborate with experts from that field. Tharp and Tharp acknowledge that this process can be challenging for designers as it takes additional time, and they have to develop a grasp of concepts that they are less fluent or confident with However, it is beneficial for designing an effective and well-informed artifact.

In Tharp \& Tharp's work, experimental design is often discussed with discursive design as the two approaches can support one another.

Understanding gleaned from a discursive design can also help

experimental design projects. Experimental design is the process of trying to discover, play with, or test something. It is an approach that questions what can come of a design rather than what should come from it. The value lies in the process and its potential rather than a refined outcome. The artifacts produced using this agenda often act as evidence of the process or potential. With experimental design, it is important to understand that it involves exploration and that there is a possibility that what comes from it might not be essential or immediately valuable. The designer should reflect on the success of the exploration through the experience and knowledge gained, and identify if more exploration is needed.

The Mushroom Burial Suit (figure 4), designed by Jae Rhim Lee (2011), encapsulates discursive and experimental design. The design critiques unsustainable burial practices, such as cremation and embalming, and the denial of death in Western culture. The burial suit is embedded with uniquely bred mushroom spores which the person is then buried in. As time goes on, the mushrooms grow and decompose the body to return it to Earth. Developed through experimentation, Lee was led by the question, "could mushrooms be the symbol and tool for a cultural shift in how we think about death and our relationship to the planet?" (Coeio, n.d). Lee first experimented by breeding different mushrooms and seeing how well they decomposed hair, skin and nails that the human body naturally sheds. Over time, the burial suit has been developed and tested on both pet and human burials.

\subsection{DESIGN RESEARCH: RESEARCH-THROUGH-DESIGN}

The design research method, research-through-design, was conducted to investigate the possible ways that discursive design could address animal welfare and environmental sustainability issues associated with New Zealand dairy farming. The term 'researchthrough-design' is described by Rodríguez (2017) as a "criteria-based approach that allows design practice to become a systematic form of enquiry without sacrificing the freedom of expression and creativity that designers expect to engage in" (p. 12). The value of this research method is found through the act of making. By making things, the researcher can find problems and discover new things that might not have been possible through other forms of research. Rodríguez suggests that the research-through-design process has two essential elements - the research question and the criteria. The research question guides the process and should only be addressable through the practice of design. Criteria are developed by researching existing knowledge within the field and can be used to describe the design and its contribution to existing knowledge. The criteria should address the research question and assist design decisions, assess design results, and report on the project (Rodríguez, 2017). Overall, researchthrough-design allows designers to investigate the research problem and freely engage in creative design practice.

For this project, research-through-design was used to develop an experimental discursive design, The Dairy Oracle. This designed artifact is centred around addressing my research question: how can cultural and design research be used to understand what NZ dairy is today and imagine what it could become in the future? The Dairy Oracle is a deck of oracle cards for opening up discussion with the public about the present and future of dairy farming in New Zealand. For this project, readings of The Dairy Oracle were held at a local farmers' market. Participants were asked to share their understanding of cultural values, practices and relationships within dairy farming and how they might imagine them in the future to improve animal welfare and environmental sustainability. The design criteria were situated within experimental and discursive design and drew heavily from design activism, the practice of speculative design and more specifically, eventful speculative design. These approaches are described in detail 
in the following sections of this chapter. The existing knowledge developed through these approaches provides specific ways that design can be used to open up discussion, debate and imagination through public engagement. The design criteria and how The Dairy Oracle was developed and assessed to meet the criteria are discussed throughout Chapter 4: The Dairy Oracle.

\subsubsection{SPECULATIVE AND ACTIVIST DESIGN}

Design activism and speculative design are forms of discursive design (Tharp and Tharp, 2018). Both design approaches encourage the audience to reflect and respond to the message communicated through a designed artifact.

Sustainable designer and design activist Thorpe (n.d) identify design activism as an approach that seeks to address social and environmental issues and create social change. Activism is approached differently through design than through political activism. Political activism comes in the form of boycotts or protests that often try to prevent things from happening (Thorpe, n.d). Design activism, however, relies on objects and spaces to intervene in people's lives. This intervention can promote social change, raise awareness about our values and encourage self-reflection about how we live, work and consume (Markussen, 2013). Design activism does not aim to solve social or environmental issues. Instead, it focuses on gaining a better understanding of the problem. With this understanding, alternative solutions to the status quo can be generated (Thorpe, n.d).

Designed by Adelaide Lala Tam, The Ultimate Milk Cow (figure 5) engages with design activism. It addresses the morality of dairy production. The three trophies are awarded to cows who are 'always fertile', 'always female' and 'always increasing'. The design explore how dairy cows are often manipulated to increase milk production rates to meet consumer demands (Tam, n.d). It invites the audience to think about dairy production and the impacts it has on a cow's physical and mental condition. The designed artifact strives to understand the issue and brings critical awareness to the way we live and consume.

When it comes to designing for social change, the Design Justice Principles (figure 6) are essential to recognise. The Design Justice

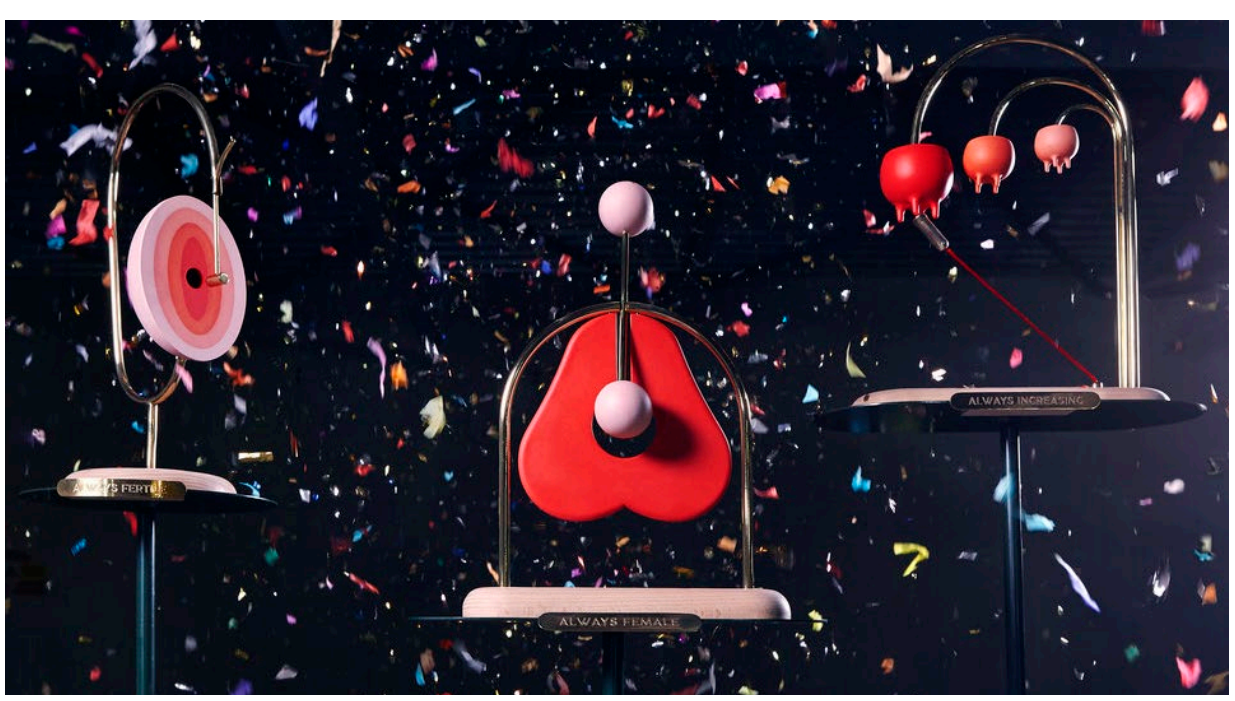

Figure 5. The Ultimate Milk Cow (Tam, n.d)

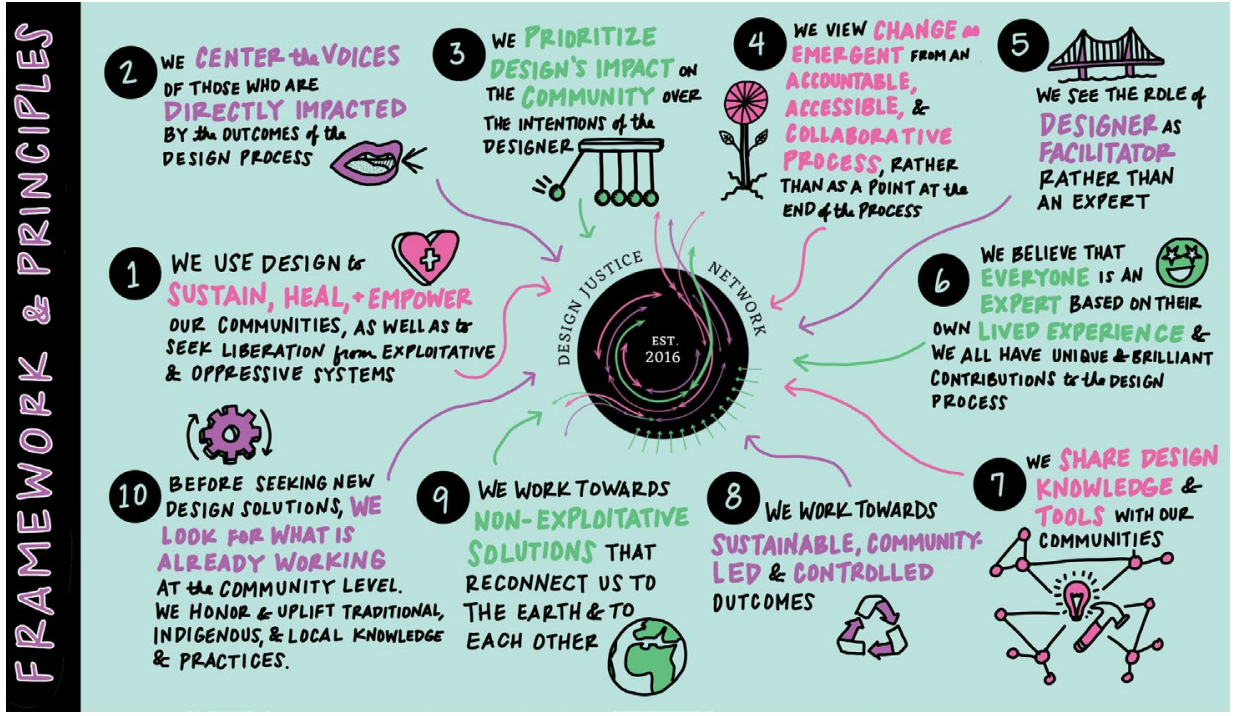

Figure 6. The Design Justice Principles (Carhart, 2021) 
Principles emerged from a community of design practitioners who work and participate in social movements and community-based organisations. The principles challenge the idea that good intentions are enough for using design as a tool for liberation and help design practitioners avoid unknowingly reproducing existing inequalities through their work (Costanza-Chock, 2020). Despite design having a significant impact on our lives, very few people are involved in actual design processes. The Design Justice Principles rethink the process of design, centre those who are the most impacted by design decisions, and embrace collaboration and creativity to address the issues we face (Design Justice Network, n.d).

In collaboration with the Design Justice Principles, I believe that speculative design is an approach that can help us imagine and create alternative, often complementary, means to promote social change.

Tharp and Tharp claim that much like discursive design, speculative design aims to encourage audience reflection, debate and response through artifacts. However, speculative design goes a step further to position these artifacts in scenarios that envision alternative futures or presents. Design educators and speculative designers Dunne and Raby (2013) describe this design approach as using imagination to open new perspectives on big social and environmental issues, such as climate change. Speculative design helps us speculate how things could be rather than feeling the urge to solve these unsolvable issues. By opening up 'what-if' questions, design artifacts create spaces that encourage the audience to discuss and debate about alternative ways of being. From this, we can better understand the present and discuss the types of futures people do and do not want.

Speculative design is not about trying to predict the future. It aims to use design to open up different possibilities that can be discussed debated and used to collectively identify the types of futures a group of people would prefer (Dunne \& Raby, 2013). Speculative designer, filmmaker and educator, Jain (2018) acknowledges there is no set destination for the future. Design can engage in the diverse potential of what could be by listening, observing and making. In this time of climate crisis, Jain proposes that speculative commitments should "suggest a change in relationships we have with the natural world". Humans should collaborate with nonhumans to re-imagine what the relationships and interactions between them could be. Relating to this concept, in later works, Jain (2020) introduces the 'more-thanhuman politics'. More-than-human politics can help us imagine alternative ways of living with and through complex problems, such as climate change, by rejecting the idea that humans are isolated or divided from the ecology that sustains us. This type of politics asks us to stop viewing ourselves as individual heroes but instead know ourselves as a part of more entangled and interdependent human and nonhuman relationships. Through this new kind of relational agency, we are able to "invent new practices of more-than-human care, humility, imagination, interdependence, resistance, revolt, loss, mourning and resurgence" (Jain, 2020).

Jain (2020) cites Anne Galloway's work as an inspiration. An example of Galloway's work is Grow Your Own Lamb (figure 7). This design is a speculative scenario created to explore emerging technoscience and increased consumer control over farming practices and meat production. The speculative scenarios re-imagine what meat production could look like in the near future if consumers control how their meat is produced, from breeding, caring, feeding, and slaughter. The scenario explores two services, in vivo (paddockraised) and in vitro (lab-raised). Both scenarios give the consumer full control over how the lamb is raised/grown in a lab and how the lamb is slaughtered/harvested. The scenarios were designed with the intention of providing somewhat plausible services that might encourage audience reflection on the relationship between technology, producers and consumers. The design was exhibited online along with an audience survey. The responses from the survey were analysed to understand what speculative design can and cannot do. From this design research, it was identified that speculative design is a promising method of research and means of asking questions rather than a research output or the generation of possible solutions to possible problems (Galloway \& Caudwell, 2019).

The Mitigation of Shock is what drew Jain into the world of many interacting species and the ideas around more-than-human politics. Jain is the co-founder and director of speculative design studio, Superflux. Designed by Superflux, The Mitigation of Shock (figure 8) is a speculative exhibition that attempts to make the size and complexity of climate change tangible. It is a slow form of critical activism which uses speculative, hands-on experimentation to provide opportunities for people to step into a familiar space, an apartment, to confront 


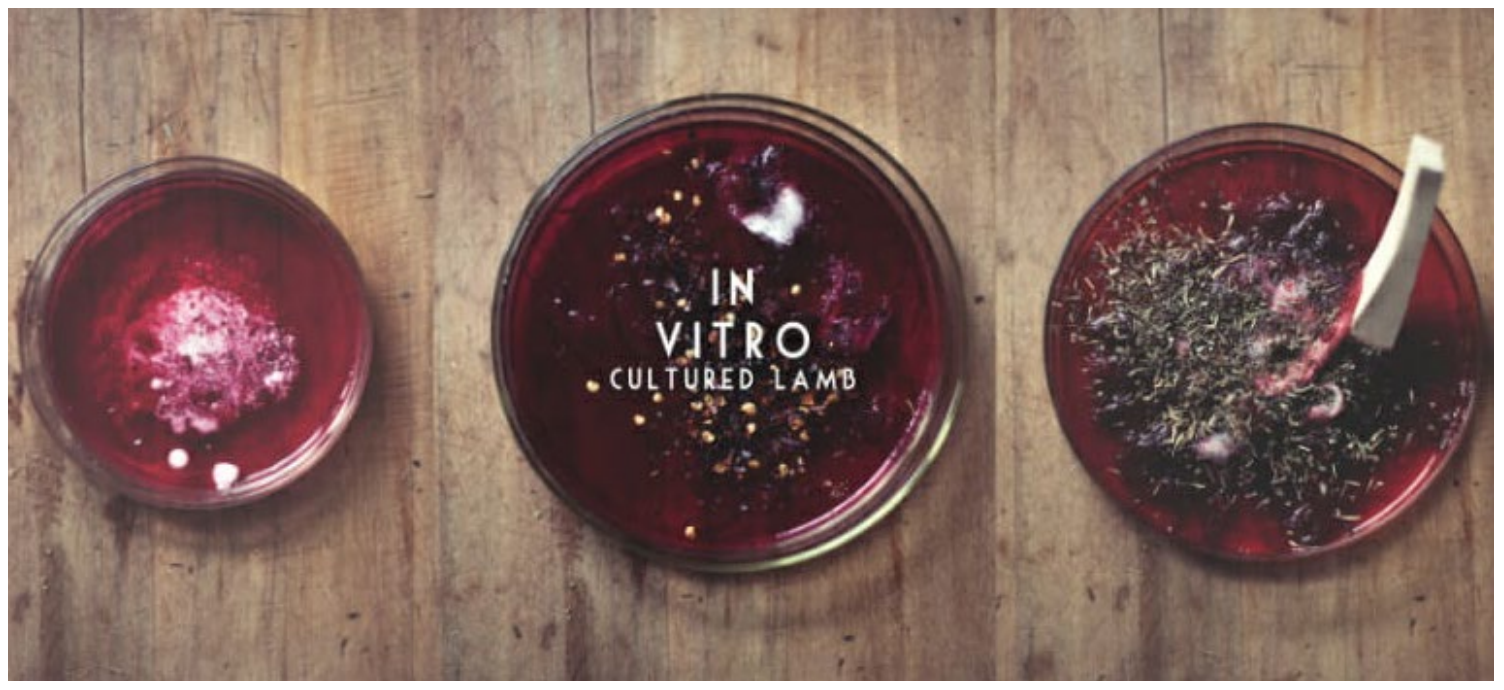

Figure 7. Grow Your Own Lamb (Freshwater, n.d)

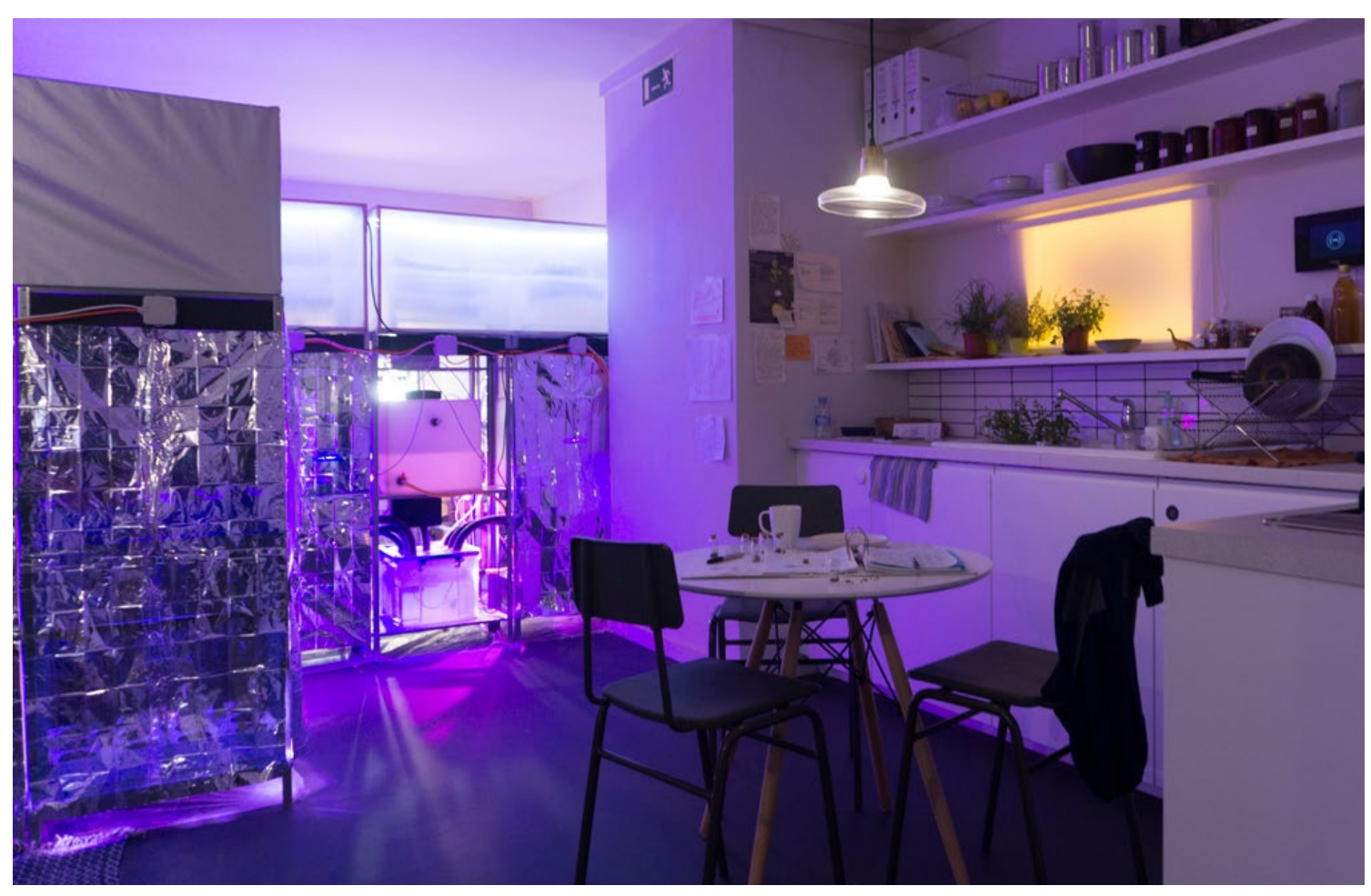

Figure 8. The Mitigation of Shock (Superflux, 2019) 


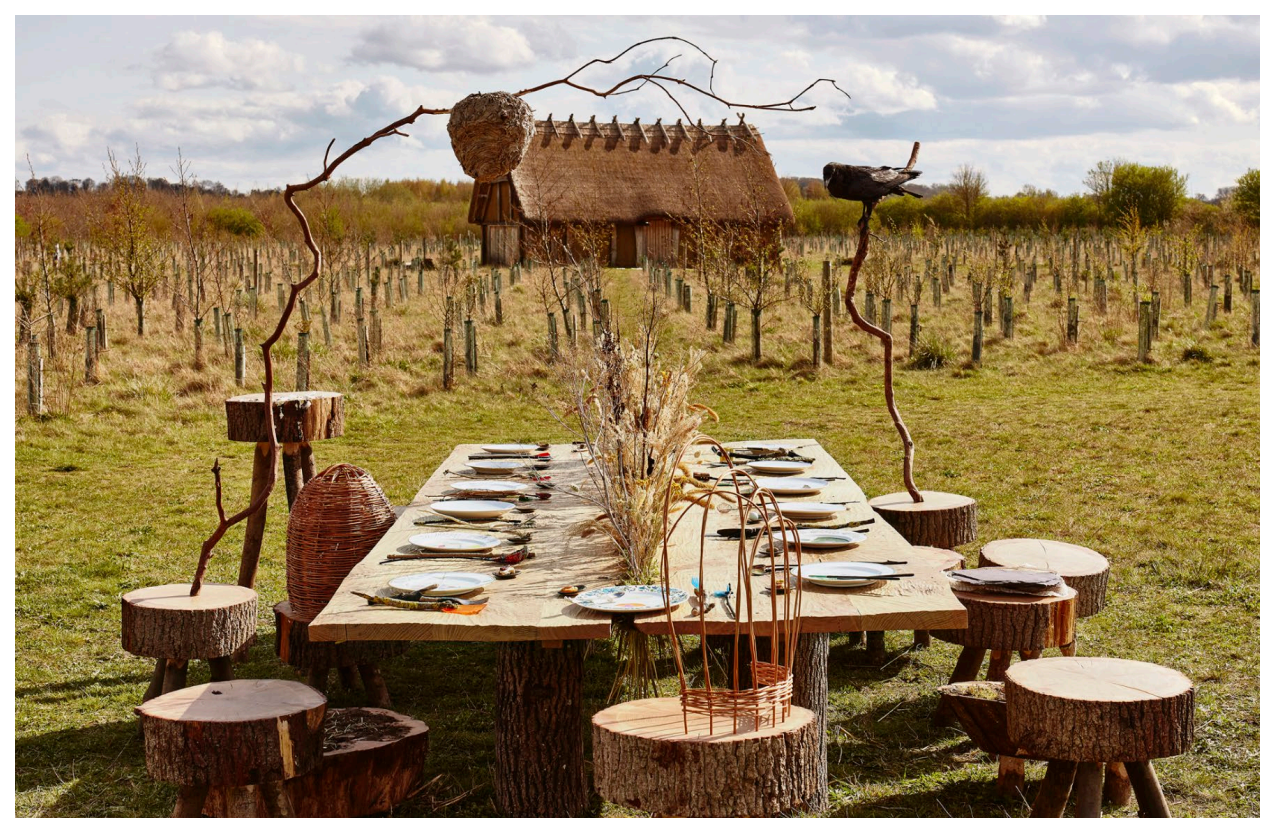

Figure 9. Refuge for Resurgence (Superflux, 2021)

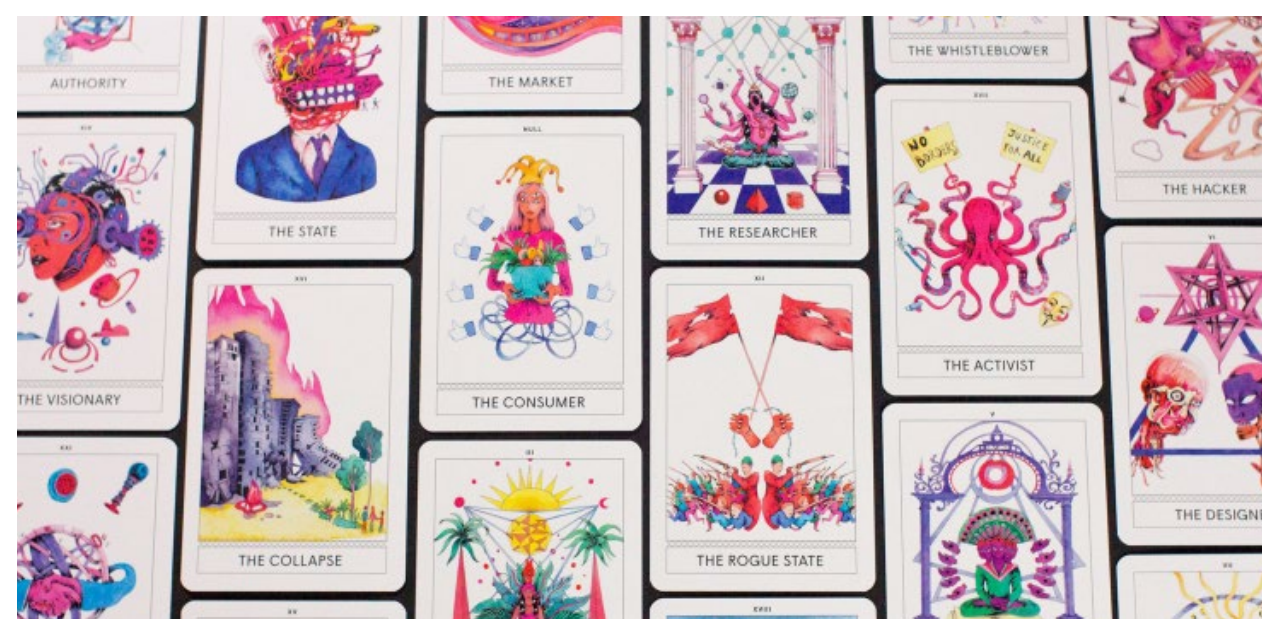

Figure 10. Instant Archetypes (Superflux, n.d) their fears but also imagine how we could not only survive but thrive in a future that is impacted by climate change. The exhibition is set in a London apartment in the year 2050, food production, storage and consumption all happen within the apartment's living room. It addresses issues around food insecurity, extreme weather, and resource scarcity that are predicted consequences of climate change by re-imagining our relationship with the nonhuman species we use for food (Superflux, 2019). Other works by Superflux include Refuge for Resurgence and Instant Archetypes. Similar to The Mitigation of Shock The Refuge for Resurgence (figure 9) imagines a more-than-human future in response to the ecological and climate emergency humans have caused. The dining experience brings together animals, birds, plants, fungi and humans to imagine how all the species on the plane might come together to celebrate their interdependence. The future is built around humility, resourcefulness and imagination and aims to imagine a "symbolic home where all species can prosper with resilience, adaptation and hope" (Superflux, 2021). Instant Archetypes does not focus on more-than-human futures, instead, it shows that speculative design can be more than exhibitions, it can also be a tool. Made in collaboration with researcher, Paul Graham Raven and illustrator, Amelie Barnathan, Instant Archetypes (figure 10) is a tarot deck that aims to make tools and future concepts tangible and accessible. The card deck reinterprets the tropes of the Major Arcana for the challenges of the 21st Century. Through creative and critical thinking, Instant Archetypes can open possibilities, ask questions and untangle the complex challenges of the 21st Century (Superflux, n.d).

\subsubsection{EVENTFUL SPECULATIVE DESIGN}

Speculative design is made up of a diverse range of approaches (SpeculativeEdu, n.d) and eventful speculative design sits among these approaches. Defined by design researcher Dolejšová (2021), eventful speculative design is an approach that invites participants to engage and intervene with a speculative artifact. It uses speculative design to open up discussions about social issues with the public and allows them to contribute their personal experiences and insights. The act of inviting participants to contribute is in response to a critique of speculative design. As reflected through the design precedents explored throughout this literature review, speculative design is often an exhibition practice. It presents finished artifacts for the audience to spectate upon. The audience has limited option to intervene with 
their inputs or interpretations. Eventful speculative design draws from participatory design and co-design, design anthropology and performative arts. Speculations are presented through events rather than exhibitions or installations; this supports critical and creative public engagement. Holding the events in accessible, everyday spaces allows a diverse range of participants to engage and reflect on the design (Dolejšová, 2021). Irony, curiosity, and spectacle can draw different kinds of people to interact with the speculative event. Together, people can imagine possible future scenarios for their communities (SpeculativeEdu, n.d). Although this speculative approach is recent, Dolejšová claims it carries "a promising yet largely unexplored potential for public engagement" (p. 8)

Tools support eventful speculative design as they help people who are not familiar with speculative design by providing possible guidelines that they can use to speculate. One of the most common tools used for eventful speculative design is card decks and games (SpeculativeEdu, n.d)

For Dolejšová's research, she designed The Parlour of Food Futures - a speculative oracle (figure 11). Inspired by the Major Arcana in the Tarot de Marseille deck, the speculative oracle includes 22 cards that explore possible food futures. Each card presents a speculative diet tribe that refers to existing or emerging food-tech trends. One-onone readings are performed with participants. The cards prompt the participants to discuss food-tech issues and encourage speculation around our eating habits in the future (Dolejšová, 2021).

Another example of how cards have been used as tools is the Oracle for Transfeminist Technologies (figure 12). Designed in partnership with Coding rights and MIT Co-design Studio, the card deck addresses the issue of technology and how it is designed to maintain the status quo of social inequality while supporting the social norms of consumerism, misogyny, racism, ableism, gender binaries and heteropatriarchy. The oracle deck is embedded with trans feminist values and was designed to help people who are excluded and targeted by today's technology. The card deck is used at workshops to understand better how we might collectively re-imagine and share ideas for future transfeminist technologies (Transfeminist Technologies \& Coding Rights, n.d).

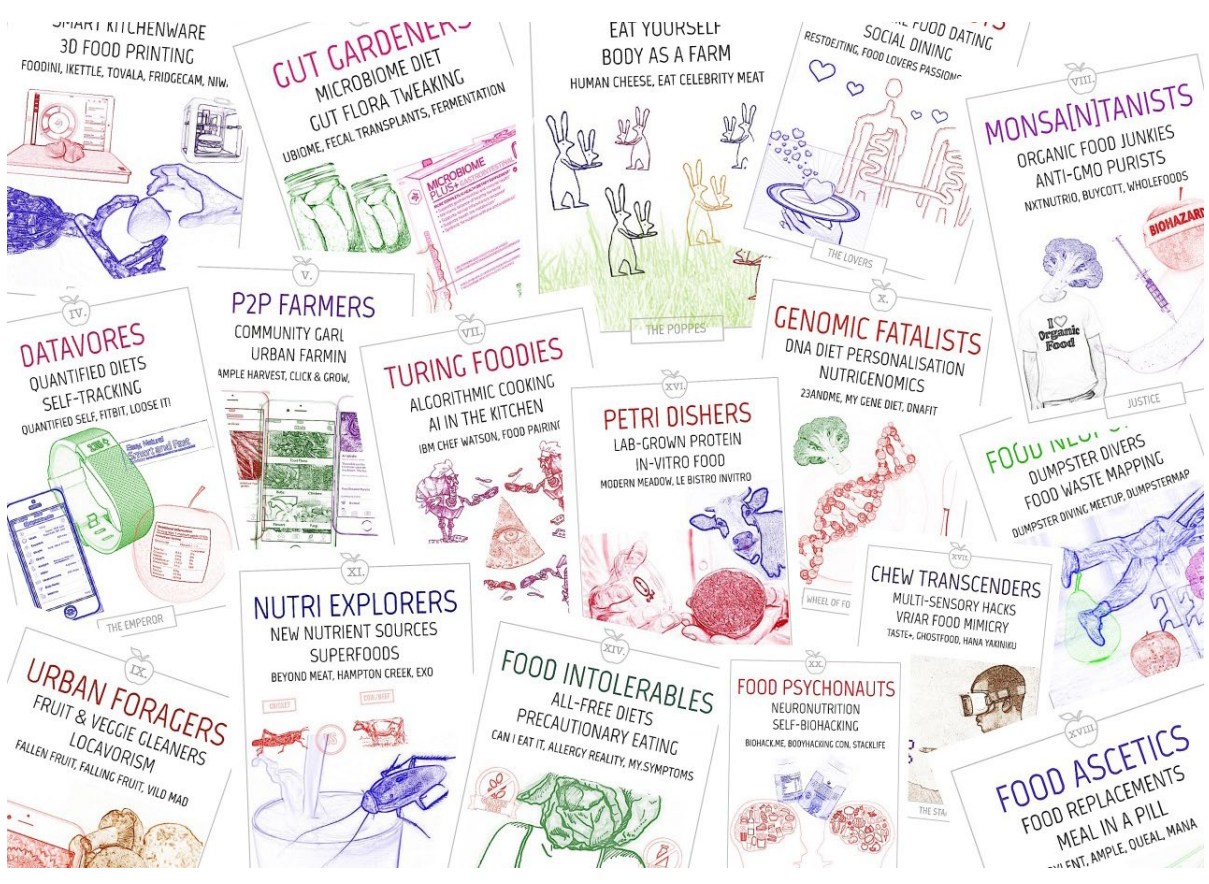

Figure 11. The Parlour of Food Futures (Dolejšová, n.d)
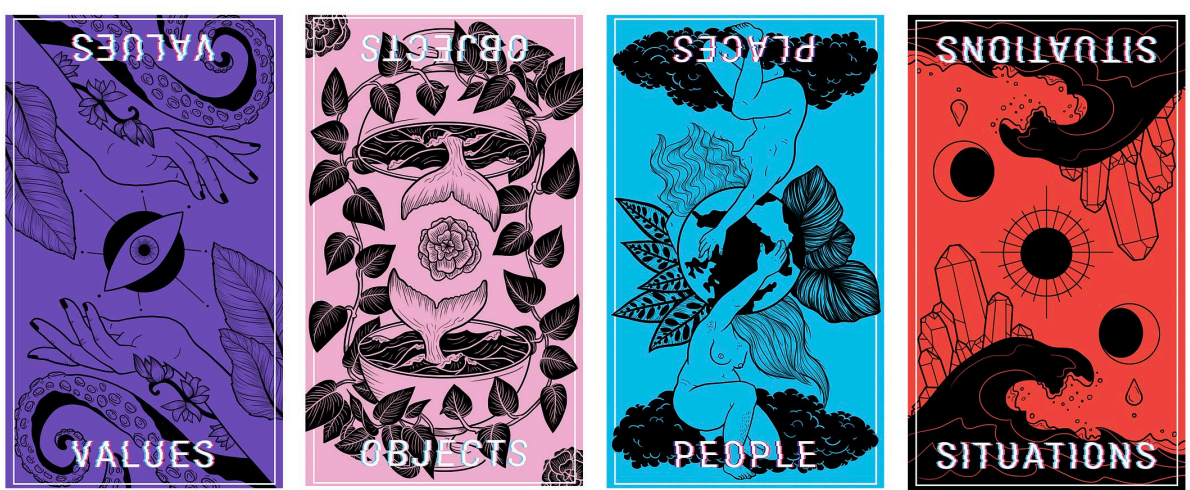

Figure 12. The Oracle for Transfeminist Technologies ("The Oracle for Transfeminist Technologies", n.d) 
CHAPTER 3.

\section{THE HAPPY COW MILK COMPANY}




\subsubsection{GETTING IN CONTACT}

Happy Cow Milk's journey to practice dairy in a more ethical and sustainable way lined up closely with my research question and could even be considered a form of speculative design. Glen Herud and Chris Falconer are finding practical ways to address animal welfare and environmental sustainability issues associated with New Zealand dairy farming. I was interested in learning more about their values, the relationships they have with their cows and the land they farm on, and how they distinguish their farming practices.

My academic supervisor, Dr. Anne Galloway, met Glen and Chris on Twitter and then got me in contact with them via email. After introducing myself and my proposed research project, I asked if Glen and Chris would be interested in participating in an interview and farm visit. Both agreed to participating in an interview, and Chris invited me to visit his farm for a day.

Both of the participants have extensive knowledge of New Zealand's dairy industry. Glen grew up on a dairy farm and has worked on and off in the dairy industry for most of his life. At the time I conducted this research, Glen was not farming but instead working hard to make the Happy Cow Milk model a reality. Chris is a first-generation dairy farmer and has worked on and off in the dairy industry since his early 20 's. Chris resides in Waikato with his herd of 400 dairy cows. It is important to note that prior to becoming a Happy Cow Milk farmer Chris was already altering his farming practices to ensure that the welfare of his cows and environmental sustainability was prioritised. Chris got involved with Happy Cow Milk because he believed that things need to be done differently, for the cow and the marketplace.

\subsubsection{ETHICS}

This research was considered low risk, but ethics approval was still required to conduct interviews and a site visit. Through Victoria University of Wellington's Human Ethics Committee, an ethics application (\#000002885) was submitted, and approved on the 15th of
October 2020 (See Appendix B for ethics approval email, Appendix C for participant information sheet and consent form).

\subsubsection{THEMATIC ANALYSIS}

As outlined in Chapter 2, the case study consisted of in-depth qualitative interviews and an observational site visit. Braun and Clarke's (2012) approach to thematic analysis was applied to the interview transcripts and site visit fieldnotes. Thematic analysis is a qualitative method of systematically identifying, organising and gaining insight from the meaning of themes across a data set. This allows the researcher to gain understanding of collective or shared meanings and experiences (Braun and Clarke, 2012).

Although thematic analysis is flexible as it can be conducted in many different ways, I followed Braun and Clarke's six-phase approach:

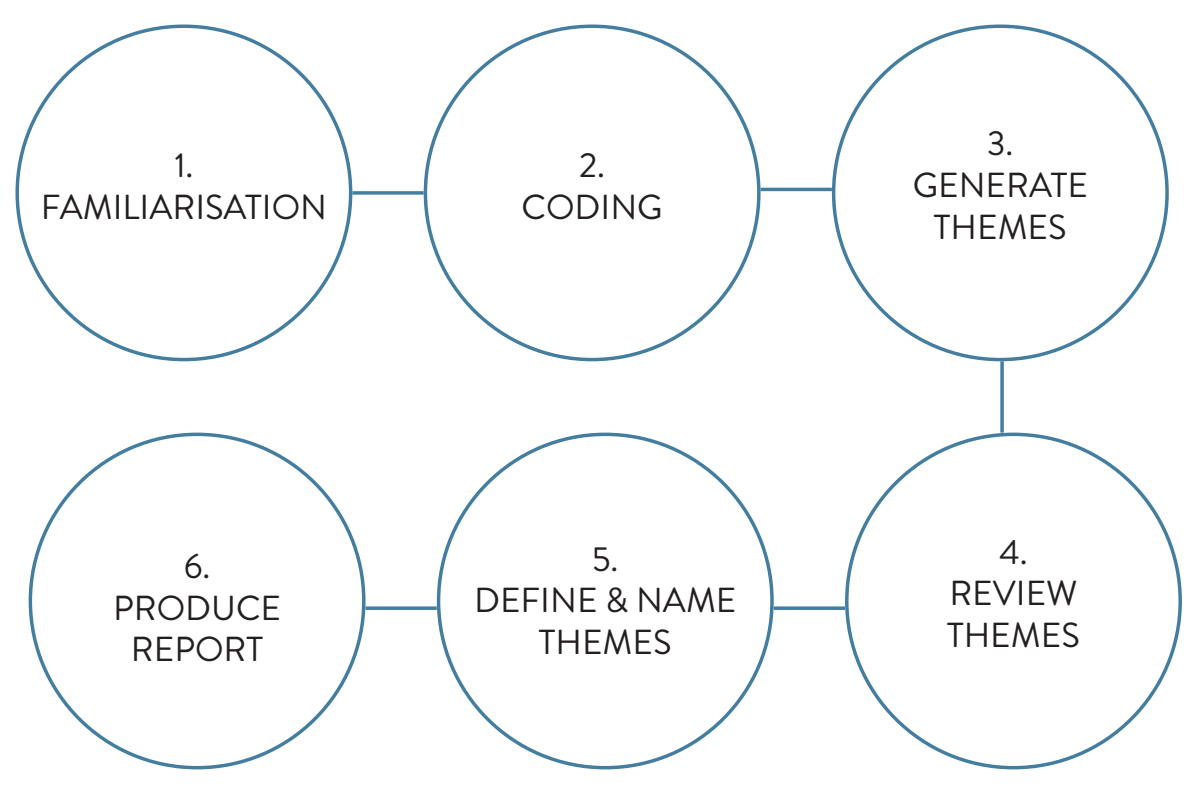


By conducting this approach, I was able to closely examine the data to identify, map and make meaning of the themes that were derived from the content. Three broad themes were identified - farmer wellbeing, cow wellbeing, and environmental wellbeing. Each of these themes included subthemes that explore the relationships, practices and values that were identified through the analysis. The subthemes were reviewed and revised to better gain an understanding of how they supported one or multiple of the broader themes.

Findings from the analysis of the qualitative interviews and observational site visit are presented in this chapter. Guided by the research question, they have been organised to tell a story (Braun and Clarke, 2012). First, the areas of dairy farming that cause concern for the participants is identified. Following this, the participants' values, practices and relationships are mapped in their relation to farmer, cow, and environmental wellbeing. Although my findings cannot be generalised to the whole of New Zealand dairy, the method was wellsuited to the task, and provided examples of situated knowledge. The experiences, opinions and perspectives drawn from the case study are unique to the participants, but the findings can be used to generate further insights into dairy farming in New Zealand and imagine ways that dairy can possibly be done differently to improve the lives of all involved.

\subsection{HAPPY COW MILK: MAKING A DIFFERENCE TO DAIRY}

\subsubsection{CONCERNS FOR NEW ZEALAND DAIRY}

In the early 2000s, New Zealand's dairy industry expanded. Glen Herud defines this as the starting point of the Happy Cow Milk Company. He began to notice that the industry's growing scale was causing land prices to rise, making it more difficult for young farmers to progress in their career pathways or go into farm ownership. As the industry grew large-scale, investor-run dairy farms became more common than family-run dairy farms. Glen comments that animal welfare issues are more likely to arise on large-scale, investorrun dairy farms because non-farmers run these types of farms and systemise them to maximise milk production from profitable returns. Profits are essential to farmers; it is how they make a living and pay their bills. However, the New Zealand dairy industry traps farmers into needing a high production rate to make a profit. Chris Falconer believes that production and profit pressures are among the greatest threats to cow welfare. Dairy farmers care about their cows, but unfortunately, high production rates are prioritised over cow welfare. An example of this is twice-a-day milking. It is a common dairy farming practice, yet, it is done to maximise production rates.

Most of New Zealand's dairy is exported overseas, as a consequence, New Zealand dairy farmers are disconnected from their customers. Glen states that "... the farmer is very removed from the customer and they struggle to see the world from the public's perspective", which causes them to interpret public concerns or feedback as a critique towards them. Chris states that many farmers fight back when consumers share their concerns about dairy farming. This type of attitude weakens the relationship between consumer and producer, and public concerns cannot be addressed because many farmers refuse to listen. Generational legacy contributes to farmer's refusal to address public concerns, and if often impacts the relationship farmers have with the land. Chris states that farmers on a family farm that has been around for generations are often pressured to follow the same farming practices as those who came before them. It can be taken as implied criticism to the previous generation if practices are changed. Furthermore, Chris explains that the value of ownership can also have an impact on the relationship farmers have with the land. Traditionally, many farmer's claim ownership over the environment and cattle on their farms. By viewing themselves as the owner, they believe they can do what they want with the cows, land, water and air. This can sometimes lead to poor decisions being made, impacting the environment, cows, and the local community.

Pasture grazing, however, is considered a positive element of New Zealand dairy by both participants. Pasture grazing is what defines New Zealand dairy from the rest of the world. Dairy farmers are knowledgeable about how to grow and care for their pastures in order to feed their cows. Both Chris and Glen agreed that pasture grazing would be the one thing they would keep about New Zealand dairy farming. Chris comments that New Zealand cows are bred to graze. If we move away from pasture grazing, animal welfare issues will arise.

By identifying Glen and Chris' concerns for New Zealand dairy farming, 
I am able to understand how their values and practices work to address these concerns and improve farmer, cow, and environmental wellbeing. This is explored in greater detail below.

\subsubsection{GLEN AND CHRIS' APPROACH TO DAIRY}

This case study employs the term 'wellbeing' and introduces the theme of 'farmer wellbeing'. Although the term 'welfare' and 'wellbeing' can be used interchangeably, the term 'wellbeing' will be used throughout this case study and the remainder of the research. 'Wellbeing' refers to the state of being comfortable, happy and healthy, and is relevant towards improving the lives of farmers, cows, and the environment. Additionally, the wellbeing of the farmer has been included towards finding possible solutions to addressing animal welfare and environmental sustainability issues. One Health is an collaborative, multisectoral and transdisciplinary approach that recognises that the health of people, animals and our shared environment is interconnected (Centers for Disease Control and Prevention, 2018). This approach focuses heavily on preventing the spread of zoonotic diseases. One Welfare is an extension of the One Health approach, it considers both mental health and physical health (RSPCA, 2020). One Welfare aims to improve human and animal welfare by highlighting the connections between the wellbeing of animals, humans and their shared environment (One Welfare, n.d). This approach promotes sustainability, to minimise human suffering and to improve productivity, especially within the farming sector (One Welfare, n.d). Similarly, throughout the case study it was identified that farmer wellbeing is entangled with cow and environmental wellbeing. Farmer wellbeing was not mentioned throughout the cultural literature review. However, the case study found that if farmers are feeling stressed and tired, or are facing financial issues, their focus on animal and environmental wellbeing is likely to be less of a priority. Therefore, as we begin to address animal welfare and environmental sustainability issues, farmer wellbeing will be an important consideration

Figure 15 maps the relation between Glen and Chris' practices, values and relationships, and their impact on farmer, cow, and environmental wellbeing. Following the diagram, each sub-theme is explained in-depth.

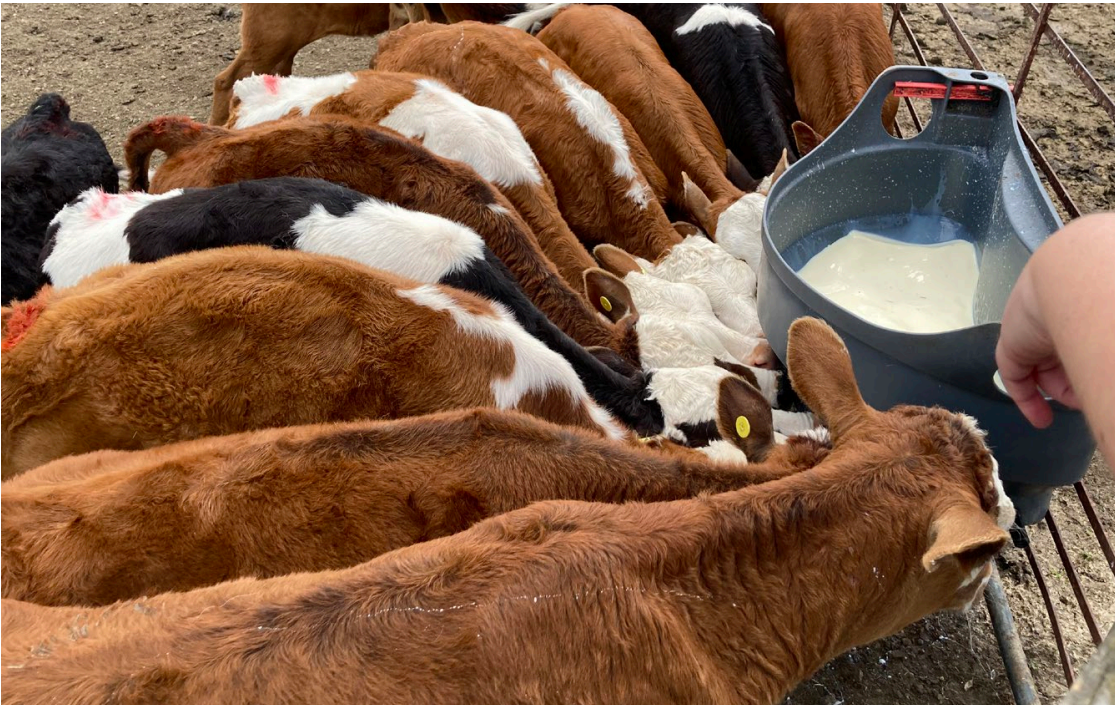

Figure 13. The calves on Chris' farm

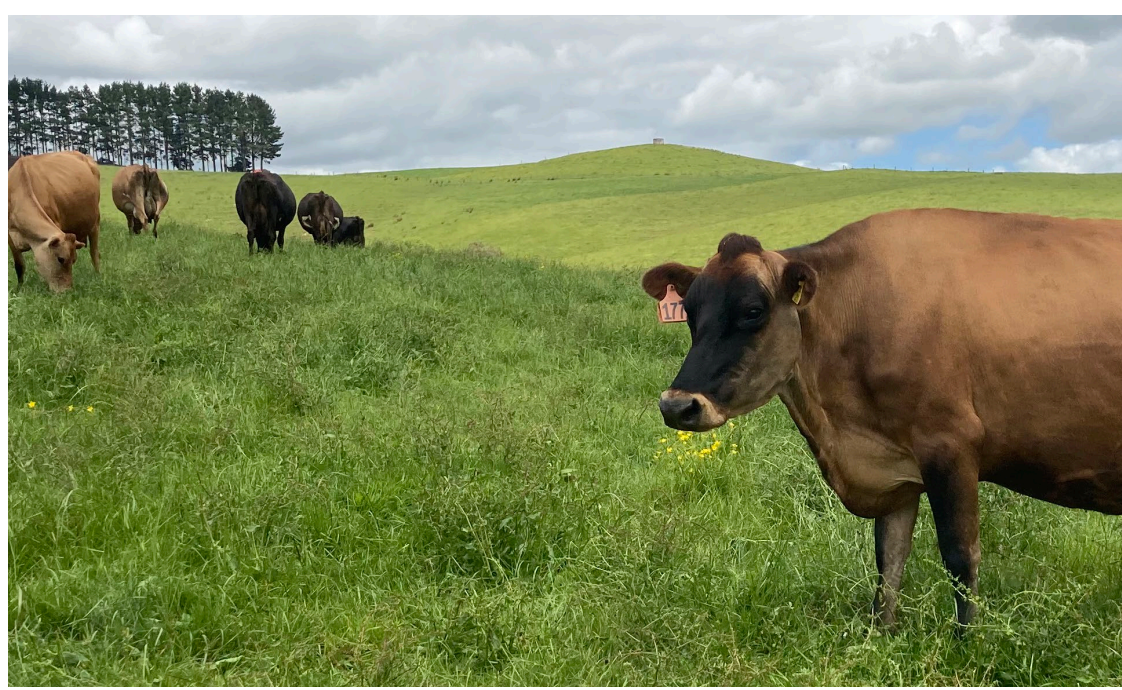

Figure 14. The cows on Chris' farm. 
Farmers connecting and building trust with consumers

Cows are valued for their milk but given space and opportunities

Small-scale, de-intensified farms

\section{Farmer wellbeing}

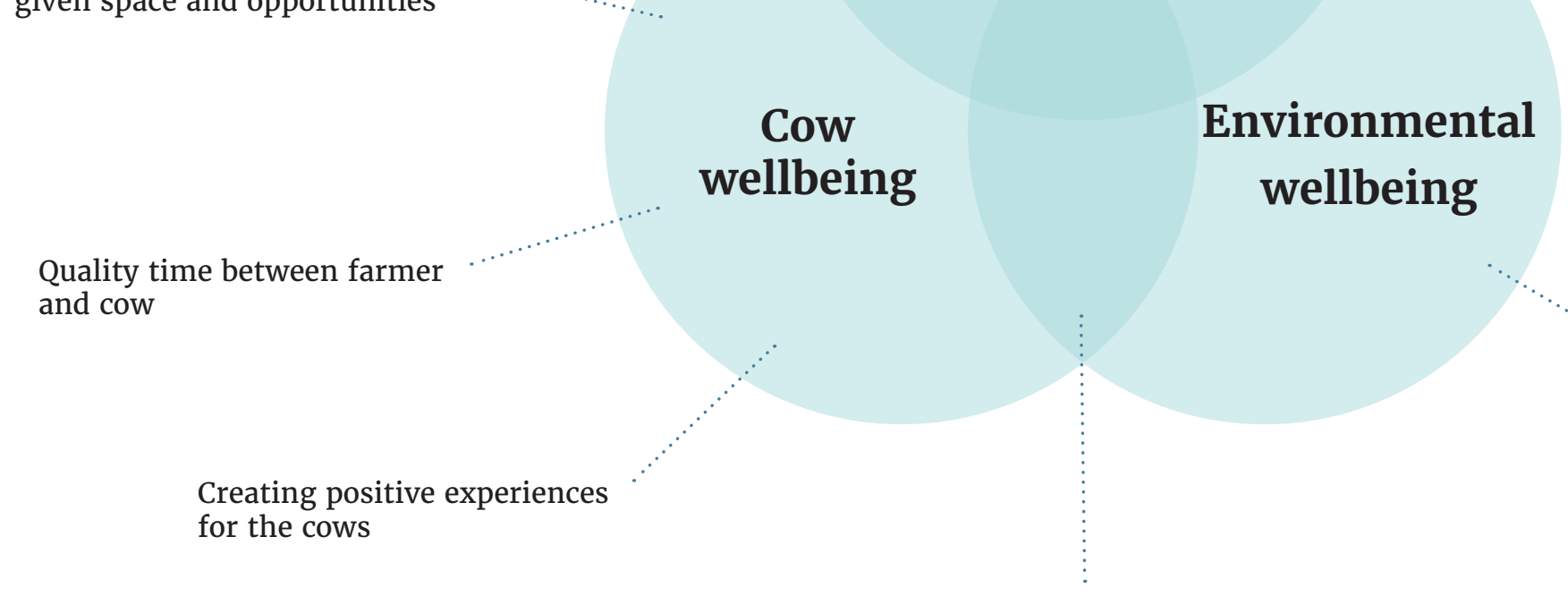

Lowering stocking rates 
FARMER WELLBEING: FARMERS CONNECTING AND BUILDING TRUST WITH CUSTOMERS.

Connecting with customers was one of Glen's main goals when starting Happy Cow Milk, and it was one reason Chris got involved as a Happy Cow Milk farmer. Chris believes having a direct connection with the consumer will allow farmers to make changes to benefit the cow and the marketplace.

"[T]here are too many people between us and the consumer, and I think if we do things differently, then we have to be in direct touch with the consumer because that is where the value lies for us and where the connection lies for them" C.F.

The Happy Cow Milk model is customer-focused and aims to form direct relationships between consumer and producer. This value distinguishes Happy Cow Milk and its farmers from most traditional farmers in New Zealand.

"I think the real difference between our farmers is that they are more customer-focused. They are more in tune with the public than your average farmer" G.H.

As discussed in the Happy Cow Milk literature review in Chapter 2, Happy Cow Milk has invented a system that allows the farmer to sell directly to the consumer. This addresses issues around intensive farms and farmer-consumer disconnection. The farmer knows where their milk is going, and the customer knows where their milk is coming from. The system allows the farmer to have a direct relationship with the consumer. It also supports small-scale farms by giving farmers more income per litre than the current system. This allows them to reduce stock numbers without losing profit.

\section{FARMER WELLBEING: LOW-PRESSURE WORK ENVIRONMENT.}

Chris believes that farming should be about working in a low-stress, low-pressure environment. He values milking once a day because it has not only had benefits for the cows, but it has also has benefits for himself, his family and his staff. Chris shared that milking once a day allows for a 39 hour work week on his farm, compared to a 70-80 hour work week on other farms. Due to this, the people involved with the farm can pursue opportunities and experience life outside of the farm.

When visiting the farm, the atmosphere was calm and slow. I arrived after milking, which I assume is the busiest part of the day, but we still carried out tasks such as feeding the calves and trimming the cow's tail hair. Although I only caught a glimpse of what a day on the farm might be like, it felt like a low-pressure environment; both us and the cows were in no rush. By having a low-pressure work environment, there is more time and space for the farmer to spend time with their cows and get to know them as individuals. This allows for relationships to form between farmer and cow, and reduces the emotional disconnection.

\section{FARMER/COW WELLBEING: SMALL-SCALE, DE-INTENSIFIED FARMS}

"[S]mall is now more powerful than big because small farmers can do things that the big ones can't" G.H.

Both participants believe that small-scale farms are better for animal welfare and the environment because they generally do not farm as intensively (at such cost) as larger, investor-run farms. The Happy Cow Milk model is directed towards smaller farms, those with herds under 1000, and aims to de-intensify dairy farming in New Zealand. Glen values small farmers because he believes they want and do what is best for the cows and the farm. They can form better connections with their cows and alter their practices to improve their cows' wellbeing. Glen mentioned that keeping cow and calf together, providing good shelter in the winter, and reducing walking by bringing the milking shed to the cows were among the things that small farmers could do. On Chris' farm, he implemented once a day milking and calving twice a year to improve cow wellbeing.

\section{FARMER/COW WELLBEING: LISTENING TO CONSUMER CONCERNS.}

Many consumers have made-up preconceptions of what dairy farming is and how it works, even if they have never visited a dairy farm or talked to a dairy farmer. Glen explains that consumers have little understanding of the different aspects, such as weather, that can affect how a farmer farms and the kinds of problems that could happen on a farm. Despite not having a deep understanding of dairy 
farming, consumers still have concerns about the practice from what they see through mainstream media; concerns include cow and calf separation, bobby calves and winter grazing.

Chris and Glen value their customer's opinions and concerns for dairy farming practices. They listen to consumers and address issues by adapting or stopping certain farming practices.

"I can say to the consumer, I hear you, and I know you don't like it, so I'm not going to do it. And that's important because I think that builds trust with the consumer" C.F.

Listening to the consumer builds trust and a connection between the farmer and the consumer. Farmers can understand what is important to the consumer and hear feedback about how they could farm differently. Chris believes that it is important to acknowledge consumer concerns and opinions because they buy the product and consume it.

Bobby calves are causing concerns among consumers. These are all calves not required for (surplus to) the milking herd. Bobby calves can be transported off farm from four days old (Dairy N.Z., n.d). They are then culled for veal, leather and rennet; some bobby calves are still killed and disposed of on-farm (RSPCA, n.d). Bobby calves cause welfare issues due to the age they are transported, and once they get to the abattoir, they are penned up without liquid feed or a comfortable area to lie down (RSPCA, nd). In response to consumer concerns about bobby calves in the dairy industry, Chris has listened and responded by rearing beef calves instead of dairy calves. This means that the calves are not valued only for whether they can be reared as dairy cows or not; there are no bobby calves because all calves can be sold as beef.

Cow and calf separation is also causing concerns among consumers. In dairy farming, calves are separated from their mothers a few hours after birth. There are mixed opinions among farmers and scientists on whether the practice is better for the cows in the long term. Regardless, consumers still hold a critical view of the practice as they see it as "unnatural", causing emotional stress on both cow and calf and compromised cow and calf health (Placzek et al., 2020). Happy Cow Milk implemented their cow and calf policy to respond to this consumer concern. Calves are kept with their mothers until they are weaned off at 8-10 weeks and go their separate ways. Glen states that "it has turned into a thing that our customers really like. It is what we are known for".

COW WELLBEING: COWS ARE VALUED FOR THEIR MILK BUT GIVEN SPACE AND OPPORTUNITIES.

Similar to every dairy farm in New Zealand, the cows on Chris' farm are primarily valued for the milk they produce. However, cows are also more than what they produce. Chris ensures that he builds

a respectful relationship with his cows by giving them space and opportunities in exchange for their milk. Chris chooses to milk once a day and believes that this practice has improved his cows' wellbeing and strengthened the farmer-cow relationship.

"Part of milking once-a-day is that you are giving something to them" C.F.

Chris explains that milking once a day gives back to the cow. The cows have the opportunity and time to rest and regain energy to do things they enjoy, like socialising and playing, or to recuperate after calving. Milking once a day has shown to improve the welfare of the cows on Chris' farm. He claims that the vet bills and empty rates are half of what the national average is, and their replacement rate is $60 \%$ of what the national average is. Chris relates this to the cows having more energy and being healthier.

"I think that once a day milking fundamentally changes your relationship with the cows" C.F.

Milking once a day decreases time pressure on the farm. Because Chris and the cows do not need to return for afternoon milking, they can slow down and enjoy the morning milking process. After milking, Chris enjoys spending quality time with his cows during the day. He will talk to them, give them scratches and play with them. Chris says he can tell the cows respond well to these interactions and the time they spend together, and he believes these interactions strengthen the bond and trust between farmer and cow.

Calving is another practice that Chris has altered on his farm to "give 
back" to his cows. Traditionally, most dairy farms calve once a year. This practice gives cows one chance to calve, and if they fail, they will likely be culled. Instead, Chris calves twice a year, in Autumn and Spring. This gives the cows two opportunities to get into calve. Chris explains, "if she is a good cow and for whatever reason she didn't calve I'm happy to run her into the next herd and give her another shot".

Alongside calving twice a year, Chris also buys replacement cows from other farms. Most of these cows would have been culled because they did not calve, but instead, Chris buys them and provides them with space and opportunity to calve again. He believes this is ethically important, and it does not put the time and resources into rearing the cow to waste.

Chris' cows are also given space and opportunity when it comes to breeding. Human intervention of a cow's breeding cycle is a common practice in dairy farming. Chris explains that getting a cow in calf is one of the key pressures in the farming calendar. Farmers will often treat the cows with hormones, use plants and devices, and inspect the cow to increase the chances of getting into calf. Chris also addresses that another issue with breeding intervention is that it weakens the gene pool. New Zealand prides itself on breeding cows that do well in the system, but this has caused certain traits to be masked as only cows with the ideal traits are kept in the herd. However, compared to breeding interventions in other parts of the world, such as the United States, New Zealand is doing a good job. Chris explains that the breeding interventions in New Zealand are not as extreme or frequent as they are in other parts of the world. However, there is still pressure to intervene because New Zealand farmers calve within a seasonal cycle, whereas other countries generally calve all year round.

Although New Zealand is doing well in this area compared to other countries, Chris believes it could be done better still. In response, Chris uses zero breeding interventions on his farm. He states that "we rely entirely upon the animal being happy and healthy and ready to go. If we haven't got that right, then that is our problem. That's on us, not the cow". Even by using zero interventions, Chris still has very high in-calve rates - in fact, they are always in the top quartile on in-calf rates. Chris believes this success is linked to milking once a day, as the cows have more time to recuperate after giving birth which helps them maintain a healthy body.

\section{COW WELLBEING: QUALITY TIME BETWEEN FARMER AND COW.}

Spending quality time with the cows and forming a bond allows Chris to identify the cows as individuals and spot irregularities in their behaviours. During the farm visit, we spent some time hanging out with the cows in the paddock. Although the cows were wary of me, they still came up to Chris, who was standing close by, for a scratch. Chris describes this response from the cows as a flight radius. A flight radius is how close a cow will let a person get before it moves away. Chris uses this to measure how happy cows are and their relationship with the farmer. If a person walks into a paddock and all the cows run away, the animals are responding to something they do not like. While we were in the paddock, Chris would occasionally introduce the cows by name and point out their unique features. This shows that Chris has spent quality time with his cows as he can identify them as individuals, recognise unique features and build trust with them.

During the interview, Chris shared a story about one of his cows, Sweetie Darling. It represented how important spending quality time with his cows was to building trust with them and identifying irregularities in their behaviour. Chris hand-reared Sweetie Darling, and she has known him her whole life. One day, she had mastitis and came to find Chris to communicate that she was not feeling well. She entered the milking shed differently than usual and looked at Chris. Because he had spent time with her, he noticed this behaviour was out of character, so he investigated what was wrong and was able to help her.

For Chris, it is essential that his farm staff also spend quality time with the cows and form relationships with them. Having no staff turnover in years has allowed the workers on Chris' farm to build a relationship with the cows and handle them with care. Chris mentions that on larger farms with higher staff turnovers, it is difficult for the workers to form these relationships, impacting cow wellbeing.

COW WELLBEING: CREATING POSITIVE EXPERIENCES FOR THE COW.

Both Chris and Glen work towards creating positive experiences for the cows. They work hard to improve their experiences by identifying 
what the cows enjoy and dislike.

"My cows like lying around, they just want to be cows, how can we do that better" C.F

During the farm visit, I noticed that Chris never forced his cows to do things; unless it was for their wellbeing, like checking the calves were healthy and trimming the cow's tail hair. In the paddock, the cows were free to eat, play and lay around. At no point were they forced to interact with us. When the cows moved from paddock to paddock, they were left to walk there in their own time. Chris believes that rushing cows just because the farmer has other tasks to complete contributes to the animal welfare issue; cows do not want to be rushed around all day.

When Glen used to farm, he noticed that his cows did not enjoy walking long distances. Glen explains that dairy cows often develop lameness when walking to and from the milking shed because of the distance, hard laneways, concrete and rocks. So, Glen designed a mobile milking shed. The cows were milked in their paddock instead of having to walk long distances to a milking shed, forcing us to go to them instead of the other way around.

ENVIRONMENTAL/COW WELLBEING: LOWERING STOCKING RATES.

Several "standard" dairy farming practices are seen to create environmental concern, many of which can be mitigated by lowering stocking rates. Intensive winter grazing is an example. Chris believes that intensive winter grazing on crops impacts water quality, soil quality and animal welfare. On Chris' farm, they practice extensive winter grazing, which causes no damage to the environment or animal welfare issues. This is achieved by having a low stocking rate. Having a high stocking rate puts more pressure on the smaller land areas, which damages the soil. There are fewer cows per square meter by lowering the stocking rate, and the cows can spread out. This reduces the chance of causing damage to the soil and waterways.

Chris brings attention to the value of soil on farm, "if you don't have soil, you don't have anything". To upkeep soil quality on his farm, Chris protects areas prone to erosion and does not disturb the soil so it can work with other organisms to maintain itself in a healthy state.
When it comes to protecting the waterways, Chris does not intensively winter graze, he is careful where and when the cows graze, and he ensures that there are low stocking rates.

\section{ENVIRONMENTAL WELLBEING: LONG TERM VIEW OF THE LAND.}

Chris and Glen both value environmentally sustainable dairy farming practices. The Happy Cow Milk model values sustainability. They want to reduce sprays, encourage diverse pasture plants, decrease nitrate leaching, and sell milk in reusable glass bottles.

When it comes to looking after the environment around Chris' farm he takes a long-term view. Chris' farm is situated on wetlands and his efforts target that unique ecosystem. He is conscious of how his actions on the farm could end up in the wetlands and the fact that the impacts of his actions might not surface for another 100 years.

"It's a 10o-year deal because some of the things you do won't materialise, you won't see what they are for 100 years and I'm not going to be here" C.F

Chris also considers the environment when making management decisions on the farm. This ensures the actions of both humans and cows do not cause harm and that the land is left better than before they arrived.

\subsection{DISCUSSION}

The knowledge that Glen Herud and Chris Falconer from the Happy Cow Milk Company shared in this case study supported the research question. After analysing the qualitative interviews and observational site visit, I was able to gain a solid understanding of what these two dairy producers consider the most significant animal welfare and environmental sustainability issues in New Zealand. Specifically, Glen and Chris provided insight into how these issues could be addressed through alternative dairy farming practices and farmer, cattle, and environmental relationships.

The findings from the case study indicate that forming respectful and 
caring relationships between humans, cattle, and the environment, and considering farmer wellbeing, will all be central to finding solutions to animal welfare and environmental sustainability issues. Collectively, Glen and Chris seek to create positive experiences for their cattle and consider both the cattle's mental and physical wellbeing - exemplifying some of Mellor's work on the Five Domains (2017). Their cattle live in a safe environment, have choice and are given the opportunity to engage in behaviours that they find rewarding. The findings from the case study also support Haraway's theory of forming meaningful relationships by cultivating 'responseability' for one another (2018). Glen and Chris treat cattle and the environment with good intentions, respect and care, and in return, positive relationships have formed. In addition, Glen and Chris

listen to their cattle and the environment to learn what is best for them rather than prioritising what is best for the human, such as production rates and profit. This supports Gillespie's theory (2018) that humans should learn from farmed animals and listen to their stories to re-imagine the relationship between them.

An unexpected finding from the case study was the importance of farmer wellbeing when addressing animal welfare and environmental sustainability issues. Although the three come together in the One Welfare initiative (One Welfare, n.d), farmer wellbeing was not identified in much of the cultural research as an aspect that needed to be considered when addressing these issues. In the case study, it was identified that farmer, cow and environmental wellbeing are entangled - hence using a Venn diagram to visualise the themes. If a farmer is expected to care for the wellbeing of their cattle and the environment, their wellbeing also needs to be respected. The case study demonstrates that this can be achieved by creating a lowpressure work environment and by farmers connecting and building trust with their consumers.

This case study was conducted to gain an in-depth understanding of the Happy Cow Milk Company's approach to dairy farming. While the results cannot be generalised, as the experiences and perspectives of the participants do not represent all dairy farmers in New Zealand, the case study provided valuable insight into the animal welfare and environmental sustainability issues associated with intensive dairy farming in New Zealand and how we might address these issues. Looking back at The Design Justice Principles, if designers wish to create social change we must "centre the voices of those who are directly impacted by the outcomes of the design process" and "before seeking new design solutions, we look for what is already working at a community level" (Design Justice Network, n.d). These principles were centred as I approached the research. As a result, I was able to learn directly from people within the industry about a topic that I was unfamiliar with, develop an in-depth understanding of the topic, and learn what the farming community is already doing to address the animal welfare and environmental sustainability issues. From this understanding, I developed ideas around how design might address the animal welfare and environmental sustainability issues within New Zealand dairy farming, knowing actual people those changes would effect.

Moreover, the findings from the case study were essential to informing and inspiring the design research and strengthening the design by grounding it in lived experience and empirical research. Both Glen and Chris expressed interest in listening to consumer concerns and actively alter their farming practices to address them. This builds trust with the consumer and allows them to contribute towards addressing issues that concern them - which is important because they should also have a say in how the food they purchase and consume is produced. This connects closely with Weary and von Keyserlingk (2017), who suggest that conversations need to open up between the public and the dairy industry. If people within the dairy industry can better understand the public's concerns, they might develop practices that begin to address them. Design can be used as a tool to open up discussion with the public about their concern for dairy farming and how they suggest we address these concerns. In the following chapter on the research-through-design process, this concept will be explored further, and the other ways in which the case study informed the design will be discussed. 
CHAPTER 4.

THE DAIRY ORACLE 


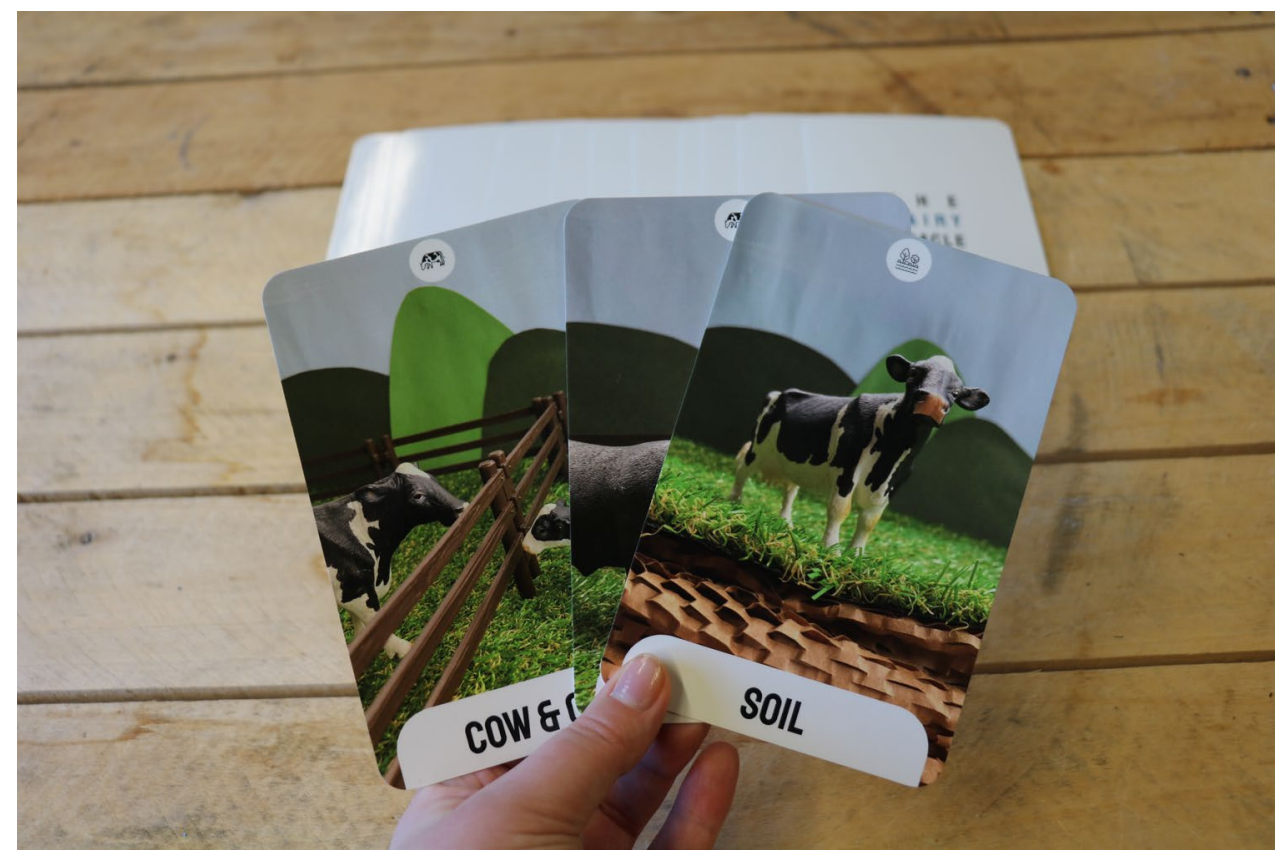

Figure 16. The Dairy Oracle - Three Card Pull

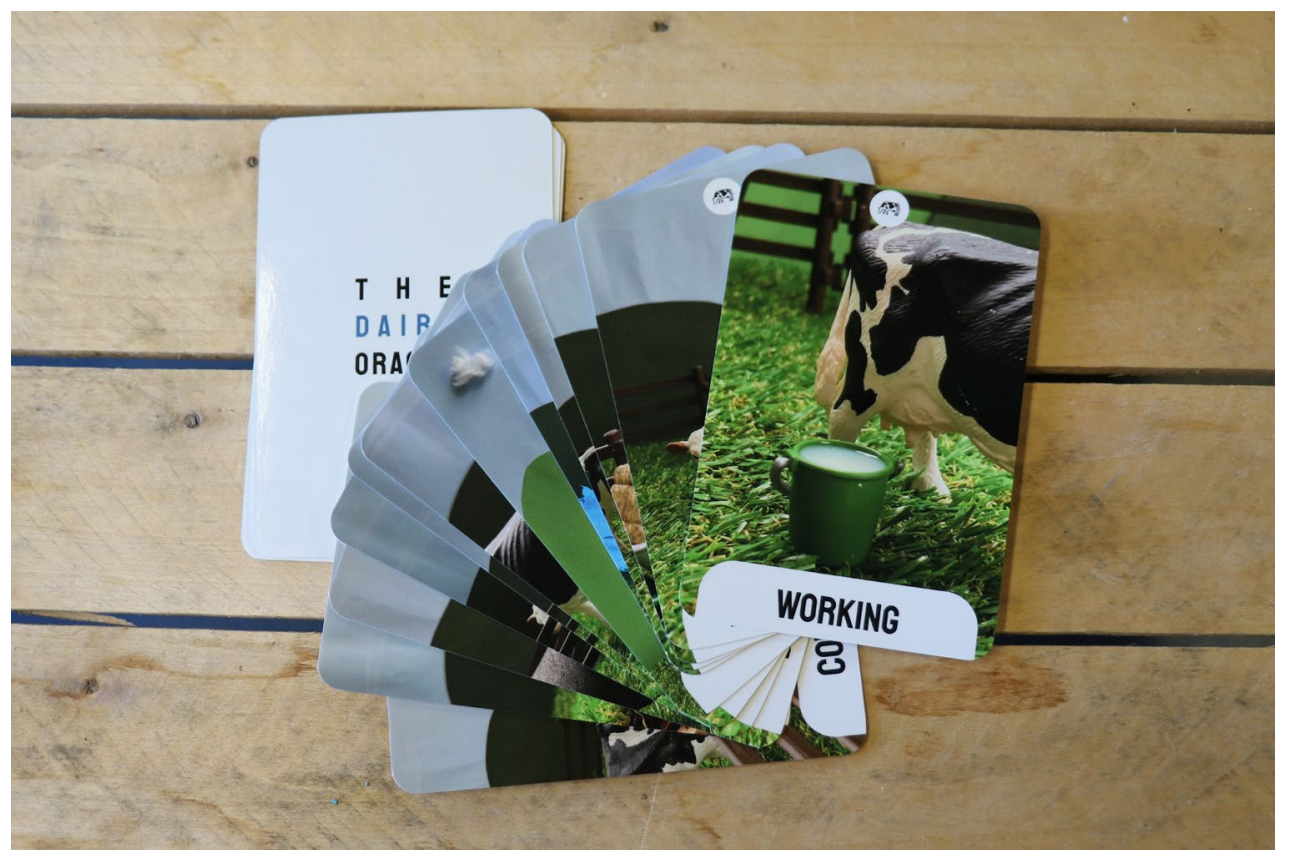

Figure 17. The Dairy Oracle - Card Spread 

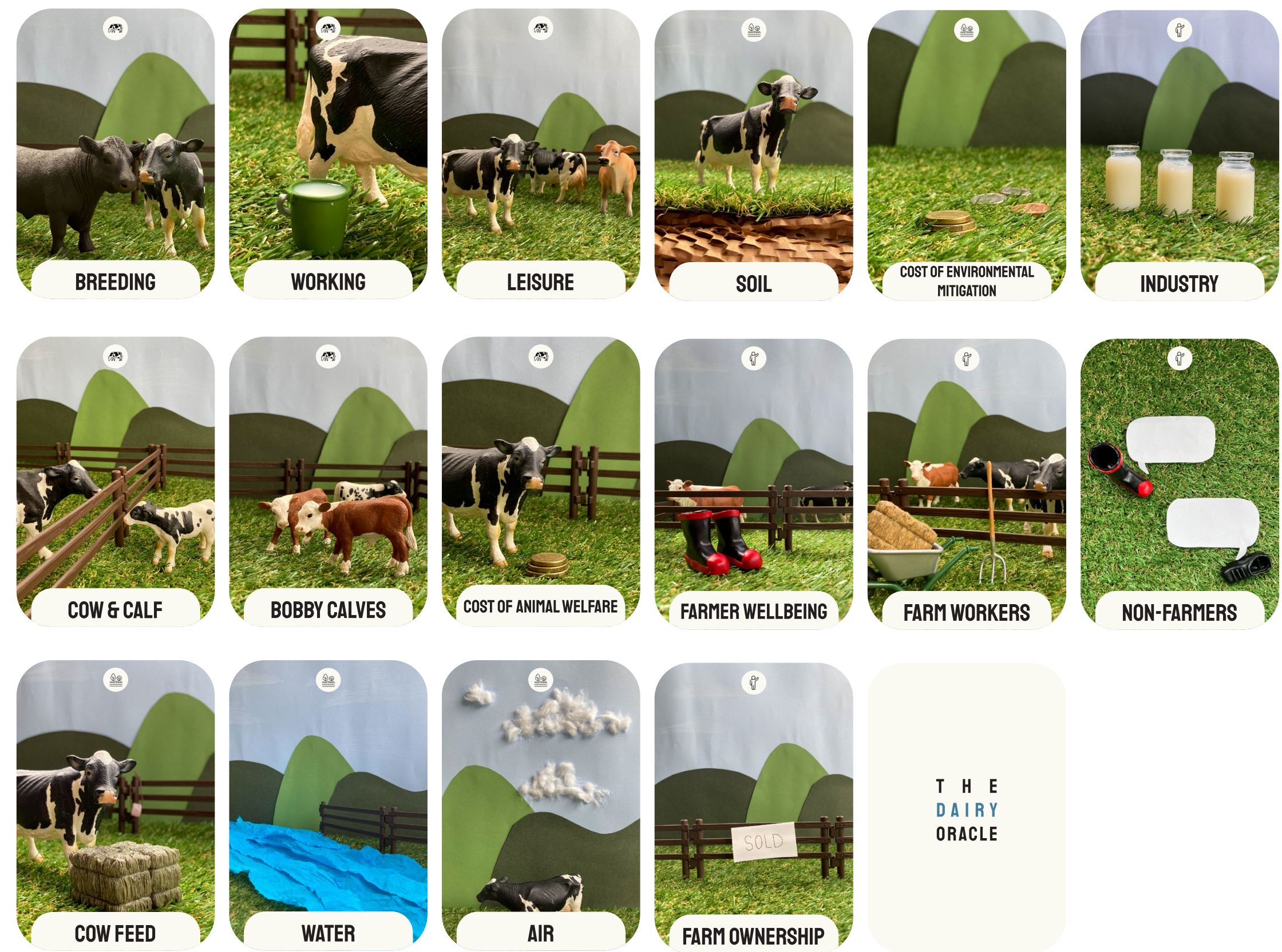

T H E

DAIRY

ORACLE

Figure 18. The Dairy Oracle - All Cards 


\subsection{DESIGNING THE DAIRY ORACLE}

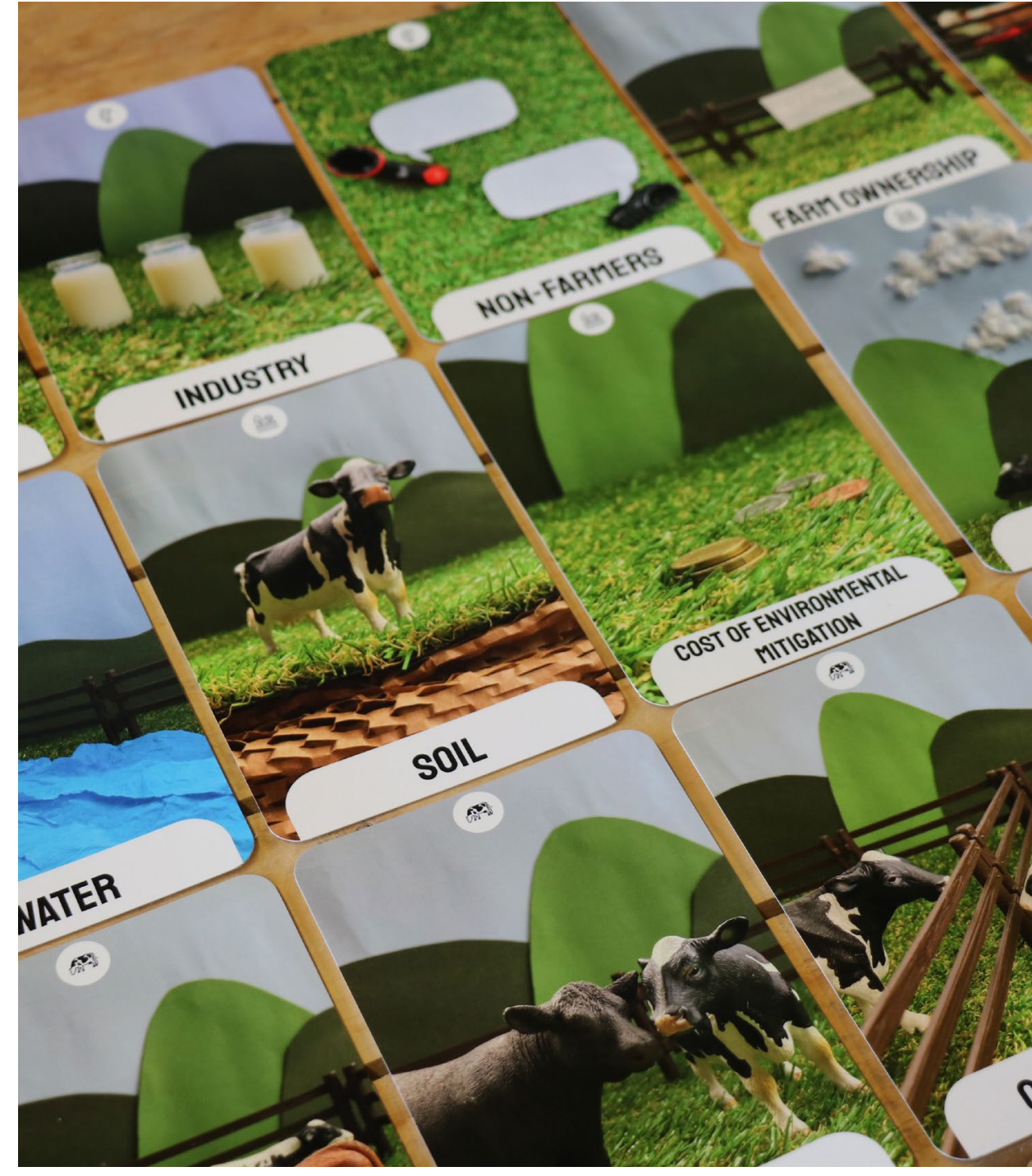

Figure 19. The Dairy Oracle
The initial objectives of the research-through-design process were to create a discursive design that aimed to 1) open up space for discussion, debate and imagination, 2) develop a tool that encourages people to reflect and respond to the animal welfare and environmenta sustainability issues associated with dairy farming in a unique way, 3) collectively generate alternative sustainable and non-exploitative solutions and 4) facilitate an accessible space for public engagement with the designed artifact.

However, due to time constraints, these objectives were revised to be more experimental, making the design process manageable within the programme time frame.

The revised experimental design aimed to 1) facilitate an accessible space for public engagement with a designed artifact that sparks discussion, debate and imagination, and 2) prototype and test a tool for collecting existing knowledge and generating new possibilities.

\subsubsection{THE DAIRY ORACLE: FINAL PROTOTYPE}

The Dairy Oracle is an experimental tool designed to encourage knowledge-sharing and discussion about the present and future of New Zealand dairy. Traditionally, oracle decks are used for inspiration or insight into a situation (Saint Thomas, 2020) or to understand the present and interpret the future ("The Oracle for Transfeminist Technologies", n.d). There are no restrictions on what an oracle can be; the number of cards in the deck, card imagery and purpose of the oracle deck is determined by the creator. Oracle cards are often confused with tarot cards. Tarot cards are a mid-15th century card game used as a tool for guidance and self-reflection. However, the deck is traditionally structured; every tarot includes the Major Arcana, the major lessons in life, and the Minor Arcana, day-to-day experiences (Smith, 2020). Both card decks achieve similar goals but have different ways of achieving this goal. By designing an oracle deck rather than a tarot deck, I had the freedom to explore card concepts that were not restricted by the Major Arcana tropes of the tarot. 
The Dairy Oracle contains 16 cards. Each card depicts a different theme associated with cow, environmental and farmer wellbeing in New Zealand dairy farming (figure 19). For example, the 'air' card explores the impact farming practices have on air quality, the 'working' card explores a cow's work life, and the 'non-farmers' card explores the relationships between farmers and non-farmers. Through the cultural literature review and case study with Happy Cow Milk, these themes were identified as areas that are currently causing concern and should be addressed if we hope to improve cow, environmental and farmer wellbeing in the future.
The Dairy Oracle was designed to be used for readings in publicly accessible places such as farmers' markets or A\&P shows. The interaction map (figure 20) illustrates how the interaction would ideally go. The public are invited to participate in one-on-one

readings, where the reader presents the participant with three cards. Participants are then prompted to discuss their understanding of the themes depicted on the oracle cards. Following this discussion, they are asked to pick one card from the three card spread, and prompted to imagine how we might farm dairy differently in relation to the theme on the card. For example, if the 'air' card is selected, they might imagine possible farming practices that improve air quality.

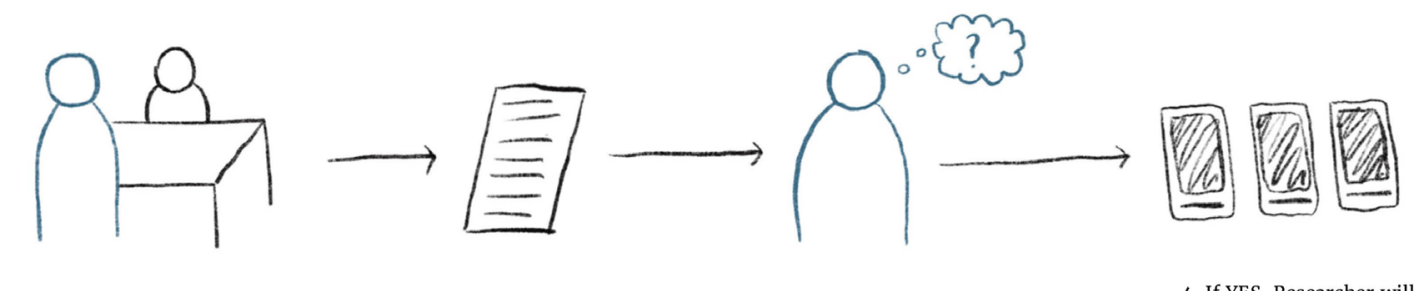
2. Researcher explains 3. Participant decides if they 4. If YES, Researcher will 1. Participant app information sheet to participant.
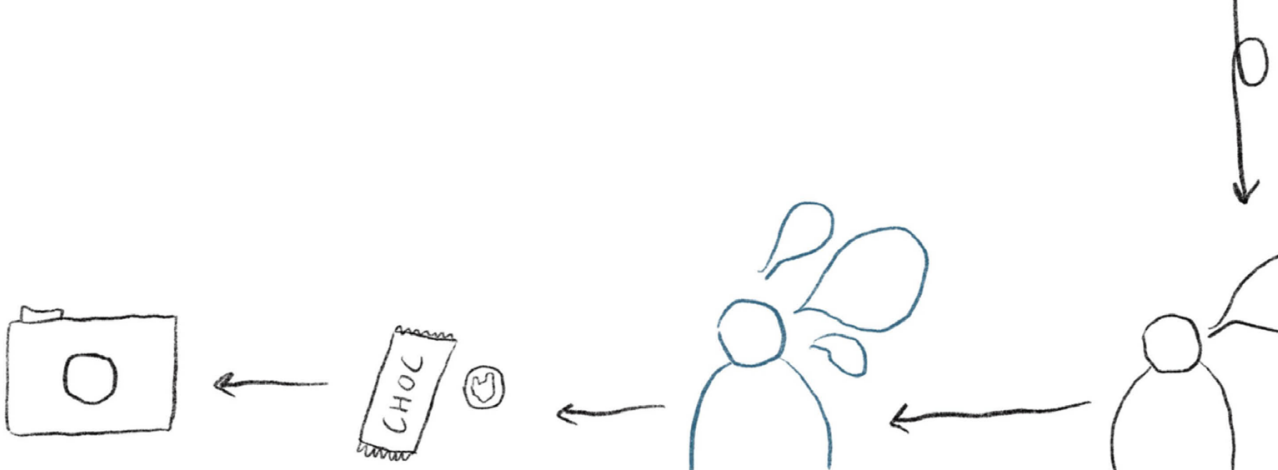

8. Researcher takes a photograph of the cards and

7. After the last card is discussed, the participant is thanked for and off.

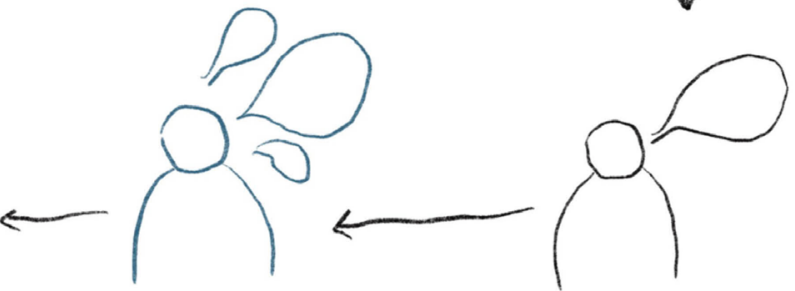

6. Participant responds and a peer of the Researcher take notes
discussion.

Figure 20. Interaction Map of The Dairy Oracle Reading 


\subsubsection{THE DAIRY ORACLE: DESIGN PROCESS}

This section explores the design of The Dairy Oracle, including the initial concepts and the development of the card content, card imagery, and card layout. Before deciding to develop oracle cards as a design output, I explored other potential outputs. These outputs included an interactive activity, such as a board or card playing game, or an interactive digital interface. I was drawn towards the concept of oracle cards as they are generally used a self-reflection tool that offers guidance, clarity and new perspectives.

\section{CONCEPT 1}
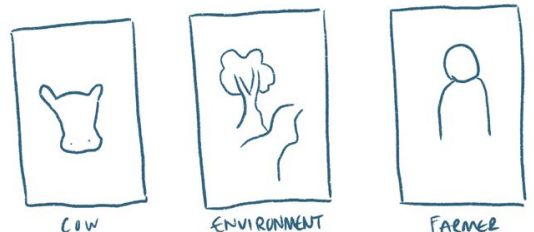

CONCEPT 2
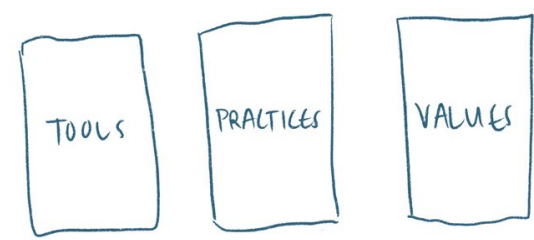

CONCEPT 3:

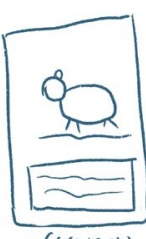

SLENARIO

Figure 21. Card Concepts
INITIAL CONCEPTS:

Concept 1: The cards are split into three themes - animals, environment and farmer. Each card depicts a different scenario associated with the themes. 3 cards are pulled from the shuffled deck and the participant is asked if together these cards depict a utopia or dystopia future and why.

Concept 2: The cards feature different tools, practices, and values associated with dairy farming. The cards are spread out on a table and the participant choose 5 cards to 'build' their ideal dairy farm. They will then be asked to explain the farm they have built and why.

Concept 3: The cards each depict a detailed speculative future associated with dairy farming. One card is pulled from the deck and discussed with the participant to understand their current concerns and if they believe the future presented on the card will help improve cow, environmental, or farmer wellbeing.

\section{DEVELOPMENT: CARD CONTENT}

In Chapter 3, it was discussed that design could be used as a tool to open up discussion with the public about their concerns for dairy farming and how they suggest society address these concerns. Although all of the concepts had potential to open up discussion in different ways, concept 1 was developed further while concept 2 and concept 3 were discarded. Concept 1 was chosen because the knowledge gained through the cultural research would be communicated well through the animal, environmental and farmer card themes. However, it still needed to be refined in order to become a useful tool for collecting existing knowledge and generating new possibilities.

The card content is the element that prompts discussion around existing knowledge, so, it was the first area to be developed and refined. Concept 1 was made up of different scenarios associated with cow, environmental and farmer wellbeing. The first stage of the development was to identify what types of scenarios would be featured on the cards. Informed by the cultural literature review and case study with the Happy Cow Milk Company, I identified the 

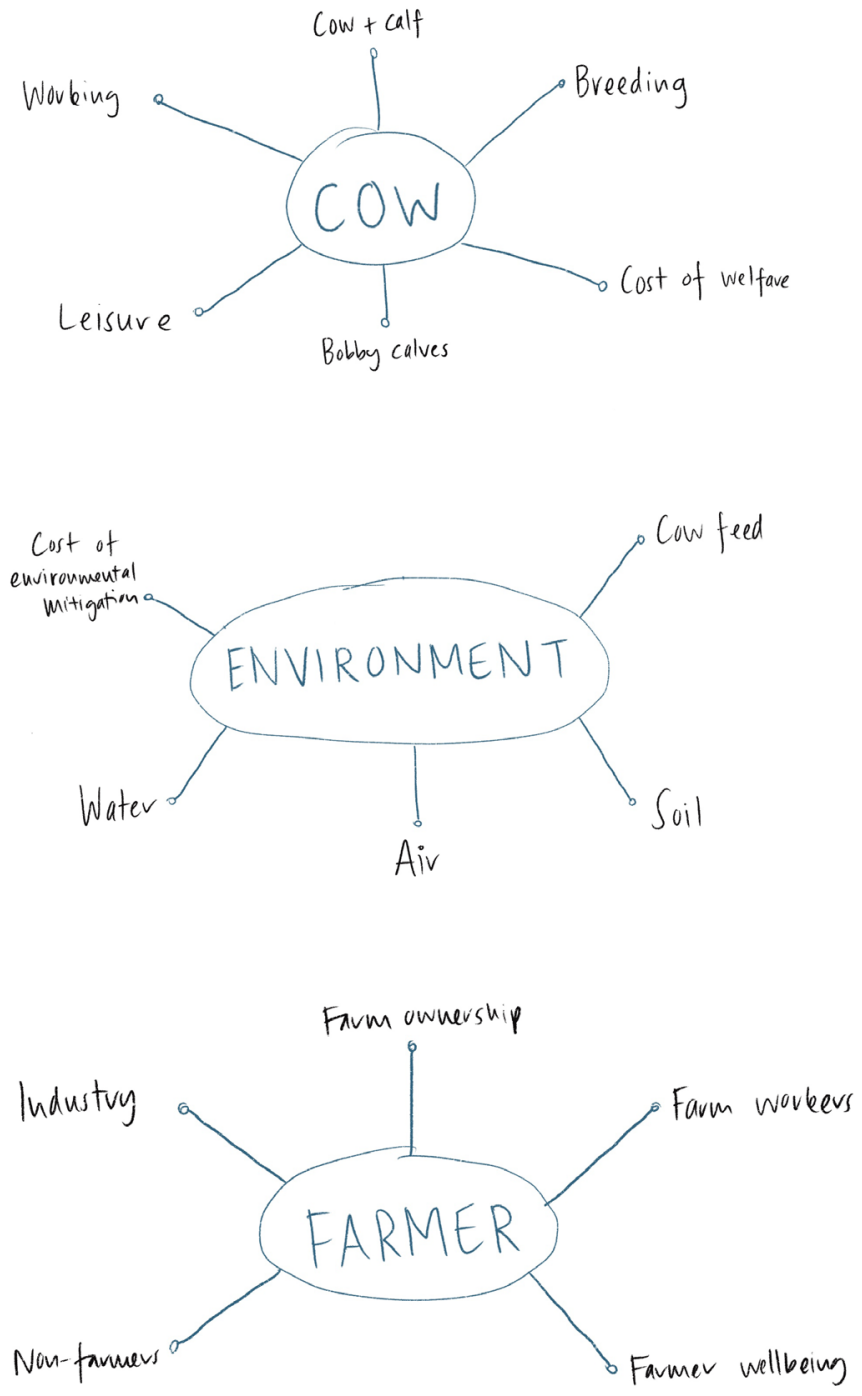

Figure 22. Card Themes values, practices, or relationships causing concern around cow, environmental, and farmer wellbeing (Figure 22).

In the initial concept, each card would depict a different realistic or fantastical scenario based on the themes outlined in figure 22 and the participant would be asked to discuss if they agreed with the scenario or not. This would hopefully provide insight into the participant's concerns and if they agreed with the scenario depicted on the card. An few example scenarios were "Breeding: cows choose when they breed and are not valued for their ability to get pregnant", "Water: if water on the farm is contaminated, the water will retaliate by leaving and going somewhere else where it'll be looked after" and "Non-farmer: For one week a year, people who consume dairy go and work on a local dairy farm".

After some exploration, I found these scenarios to be restricting. The participant would likely respond to the scenario on the card rather than the overall theme, which might restrict them from sharing their genuine concerns. The cards were then simplified to feature just the themes depicted in figure 22 . These themes are relatively vague and would rely heavily on verbal prompts to communicate their meaning. This might sound like a limitation, but I see it as a strength because the cards can be used in versatile ways if needed.

As the design developed, I wanted the cards to open up more space for the participants to discuss their understanding of dairy farming, not just their concerns. This would give the reader-researcher insight into what the participants do (and do not) understand about dairy farming - something often overlooked in forward-focussed speculative design - as well as what, if any, concerns they have. Only then would the reader ask what participants think the future of dairy could or should be. This broader mandate allowed the tool to be used for "divining" both current and alternative understandings, expanding its research and design value.

\section{DEVELOPMENT. CARD IMAGERY}

Visual design enhances the experience of the reading and communicates the meaning of the card. On many oracle cards, the imagery is communicated through illustration, hand-drawn and digital. As I developed the imagery of The Dairy Oracle, I 
researched alternative styles that used a range of media, including physical props and photography (figure 23).

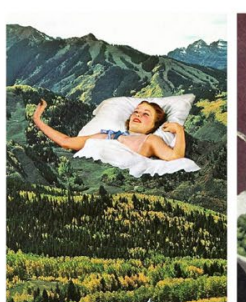

(1)

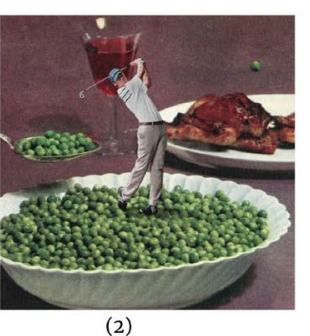

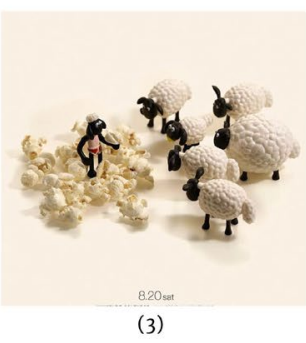

Studio shots with props.

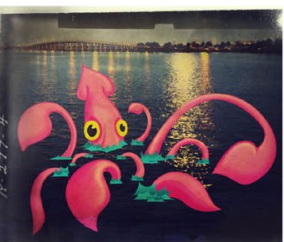

(7)

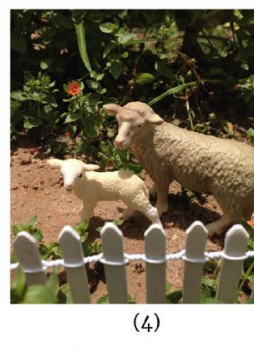

Shots in natural settings.

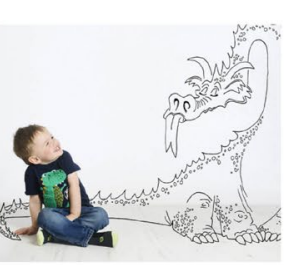

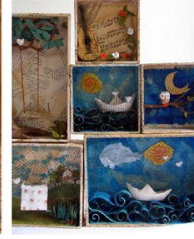

(6)
Scenes created with dioramas and then photographed.

Photographs with illustrations over the top.

Figure 23. Research into card imagery styles

In order from 1-8: ([Untitled photographic collage of girl sleeping in a valley], n.d), ([Untitled photographic collage of man playing golf on peas], n.d), ("Corn the Sheep", n.d), ([Photograph of sheep figures], n.d), ("Hoppy bunny thanksgiving dinner", 2011), (Ferreira, 2011), (Aguilera, 2010), (Schmidt, n.d)

I decided to create and photograph a diorama scene. This visual style was chosen as there was more freedom to craft scenes and props that would help communicate the themes on the cards. The diorama scene was planned and built around a herd of toy cow, calf and bull figurines. It was designed in a way that could represent a New Zealand pasture-based dairy farm. The scene included green grass, blue skies, rolling hills and wooden fences (figure 24) and was crafted using a mixture of materials and textures - artificial turf, paper, glass, clay and plastic figurines.

The scenes are rather idealistic as they present artificial versions of

reality. They illustrate scenes that are familiar but not quite real, this helps prompt discussion around present-day dairy farming, however, it was uncertain if the imagery would assist with creative imagining.

At this point of the design development, the idea was to have two cards for each theme. The imagery on one card would communicate present dairy farming, and the other card imagery would prompt future imagination. The participant would be prompted to discuss either the present or future of the card theme, depending on what card they pulled. This idea was abandoned because having 'future' cards might have put pressure on the participant to imagine a future for a theme they might not understand; future imaginings would likely build on the participants current understanding.

In the end, I decided that the oracle deck would only consist of the 16 theme-based cards, and verbal prompts would instead be used to guide the conversation. It was my hope that the reader (and the event) could then take on some of the design burden I had, until then, placed exclusively on the cards.

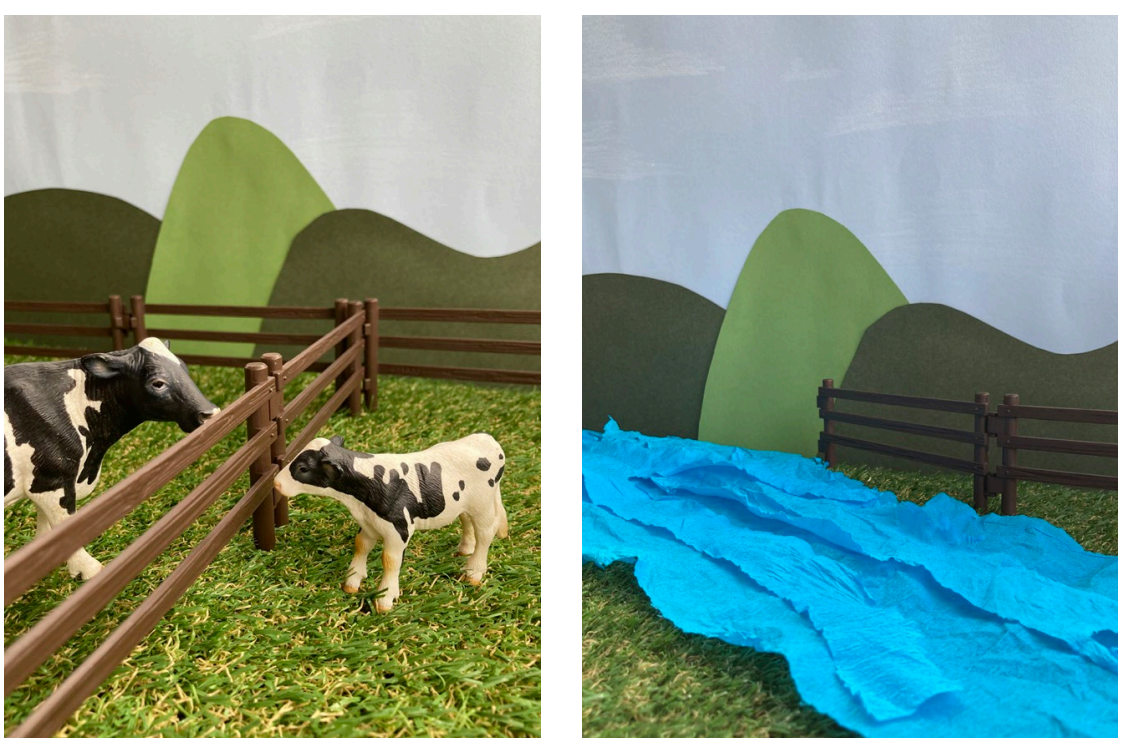

Figure 24. The Dairy Oracle diorama scene 


\section{DEVELOPMENT: CARD LAYOUT}

The last stage of designing the oracle cards was the layout. Existing oracle cards were used as precedents to explore how they combined imagery and text to communicate the cards' meaning effectively.

Most oracle cards have similar layouts. The imagery takes up most of the card and is often surrounded by a border, the text sits below the imagery and uses an uppercase font. As I began to develop the card layouts, I used these as 'rules'. I explored a few layout iterations (figure 25) by playing with borders, shapes, icon locations. The icons were incorporated to indicate whether the theme related directly to cow, environmental or farmer wellbeing. The last iteration was chosen as the final layout. The cards were then sent away to be printed on 4" 6 6" card.

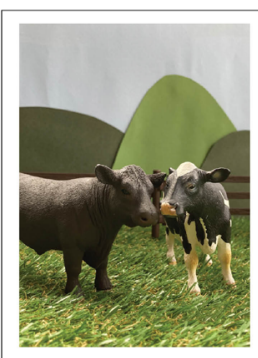

BREEDING

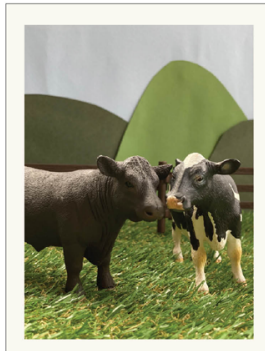

breeding

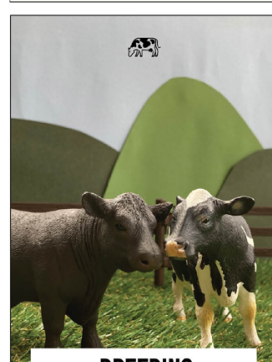

BREEDING

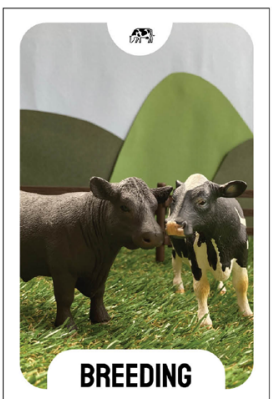

(4)

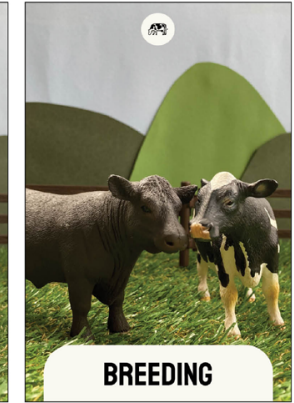

Figure 25. Card layout iterations

\subsection{TESTING THE DAIRY ORACLE}

\subsubsection{THE EVENT: PLANNING}

To test The Dairy Oracle prototype, I planned to present it for public engagement at a local farmers' market. Before I was able to present The Dairy Oracle, an amendment to my ethics application (\#000002885) was submitted and a stall space at a local farmers' market was organised. On the terms that the research would be confidential, the ethics amendment was approved (See Appendix D for approval email and Appendix E for information sheet). Next, was the stall space. After sending out emails to a majority of the farmers' markets in Wellington City, I got a response from Wellington's oldest and most popular farmers' market, the Harbourside Market. A reading of The Dairy Oracle was organised, however, it was cancelled due to unforeseeable circumstances and was re-scheduled for a few weeks later.

The way the design was interacted with by the public was just as important as the design itself. Leading up to the event, one-on-one readings of The Dairy Oracle were planned and practiced. I created an interaction map, a prompt script, and ran practice readings with peers. The interaction map (figure 20) was submitted as a part of the amendment to the existing ethics application. Participating in a reading of The Dairy Oracle would be voluntary and the participants would be free stop the reading at any time. Depending on the participant, the readings were planned to run for about 5-10 minutes. As the reader-researcher, I would have to guide the conversation but also recognise when the participant was finished discussing a card or ready to finish the reading. During the reading, a peer of mine would take detailed notes of the discussion and interaction, and I would later add to these notes with my own observations. Once the reading was over, the participant would be offered a chocolate and sticker as a

'thank you' and I would take a photograph of the cards for reference.

The one-on-one readings of The Dairy Oracle were guided by Dolejšová's (2021) readings of the speculative oracle, The Parlour of Food Futures. Dolejšová's readings go as follows:

1. The participant would sit down, the reader would then shuffle the deck and lay down one card. 
2. The reader would then initiate conversation with the participant by explaining the card that was presented and asking the participant questions about their experiences, ideas and opinions.

3. 2-4 additional cards would then be presented and discussed.

4. Once the reading was finished, the participant was asked to select one card from their spread that they thought was "important" and create a short 'what-if' scenario where they imagined what it would look like to be a member of the future presented on the card.

5. The participant could articulate their future in the form of written text, a drawing, or a crafted artefact.

The Dairy Oracle readings were planned to go as follows:

1. The participant would sit down, I would then spread out the cards and ask the participant to pull out 3 cards.

2. I would ask the participant to turn over one card.

3. I would then initiate conversation with the participant by briefly explaining the card and asking them a question about their understanding of the card presented.

4. The remaining cards would be turned over one at a time and discussed.

5. Once the reading was finished, the participant would be asked to select one card from the spread that they would be interested in re-imagining a future for.

6 . I would then prompt the reader to verbally explain their future.

After planning the interaction, I prepared a prompt script (see Appendix F). I needed prompts that explained each individual card, followed by a question that would open up the discussion and finally, prompts to encourage the participants to re-imagine what they had just shared as their understanding. The verbal prompts went through a few iterations as I practiced them with my peers. I found that providing them with a fact about the card topic was helpful as it provided them with something to discuss further.
Developing the prompts for creative imaginings was challenging After testing with a diverse range of peers, I noticed that imagination was not easy for everyone. At first, the only prompt I was giving was to pick one card to imagine a future for; ideally it would aim to improve cow, environmental or farmer wellbeing. Some people could easily work with this prompt whereas others expressed that they did not understand what they needed to do. As a designer this was important, I had to understand and recognise that non-designers approach creative tasks differently. With the assumption that the potential participants would likely not be from a creative background, I developed verbal prompts to assist with the creative element of the reading. They prompted discussion around what their future aimed to achieve, what types of relationships, values and practices might exist and the overall setting of the future.

After planning the event, I was ready to share The Dairy Oracle for public engagement at the Harbourside Market. The next section is a critical reflection of the event, how the public engaged with The Dairy Oracle and how it could be further developed in the future.

\subsubsection{THE EVENT: CRITICAL REFLECTION}

The day to present The Dairy Oracle came. It was a sunny day with minimal wind, so there were many people out and about enjoying the weather and the farmers' market. The Harbourside Market manager kindly allocated me a space facing the produce area as it attracted a lot of foot traffic. I set up my stall and decorated it with the cow figurines featured in the oracle card imagery. At the front of the stall, I placed a board that said, "This MDI research project presents The Dairy Oracle - let's re-imagine NZ dairy futures", and next to it, I placed some information sheets for people to read if they were interested (see figure 26).

I began readings of The Dairy Oracle at 9 am and stayed until $1 \mathrm{pm}$. Although the market was consistently busy the entire period, most people stopped by at the beginning and end of my time there. Despite there being a lot of foot traffic passing my stall and a few people 

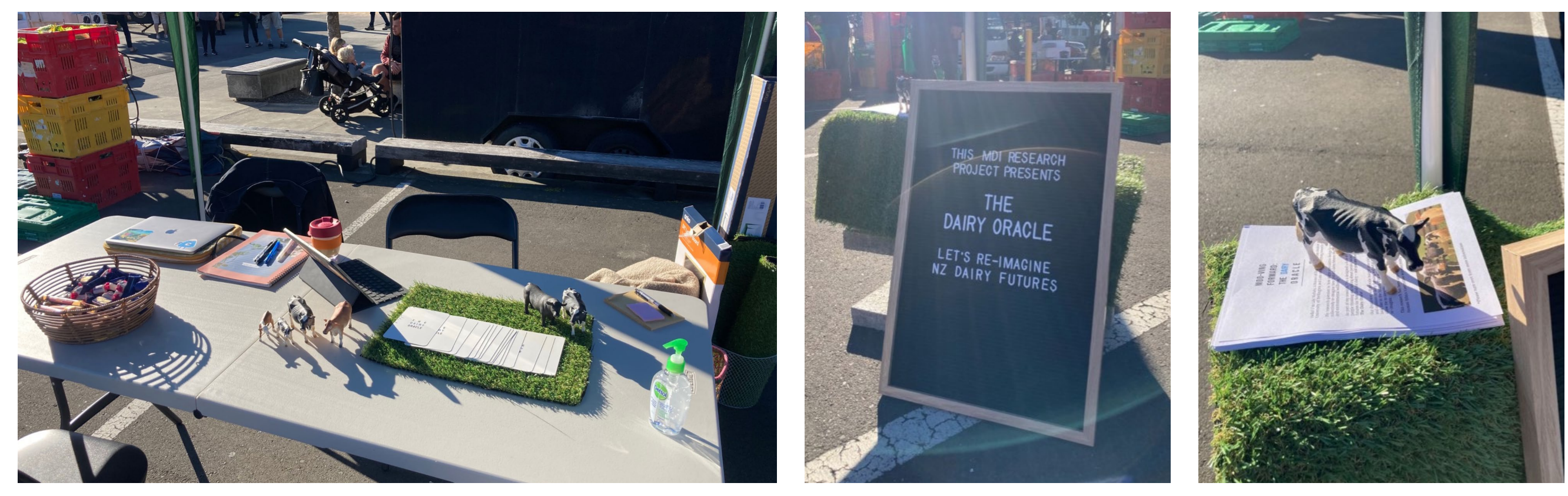

Figure 26. Photographs of stall set-up.
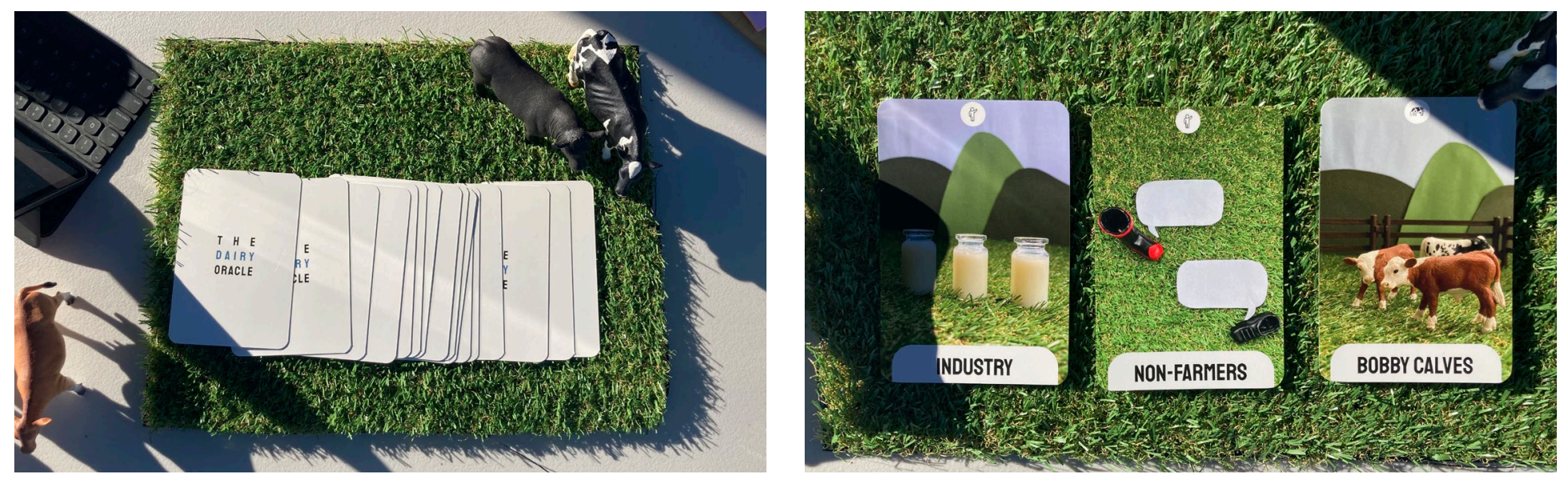

Figure 27. Photographs of card spread. 
taking information sheets, overall, there was very little engagement. I had 7 people stop by, and 5 of those people engaged in a reading of the oracle. Unfortunately, due to time constraints, I could only hold one event for The Dairy Oracle. This, coupled with the low engagement rate, makes it is impossible to claim design "success" or "failure" However, my objective was simply to test my prototype and in this regard, I was able to gain valuable insights into how people interacted with my design, and how it met the experimental design objectives.

Documenting and analysing the event was also complicated. With the help of a peer, I was able to document participant's responses. My peer took detailed notes during the readings, paying close attention to the interaction and participant's responses. Following the readings, I also took notes on my observations, thoughts and experiences. I decided to record the readings through notetaking because it was less intrusive than audio or video recording and not covered in my ethics approval. In addition, having a note-taker allowed me to be present with the participant during the reading and not have to worry about stopping to write notes or trying to recall what they said after the reading. I recognise that some responses and descriptions of the interaction may have been missed through this form of documentation. However, my peer worked hard to document the participant's responses accurately, and it was a successful way of documenting the most important or interesting moments from the day. For complex research scenarios, the design of the event would need to include multiple means of participation, observation, and documentation.

The readings were one-on-one, except for one reading where two participants engaged in the reading together. When potential participants approached the stall, I would greet them and chat with them about my research and the purpose of The Dairy Oracle. Those that wanted to participate took a seat. Before starting the reading, the participants would ask me questions about the research and my background in dairy. I took this opportunity to ask them a bit about their association with dairy; this gave me an insight into who was interested in engaging with The Dairy Oracle. The intended audience was shoppers at the farmer's market. I assumed this would include people from outside the agricultural industry, but this assumption was challenged as I found that most participants were associated with the agricultural industry - one participant was even a dairy farmer.
After getting to know the participants a bit more and allowing them the space to ask me questions, I began the reading. I spread the cards out (figure 27) and asked the participant to pick out three cards. I favoured this method over shuffling and dealing because it allowed the participant to engage with the cards. They were then asked the flip all the cards over. I originally wanted them to flip over one card at a time, but after doing this with the first participant, I found it harder to move the conversation onto the next card if it was not turned over. By having all the cards turned over, it was easier to introduce the next card when the conversation lulled or when the conversation led away from dairy.

My role as the reader of The Dairy Oracle was an important aspect of how the participants interacted with the design. It was my job to introduce the card and guide the conversation. When the conversation lulled, I had to recognise whether I should embrace the silence to give the participant time to think or move onto the next card. When the conversation went off on a tangent, I had to find appropriate times to intervene and bring it back on topic. It was also important that I held a neutral presence to avoid influencing the participants with my interpretations or understandings. However, this proved challenging because the card explanations were all based on my interpretation of the card, and I would often share my understanding when participants asked me to do so.

During the readings, the oracle cards and the reader prompted the participants to discuss their understanding of dairy farming in New Zealand. Once we discussed their knowledge of dairy farming, the participant would be prompted to pick one card and think about a future that might address concerns that they discussed during the reading or improve cow, environmental or farmer welfare.

Figure 28 maps the participants' understandings and figure 29 maps their future imaginings in relation to farmer, cow and environmental wellbeing. Due to there only being 5 participants, these responses are specific to the participants and cannot be generalised to the public. However, the participant's responses allowed me identify what worked and what did not work well with the design. 


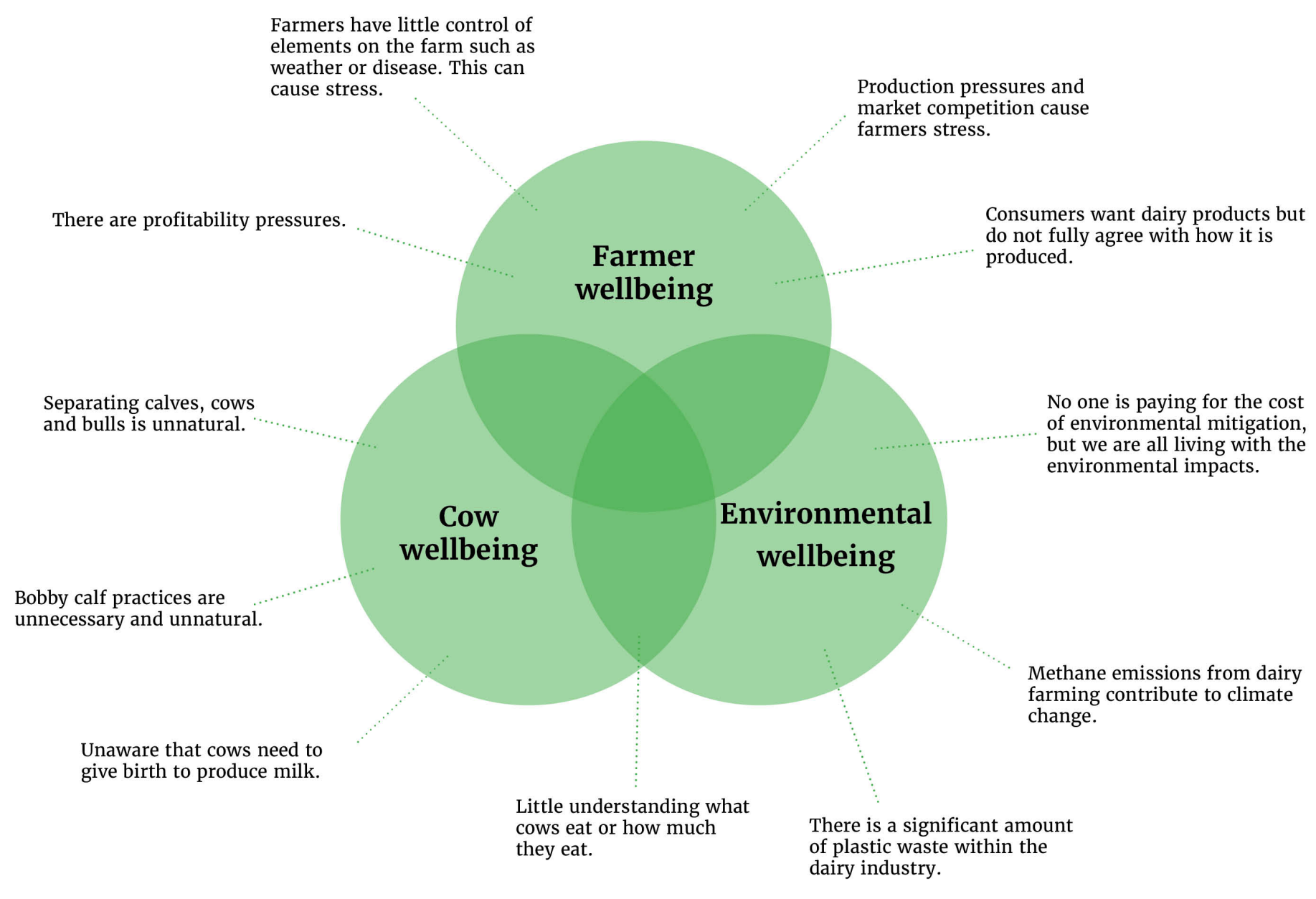

Figure 28. Venn Diagram of the participants' understandings in relation to farmer, cow and environmental wellbeing. 


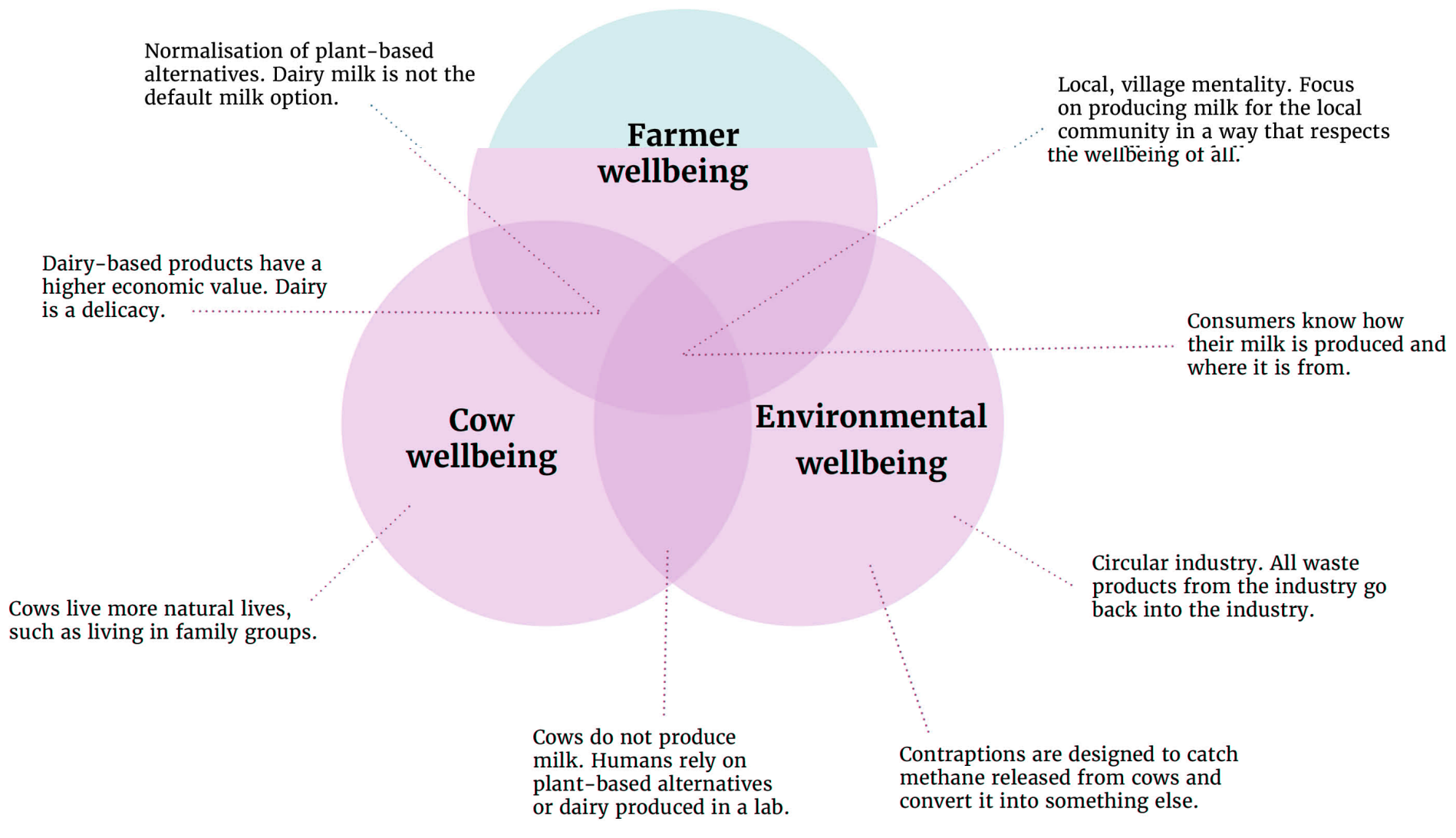

Figure 29. Venn Diagram of the participants' future imaginings in relation to farmer, cow and environmental wellbeing. 
The Dairy Oracle worked well as a prompt to get people thinking and talking about dairy farming in New Zealand. The aim of the design was simple, and participants understood the intent of the interaction - to talk about their understanding of dairy farming and what they think it could or should look like in the future. The level of understanding varied from each participant; some had an in-depth understanding, whereas others had very little. I found myself sharing the knowledge I had acquired through my research with those who had little understanding of the topic, which helped the conversation open up. The participant's reaction to the information I shared often showed whether they were concerned about the topic or not. For example, one participant picked the 'breeding' card in which I explained that breeding is an important part of dairy farming because cows can only produce milk if they have been pregnant. This fact surprised the participant as they were unaware of this practice and it also made them think about what happens to the calves. Participants who had a deeper understanding often shared their concerns for dairy farming alongside their understanding. For example, one participant shared that they understand dairy farming practices release methane into the atmosphere and they find this concerning because it contributes to climate change.

After reflecting on the participant's responses, it became clear that although they were asked to 'imagine' a new future for dairy, no one actually imagined anything new. Rather, they imagined something different from what they already understood. For example, one participant shared that they understand that bobby calves are separated from their mothers at an early age. They commented that this practices was unnecessary and creates a disconnect, so, they would like to see a future where calves, cows and bulls live in family groups. Another participant shared that they understand many people know about the issues that arise from dairy farming but do not want to stop consuming it. In their imagined future, dairy products would still exist but they would be produced in a lab environment to minimise animal suffering.

\subsection{DISCUSSION}

The Dairy Oracle is an experimental tool that aims to spark discussion, debate and imagination. Inspired by cultural research into New Zealand dairy farming, The Dairy Oracle was prototyped and tested as a means to prompt discussion around existing understandings of New Zealand dairy farming, and spark future possibilities for dairy farming. Due to the experimental agenda of the design, it is important to reflect on the experience and knowledge gained through the process rather than assess its success as a refined outcome.

Therefore, it was beyond the scope of this project to say much about what those understandings and imaginaries might be, but I was able to assess some of my proposed tool's potential for future research and public engagement.

Through the process of creating The Dairy Oracle, I found that the knowledge gained from the cultural literature review and case study with the Happy Cow Milk Company was central to inspiring and informing the final prototype. This supports Tharp and Tharp's (2018) claim that when working with an external, non-design topic, such as dairy farming, it is beneficial for the designer to research relevant literature and conduct primary research. This research will support the design of an effective and well-informed artifact. From the background research, I was able to identify themes within dairy farming that were causing concern and needed to be addressed if we hoped to find solutions that improved the lives of farmers, cattle and the environment; these themes were depicted on the oracle cards. Through the background research, I was also able to identify the ideal audience to test The Dairy Oracle prototype with. Weary \& von Keyserlingk (2017) and the case study participants, Glen and Chris, expressed the importance of listening to the public's concerns to find possible solutions to address animal welfare and environmental sustainability issues. For this reason, the audience for this prototype of The Dairy Oracle was the shoppers at The Harbourside Market.

The Dairy Oracle event at the Harbourside Farmers' Market was the most valuable part of the design process. This event gave insight into how people interacted with the oracle deck. From this, I was able to reflect on the design objectives and if they were achieved through the final prototype. The first objective was to facilitate an accessible space 
for public engagement with a designed artifact that sparks discussion, debate and imagination. The findings supported Dolejšová's (2021) eventful speculative design approach. The Dairy Oracle event opened up space for the public to discuss issues associated with dairy farming and contribute their experiences and insights. However, it was challenging to hold the event in a publicly accessible place such as the farmers' market. Going into the event, I was unsure of how many people would participate or if anyone would participate at all. Only a few people participated in The Dairy Oracle event despite the Harbourside Market being a busy public space and a majority of those that did participate were from an agricultural background. I am uncertain as to why there was a low engagement rate, and why those with a background in agriculture engaged more often than consumers that day. More public readings of The Dairy Oracle would need to be conducted to make a claim about this.

Another challenge of holding the event in a publicly accessible place was the advertisement. For this event, there was little advertisement apart from the letter board (figure 26). I chose not to approach people or hand out information sheets because participation was voluntary and I did not want to pressure anyone into feeling like they needed to participate. As I reflect back on the statement on the board "let's re-imagine New Zealand dairy futures", I question if it was enough to communicate what I was doing, or spark people's interest to participate. The letter board could have possibly posed a question to spark the interest of potential participants and the stall might have benefitted from more signs that better explained The Dairy Oracle and what was expected from the participants.

The second design objective was to prototype and test a tool for collecting existing knowledge and generating new possibilities. Every person that participated in a reading at the Harbourside Market shared their existing knowledge and imagined a future of dairy farming that they would like to see. However, it was identified that the futures that participants were imagining were based on existing knowledge rather than re-imagining something new. Although their futures aimed to address animal welfare and environmental sustainability issues, they did not generate new possibilities.

In future research, there could be further exploration into how The Dairy Oracle could be more successful at prompting the imagination of new possibilities. This could be done through the development of the imagery on the cards, possibly re-exploring the dual-version concept that was abandoned earlier in the design development. It is possible that different imagery is needed to help people imagine something new. Alternative ways of reading The Dairy Oracle could also be explored further. The way the reading is structured or the prompts that the participants are guided with could be iterated to investigate the best way to encourage imagination, or to understand if imagination is achievable through eventful speculative design especially with participants from a non-design background.

Additionally, eventful speculative design relies on participants participating with the design in an intended way. A couple of participants at The Dairy Oracle event did not interact with the oracle in the way I had intended, their discussion went off on a tangent multiple times and at one point two participants engaged in one reading together. It is important to recognise that participants will not always engage with the designed artifact in the way it was intended. As the reader-researcher, all I could do was redirect the conversation and ask relevant follow-up questions. There is still potential for the participant to share a meaningful contribution, even if they are not interacting with the design in the intended way.

The Dairy Oracle does not seek to fix the welfare and sustainability issues associated with dairy farming. However, through public engagement the oracle deck encouraged people to think about what they believe the future of dairy farming in New Zealand could be. Imagining what could be is the first step to creating change. 
CHAPTER 5.

\section{CONCLUSIONS}




\subsection{CONCLUSIONS}

The animal welfare and environmental sustainability issues that arise from intensive dairy farming in New Zealand are causing concern with people both within and outside the industry. To create a better world for dairy cattle and sustain the environment for future generations, we must find solutions that address these issues. Throughout this research, possible solutions were identified through cultural and design research, which developed an understanding of what New Zealand dairy farming is today and imagining what it could become in the future. As we begin to find solutions that address animal welfare and environmental sustainability issues, we must form and nurture respectful and caring relationships between humans, cattle and the environment and centre farmer wellbeing alongside cattle and environmental wellbeing. It will also be essential to discuss the new possibilities of dairy farming with people both within and outside the industry.

To do so, The Dairy Oracle was designed as an experimental tool to open up discussion about the present and future of the relationships and practices within dairy farming. The oracle encourages the public to share their understandings and imaginings of themes associated with farmer, cattle and environmental wellbeing through one-onone readings. Although it was beyond the scope of this research to comment on the understandings and imaginings that came from The Dairy Oracle event at the local farmers' market, with further research, the oracle deck has the potential to foster discussion, debate and imagination in publicly accessible spaces.

If I were to take this research further into a $\mathrm{PhD}$ project, attention would be given to the development of The Dairy Oracle prototype. The oracle deck and public engagement events would be iterated to better understand the value public engagement has to the discursive design agenda, specifically eventful speculative design. I would also be interested in further exploring the value imagination has to addressing complex social issues, such as intensive agriculture.

As I come to the end of this research portfolio, I must look back on what I've learned throughout the process. The methods used to conduct this research were relatively new to me and took me out of my comfort zone. As a designer, I believe that we should not design in isolation, especially when designing to address social issues. Instead, we should design with local communities and honour existing knowledge. For this reason, I found the case study research method rewarding as I could connect with and honour the existing knowledge and efforts of two New Zealand dairy producers. I found value in learning what is already being done to address animal welfare and environmental sustainability issues within New Zealand and identifying how design could assist these efforts.

Another aspect of my research that was rewarding was The Dairy Oracle event. In the past, I have had little to no opportunities to understand how my designs exist in the world. Despite the public engagement event being rather challenging due to time constraints and a low engagement rate, the responses from the few people who engaged with The Dairy Oracle were valuable to understanding how people interacted and interpreted the design and provided insight into the future research directions. These insights would not have been possible without public engagement. 


\section{REFERENCES}


Baskaran, R., Cullen, R., \& Colombo, S. (2009). Estimating values of environmental impacts of dairy farming in New Zealand. New Zealand Journal of Agricultural Research, 52(4), 377-389. https://doi.org/10.1080/00288230909510520

Boogaard, B. K., Bock, B. B.,Oosting, S. J., Wiskerke, J. S. C., van der Zijpp, A. J. (2011). Social acceptance of dairy farming: the ambivalence between the two faces of modernity. Journal of Agricultural \& Environmental Ethics, 24(3), 259-282. https://doi.org/10.1007/s10806-010-9256-4

Braun, V., \& Clarke, V. (2012). Thematic analysis. In APA handbook of research methods in psychology, Vol 2: Research designs: Quantitative, qualitative, neuropsychological, and biological (pp. 57-71). American Psychological Association. https://doi.org/10.1037/13620-004

Britannica, T. Editors of Encyclopaedia (2017, June 28). Intensive agriculture. Encyclopedia. Britannica. https://www.britannica.com/topic/intensive-agriculture

Cardoso, C. S., José Hötzel, M., Weary, D. M., Robbins, J. A., \& von Keyserlingk, M. A. G. (2016). Imagining the ideal dairy farm. Journal of Dairy Science, 99(2), 1663-1671. https://doi.org/10.3168/jds.2015-9925

Centers for Diseaese Control and Prevention. (2018, Novemeber 5). One health basics. https://www.cdc.gov/onehealth/basics/index.html

Coeio. (n.d). The story of a green burial company. Coeio. https://coeio.com/coeio-story/

Costanza-Chock, S. (2020). Design justice: community-led practices to build the worlds we need. The MIT Press.

Dairy NZ. (2019, July 1). Insight into winter on dairy farms. DairyNZ. https://www.dairynznewslink.co.nz/wintering/winter-on-dairy-farms

Dairy NZ. (n.d). Transporting calves. https://www.dairynz.co.nz/animal/calves/bobby-calves/transporting-calves/

DeMello, M. (2018). Online animal (auto-)biographies: what does it mean when we "give animals a voice?" In A. Krebber \& M. Roscher (Eds.), Animal Biography (pp. 243-259). Springer International Publishing. https://doi.org/10.1007/978-3-319-98288-5_13 
Design Justice Network. (n.d). Design justice network principles. Design Justice Network. https://designjustice.org/read-the-principles

Dolejšová, M. (2021). Edible speculations: Designing everyday oracles for food futures. Global Discourse, (11)1-2. $10.1332 / 204378920 X 16069559218265$

Dunne, A., \& Raby, F. (2013). Speculative everything: design, fiction, and social dreaming. The MIT Press.

Foote, K. J., Joy, M. K., \& Death, R. G. (2015). New Zealand dairy farming: milking our environment for all its worth. Environmental Management (New York), 56(3), 709-720. https://doi.org/10.1007/s00267-015-0517-X

Galletta, A., \& Cross, W. (2013). The semi-structured interview as a repertoire of possibilities. In Mastering the semi-structured interview and beyond: from research design to analysis and publication (pp. 45-72). NYU Press.

Galloway, A., \& Caudwell, C. (2019). Speculative design as research method: From answers to questions and "staying with the trouble". In Coombs, G., McNamara, A., \& Sade, G. (Eds.), Undesign: critical practices at the intersection of art and design (pp. 8596). Routledge.

Gillespie, K. (2018). The Cow with Ear Tag \#1389. University of Chicago Press.

Hanington, B., \& Martin, B. (2012). Universal methods of design: 100 ways to explore complex problems, develop innovative strategies, and deliver effective design solutions. Rockport Publishers.

Happy Cow Milk. (2019, November 14). Meet our first Happy Cow farmer. https://happycowmilk.co.nz/meet-our-first-happy-cow-farmer/

Happy Cow Milk. (n.d1). Home. https://happycowmilk.co.nz/

Happy Cow Milk. (n.d2). Principles. https://happycowmilk.co.nz/happy-cow-way/

Happy Cow Milk. (n.d3). Our Story. https://happycowmilk.co.nz/the-story-of-happy-cow-milk-company/

Haraway, D. (2018). Staying with the trouble for multispecies environmental justice. Dialogues in Human Geography, 8(1), $102-105$. https://doi.org/10.1177/2043820617739208

Herud, G. (2018, April 21). I founded Happy Cow Milk to make a difference to dairying. I failed. The Spinoff. https://thespinoff.co.nz/business/21-04-2018/i-founded-happy-cow-to-make-a-difference-in-dairying-i-failed/ 
Jain A. (2020, February 20). Calling for a more-than-human politics. Medium.

https://medium.com/@anabjain/calling-for-a-more-than-human-politics-f558b57983e6

Jain, A. (2018). More-than-human centred design. Open Transcripts.

http://opentranscripts.org/transcript/more-than-human-centred-design/

Joy, M. (2015) Polluted inheritance: New Zealand's freshwater crisis. Bridget Williams Books Limited.

Le Guin, U. K. (2009). Animals in children's literature. In U.K. Le Guin (Ed.), Cheek by Jowl (pp. 43 - 108). Aqueduct Press.

Lee, J.R. (2011). My mushroom burial suit. [video] TED Conferences. https://www.ted.com/talks/jae_rhim_lee_my_mushroom_burial_suit

Markussen, T. (2013). The disruptive aesthetics of design activism: enacting design between art and politics. Design Issues, 29(1), 3850. https://www.jstor.org/stable/24267101

Mellor, D. J. (2017). Operational details of the five Domains model and its key applications to the assessment and management of animal welfare. Animals, 7 (8). https://doi.org/10.3390/ani7080060

Ministry of the Environment. (2021, April). Agricultural emissions and climate change. Ministry of the Environment. https://environment.govt.nz/guides/agriculture-emissions-climate-change/

Neira, J. (2017). Sickly 'pollution popsicles' highlight the problem of water contamination in Taiwan. Design Boom. https://www.designboom.com/art/polluted-water-popsicles-06-08-2017/

NZ Herald. (2020, October 7). How to marry green farming \& business success. https://www.nzherald.co.nz/the-vision-is-clear/news/how-to-marry-green-farming-business-success/2KDIWE2S4L5BZUH XBKW5OPAERI/

One Welfare. (n.d). About one welfare. https://www.onewelfareworld.org/about.html

Placzek, M., Christoph-Schulz, I., \& Barth, K. (2020). Public attitude towards cow-calf separation and other common practices of calf rearing in dairy farming - a review. Organic Agriculture. https://doi.org/10.1007/s13165-020-00321-3

Rittel, H. W. J., \& Webber, M. M. (1973). Dilemmas in a general theory of planning. Policy Sciences, 4(2), 155-169. http://www.jstor.org/stable/4531523 
Rodríguez Ramírez, E.R. (2017). A postgraduate thesis model for research through design based on design criteria. The International Journal of Designed Objects, 11(4). 11-27. doi:10.18848/2325-1379/CGP/v11i04/11-27

RSPCA. (2020, May 19). What is 'one welfare'?. https://kb.rspca.org.au/knowledgebase/what-is-one-welfare/\#ftn1

RSPCA. (n.d). What happens to bobby calves?. https://kb.rspca.org.au/knowledgebase/what-happens-to-bobby-calves/

Saint Thomas, S. (2020, February 16). How oracle cards are different from tarot. Allure. https://www.allure.com/gallery/oracle-cards-best-decks

Smith, E. W. (2020, January 24). How to add oracle cards to your tarot practice. Refinery29. https://www.refinery29.com/en-us/oracle-cards-reading

SpeculativeEdu. (2019, June 27). Approaches, methods and tools for speculative design. SpeculativeEdu. https://speculativeedu.eu/approaches-methods-and-tools-for-speculative-design/

Stafford, K. (2013). Animal welfare in New Zealand (1 $1^{\text {st }}$ ed.). New Zealand Society of Animal Production Inc.

Statistics NZ. (2019, April 18). Nitrate leaching from livestock. Statistics, NZ. https://www.stats.govt.nz/indicators/nitrate-leaching-from-livestock

Statistics NZ. (2020, January 30). Records all round for dairy and meat exports. https://www.stats.govt.nz/news/records-all-round-for-dairy-and-meat-exports

Superflux. (n.d). Instant archetypes: a toolkit to imagine plural futures. https://superflux.in/index.php/and-now-for-something-completely-different/\#

Superflux. (2019). Mitigation of shock (London). https://superflux.in/index.php/work/mitigation-of-shock/\#

Superflux. (2021). Refuge for resurgence at La Biennale Di Venezia 2021. https://superflux.in/index.php/work/refuge-for-resurgence/\#

Tam, A. L. (n.d). The Ultimate Milk Cow. https://adelaidetam.net/the-ultimate-milk-cow

Tharp, B., \& Tharp, S. (2018). Discursive design: critical, speculative, and alternative things. The MIT Press. 
Thorpe, A. (n.d). Design as Activism: to resist or to generate. Current. https://current.ecuad.ca/design-as-activism-to-resist-or-to-generate

Transfeminist Technologies \& Coding Rights. (n.d). The Oracle for Transfeminist Technologies. https://www.transfeministech.codingrights.org/

Velten, H. (2007). Cow. London: Reaktion Books, Limited.

Weary, D. M., \& von Keyserlingk, M. A. G. (2017). Public concerns about dairy-cow welfare: how should the industry respond?. Animal Production Science, 57 (7). 1201-1209. http://dx.doi.org/10.1071/AN16680

Young, R. (2018). The secret life of cows. Faber \& Faber Limited. 
Aguilera, L. (2010). How to create a vintage squid illustration [online image]. Envantotuts+.

https://design.tutsplus.com/tutorials/how-to-create-a-vintage-squid-illustration--psd-9629

Carhart, T. (2021, April 20). Design justice principles in philanthropy workshop: April $14^{\text {th }}$ report back [Digital Image]. Design Justice Network. https://designjustice.org/news-1/2021/philanthropy-workshop

Coeio. (n.d). The story of a green burial company - chapter II: the suit [Photograph]. http://coeio.com/coeio-story/

Corn the Sheep [online image]. (n.d). Miniature Calendar. https://miniature-calendar.com/160820/

Dolejšová, M. (n.d). The parlour of food futures [Photograph]. https://materie.me/foodparlour

Ferreira, M. (2011). [Online image of crafted diorama]. Flickr. https://www.flickr.com/photos/marcellaferreira/6433220065/

Freshwater, M. (n.d). [Photograph of In Vitro Cultured Lamb]. Modern Farmer. https://modernfarmer.com/2014/02/internet-wooly-things/

Happy Cow Milk. (n.d4). Plastic is out, re-usable is in! [Online image]. https://happycowmilk.co.nz/buy-happy-cow-milk/

Hoppy bunny thanksgiving dinner [online image]. (2011). The Bare Bear Workbench. http://thebarebearworkbench.blogspot.com/2011/01/hoppy-bunny-thanksgiving-dinner-diorama.html

PETA [@peta]. (2020a, May 26). “Their life is an endless cycle. They're impregnated, their babies are taken, and they're milked over and over until they're killed. Just so humans can steal their milk”. [Photograph]. Instagram. https://www.instagram.com/p/CAntEVanvck/

PETA [@peta]. (2020b, April 1). "Baby cows are separated from their mothers then kept behind bars until they're slaughtered, just weeks later - all for cheese. \#DitchDairy. [Photograph]. Instagram. https://www.instagram.com/p/B-aizEonUlm/

SAFE New Zealand [@safenewzealand]. (2020a, August 14). "Her milk is made especially for her baby calf. It helps him/her grow to 30o$400 \mathrm{~kg}$ in the first year of his/her life. That's why her milk contains a lot of fat, hormones and proteins. Just right for a calf, less suited - and even harmful for a human." [Photograph]. Instagram. https://www.instagram.com/p/CD2iZ5FB]8Y/ 
SAFE New Zealand [@safenewzealand]. (2020b, July 21). "“If we could live happy and healthy lives without harming others ... why wouldn't we?”@edgarmission”. [Photograph]. Instagram. https://www.instagram.com/p/CC5LeziB_hX/

Schmidt, C. (n.d). Weekend project: create your own photo-illustrations [online image]. Digital SLR Photography. https://digitalslrphoto.raspberrypi.org/articles/project-create-your-own-photo-illustrations

Sierzputowski, K. (2017, June 7). Pollution popsicles: faux frozen treats highlight Taiwan's water pollution problem [Photograph]. Colossal. https://www.thisiscolossal.com/2017/06/polluted-water-popsicles/

Superflux. (n.d). Instant archetypes: a toolkit to imagine plural futures [Photograph]. https://superflux.in/index.php/and-now-for-something-completely-different/\#

Superflux. (2019). Mitigation of shock (London) [Photograph]. https://superflux.in/index.php/work/mitigation-of-shock/\#

Superflux. (2021). Refuge for resurgence at La Biennale Di Venezia 2021 [Photograph]. https://superflux.in/index.php/work/refuge-for-resurgence/\#

Tam, A. L. (n.d). The ultimate milk cow [Photograph]. https://adelaidetam.net/the-ultimate-milk-cow

The oracle for transfeminist technologies [Online image]. (n.d). Transfeminist Technologies \& Coding Rights. https://www.transfeministech.codingrights.org/

[Untitled photograph of sheep figures]. (n.d). Pinterest. https://www.pinterest.nz/pin/416090453049174544/

[Untitled photographic collage of girl sleeping in a valley]. (n.d). Pinterest. https://www.pinterest.ch/pin/667095763528813281/

[Untitled photographic collage of man playing golf on peas]. (n.d). Fubiz.

http://www.fubiz.net/2016/05/09/surrealist-collages-playing-with-stereotypes/ 
Glen:

1. What is your history with dairy farming?

2. What motivated you to start-up Happy Cow Milk? What issues about dairy farming led you to make changes?

3. Can you describe the Happy Cow Milk business model?

4. How would you describe the relationships Happy Cow farmers have with their cows and the land?

5. Can you tell me more about the cow and calf policy? What motivated you to include this policy?

6. How do you know a cow is happy? What do you need to do to keep a cow happy?

7. What do you consider the greatest threats to cow welfare?

8. Are you familiar with the Five Freedoms? Do you think they are sufficient?

9. Are you familiar Five Domains model? What do you see as the biggest challenge in adopting this model instead?

10. What kinds of responses have you received from other dairy farmers about the Happy Cow Milk model?

11. What perception do you think the general public (consumers) has of dairy farmers? Is there anything you think the general public don't understand about dairy farming?

12. How do non-farmers respond to the Happy Cow model?

13. If you could change one thing in dairy farming to improve cow welfare, what would it be?

14. If you could keep one thing about New Zealand dairy farming culture, what would it be?

Chris:

1. What brought you into dairy farming? How long have you been doing this?

2. What motivated you to become a Happy Cow Milk farmer?

3. How would you describe the farming system you use?

4. How would you describe your relationship with the land you farm?

5. How would you describe the relationship you have with your cows? (What roles do you play in their life? What roles do they play in your life?)

6. What does it mean to you to "take good care of cows"?

7. How do you know a cow is happy? What do you need to understand or do to keep a cow happy?
8. What do you consider the greatest threats to cow welfare?

9. Are you familiar with the Five Freedoms? Do you think they are sufficient?

10. Are you familiar Five Domains model? What do you see as the biggest challenge in adopting this model instead?

11. What perception do you think the general public has of dairy farmers? Is there anything you think the general public (consumers) don't understand about dairy farming?

12. What kind of response does your model of dairy farming / the Happy Cow Milk model get from non-farmers? What about from other dairy farmers?

13. If you could change one thing in dairy farming to improve cow welfare, what would it be?

14. If you could keep one thing about New Zealand dairy farming culture, what would it be?

\section{Follow-up questions:}

1. How would you describe a 'traditional' or 'typical' NZ dairy farmer's relationship with the land, water and air? What about with the animals (cows, calves and bulls)?

2. What do you think the biggest environmental concerns for NZ dairy farming are?

3. How does Happy Cow / your farm respond to these or other environmental concerns?

4. What do you think the biggest animal welfare concerns for NZ dairy farming are?

5. How do you think that Happy Cow / your farm stands to improve cow welfare? How are you assessing cow well-being? Do you have any concerns about company policy or NZ regulations/laws?

6. What kind of future dairy farming scenario scares or angers you? Why?

7. What kind future dairy farming scenario brings you hope and joy? Why? 
Human Ethics Application Approved (as a Category B) 0000028885 Vs N/A Automated Email

researchmaster-help@vuw.ac.nz <researchmaster-help@vuw.ac.nz>

Thu 15/10/2020 921 PM

\section{Kia ora Lily,}

Application ID: 0000028885 Vs N/A

Title: Imagining NZ Dairy Futures

Primary investigator: Lily Nichols

Thank you for your application for human ethics approval. Your project, as described in the

application, is approved as of today. Your approval applies for three years from the date of this

If you would like to receive a formal letter, please contact the Research Office. If you need to make changes to your project, you will need to apply for an amendment to this application.

Best wishes with the research.

Ngā mihi,

the Research Office 


\section{Z WELLINGTON \\ WELLINGTON}

\section{Imagining NZ Dairy Futures}

\section{INFORMATION SHEET FOR PARTICIPANTS}

You are invited to take part in this research. Please read this information before deciding whether or not to take part If you decide to participate, thank you If you decide not to participate, thank you for considering this request.

\section{Who am I?}

My name is Lily Nichols and I am a Master of Design Innovation student at Victoria University of Wellington. This research project is work towards my thesis portfolio.

\section{What is the aim of the project?}

This project aims to provide a case study in speculative design for New Zealand dairy futures. Starting with a small-scale ethnographic study of dairy farming and farmer-cow relations, my research aims to ground itself in lived experience before imagining what might come next. You participation will support this research by sharing your knowledge about dairy farming in New Zealand and the relationships you have with your cows. This research has been approved by the Victoria University of Wellington Human Ethics Committee \#0000028885.

\section{How can you help?}

You have been invited to participate because I am interested in dairy farming and the work you do, and I believe your knowledge in the field will be valuable to my research. If you agree to take part, I will first interview you via Zoom. If the COVID-19 situation permits, I will also

conduct a 1-2 days farm visit to learn more about how you interact with your cows. This could be mostly observational, but I would welcome the opportunity to work alongside you as much as possible. Your consent will be sought before any photographs or video of this visit are used in the final report.

In our interview, I will ask you questions about Happy Cow Milk Company and your experience as a dairy farmer. The interview will take 45-60 minutes. I will video record the interview with your permission and write it up later. You can choose to not answer any question or stop the interview at any time, without giving a reason. You can withdraw from the study by contacting me at any time before $01 / 12 / 2020$. If you withdraw, the information you provided will be destroyed or returned to you.
What will happen to the information you give?

You will be given the opportunity to be identified by role or by name, but your organisation will be named.

You will have the opportunity to review a summary of our interview and my site visit, and to correct any misunderstandings or direct quotes.

Only my supervisor and I will read the transcript of the interview and notes on my visit. The interview transcripts, summaries and any recordings will be kept securely and destroyed on $12 / 07 / 2021$

\section{What will the project produce?}

The information from my research will be used to produce a speculative design for my Masters research portfolio. I may also use the information you provide for academic publication and/or presentation.

\section{If you accept this invitation, what are your rights as a research participant?}

You do not have to accept this invitation if you don't want to. If you do decide to participate, you have the right to:

choose not to answer any question;

- ask for recording to be turned off at any time during the interview;

- $\quad$ withdraw from the study before $01 / 12 / 2020$;

- ask any questions about the study at any time;

- read over and comment on a written summary of your interview and my participant observation;

- be able to read any reports of this research by emailing the researcher to request a copy.

If you have any questions or problems, who can you contact?

If you have any questions, either now or in the future, please feel free to contact either:

Student:

Supervisor:

Lily Nichol

Dr Anne Galloway

\section{Human Ethics Committee information}

If you have any concerns about the ethical conduct of the research you may contact the Victoria University of Wellington HEC Convenor: Associate Professor Judith Loveridge. Email 


\section{VICTORIA UNIVERSITY OF \\ TE HERENGA WAKA}

\section{Imagining NZ Dairy Futures}

\section{CONSENT TO INTERVIEW \& PARTICIPANT OBSERVATION}

This consent form will be held for 5 years.
Signature of participant:

Name of participant

Date:

Contact details

Researcher: Lily Nichols, FADI, Victoria University of Wellington

- I have read the Information Sheet and the project has been explained to me. My questions have been answered to my satisfaction. I understand that I can ask further questions at any time.

- I agree to take part in an audio-video recorded interview and participant observation.

I understand that:

- I will be given a summary of my interview and the site visit, and the opportunity to correct any misunderstandings or direct quotes.

- My consent will be sought before any photos or videos are used in the design or final report.

- I understand that the results will be used for a Masters report, academic publications and/or presentations.

- I may withdraw from this study at any point before $1 / 12 / 2020$, and any information that have provided will be returned to me or destroyed.

- The identifiable information I have provided will be destroyed by 12/07/2021.

- I understand that organisational consent has been provided and the organisation will be named in the reports.

- | consent to information or opinions which I have given being attributed Yes $\square$ No $\square$ to me in any reports on this research.

- | would like a summary of my interview $\quad$ Yes $\square$ No $\square$

- $\quad$ I would like to receive a copy of the final report and have added my email Yes $\square$ No $\square$ address below. 


\section{Z WELLINGTON \\ WELLINGTON}

\section{Imagining NZ Dairy Futures}

\section{INFORMATION SHEET FOR ORGANISATIONS}

Thank you for your interest in this project. Please read this information before deciding whether or not your organisation will take part. If you decide to participate, thank you. If you decide not to take part, thank you for consider

\section{Who am I?}

My name is Lily Nichols and I am a Master of Design Innovation student at Victoria University of Wellington. This research project is work towards my thesis portfolio.

\section{What is the aim of the project?}

This project aims to provide a case study in speculative design for New Zealand dairy futures. Starting with a small-scale ethnographic study of dairy farming and farmer-cow relations, my research aims to ground itself in lived experience before imagining what might come next. Your participation will support this research by sharing your knowledge about dairy farming in New Zealand and the relationships you have with your cows. This research has been approved by the Victoria University of Wellington Human Ethics Committee $\# 0000028885$.

\section{How can you help?}

If you agree to take part, I will interview you and one of your contractors. I will ask questions about Happy Cow Milk and dairy farming experiences. The interviews will take place via Zoom and will take 45-60 minutes, at a time convenient to you. Participants will be asked to provide consent before the interview begins. I will video record the interview with the permission of the participants and write it up later. If travel is permitted, I will also observe you and one of your contractors during 1-2 day farm visits in order to learn more about how you interact with your cows.

Participants will be asked to provide consent before their involvement in the research and given the opportunity to be identified by role or by name in the research outputs.
What will happen to the information the participants give?

Participants will be given the opportunity to be identified by role or by name, but your organisation will be named.

Only my supervisor and I will have access to any information you provide. The interview transcripts, summaries and any recordings will be kept securely and destroyed on 12/07/2021.

\section{What will the project produce?}

The information from my research will be used to produce a speculative design for my Masters research portfolio. I may also use this information for academic publication and/or presentation.

\section{If you accept this invitation, what are the rights of your organisation?}

You do not have to accept this invitation if you don't want to. If you do decide that you organisation will participate, you have the right to:

- $\quad$ ask any questions about the study at any time;

- withdraw your organisation's participation from the study before $01 / 12 / 2020$

- be able to read a report of this research.

If you have any questions or problems, who can you contact?

If you have any questions, either now or in the future, please feel free to contact either:

Student:

Supervisor:

Lily Nichols

Dr Anne Galloway

\section{Human Ethics Committee information}

If you have any concerns about the ethical conduct of the research you may contact the Convenor of the Victoria University of Wellington Human Ethics Committee: Associate Professor Judith Loveridge, email hec@vuw.ac.nz or telephone +64-4-4636028. 


\section{VICTORIA UNIVERSITY OF \\ TE HERENGA WAKA}

\section{Imagining NZ Dairy Futures}

CONSENT TO PARTICIPATE (ORGANISATION)

This consent form will be held for 5 years.

Researcher: Lily Nichols, FADI, Victoria University of Wellington.

- I have read the Information Sheet and the project has been explained to me. My questions have been answered to my satisfaction. I understand that I can ask further questions at any time.

- $\quad$ agree that my organisation will take part.

I understand that:

- I may withdraw this organisation from this study at any point before $1 / 12 / 2020$

- Any information the participants provide will be included in a final report but the transcripts, observation notes and recordings will be kept confidential to the researcher and the supervisor.

- The participants will be given the opportunity to be identified by role or by name.

- I understand that the results will be used for a Masters report, academic publications and/or presentations.

- I consent to information or opinions which are given by the participants

being attributed to the organisation in any reports on this research and Yes $\square$ No $\square$ have the authority to agree to this on behalf of the organisation.

- I would like to receive a copy of the final report and have added my email Yes $\square$ № $\square$ address below.

\section{Signature of participant:}

Name of participant:

Name of organisation:

Date:

Contact details: 
Amendment/extensions to Human Ethics Application approved 0000028885 Vs 1 researchmaster-help@vuw.ac.nz <researchmaster-help@vuw.ac.nz>

Tue 2/03/2021 156 PM

\section{Kia ora Lily,}

Thank you for your application to amend/extend your human ethics approval.

The amendment/extension is approved as of today. In the case of an amendment, this approval is valid until the end date of your original ethics approval; in the case of an extension, this approval applies until the new end date that you have nominated.

Application ID: 0000028885 Vs 1

Primary investigator: Lily Nichols

If you would like to receive a formal letter, please contact the Research Office. If you need to make further changes to your project, you will need to apply for another amendment to this application.

Best wishes with the research.

Ngā mihi,

the Research Office 


\section{MOO-VING}

FORWARD:

\section{THE DAIRY \\ ORACLE}

Hello! I'm Lily Nichols, a Master of Design Innovation student at Victori University of Wellington and I am currently working towards my thesis.

My research question is: how might speculative design be used to collectively re-imagine New Zealand dairy futures, including animal welfare and environmental sustainability concerns?

As part of my research, I've a designed a deck of oracle cards to get people thinking and talking about people, animal, and environmental futures for New Zealand dairy - and you are invited to a reading with The Dairy Oracle!

Your participation will be valuable to this research as it will provide insights into current public concerns for dairy farming practices in Zealand and perspectives on alternative future practices and scenarios. Zealan and pers collectively want to re-imagine.

This research has been approved by the Victoria University of Wellington Human Ethics Committee \#0000028885.

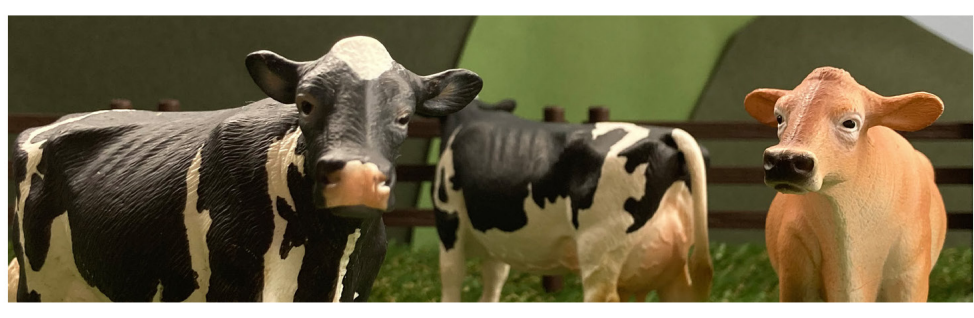

*Please turn over from more information.
Please note: Those under 18 are not eligible to participate but they may accompany an adult to the reading.

If you choose to participate:

- I will present you with 3 cards - each with a unique image and relationship.

- When I turn over each card, I will ask you to describe what you think the current relationship is and/or what you think the relationship could or should be. I may also ask you follow-up questions for clarification.

- Each card spread will be photographed, but you do not need to provide your name and you will not be photographed.

- Notes will be taken during and/or after each reading. Every effort will be made to accurately represent the conversation, but no comment will be connected to you.

Agreeing to participate in a reading with The Dairy Oracle confirms:

- You consent to participate in this research and have your un-attributed responses used in my Masters' report, and other research presentations and publications.

- You can stop the reading at any time without giving me a reason. If you ask to stop, all records of the reading will be destroyed.

Contact:

If you have any questions or concerns about this project please contact my academic supervisor:

Associate Professor Anne Galloway.

Human Ethics Committee information:

If you have any concerns about the ethical conduct of the research you may contact the Victoria University of Wellington HEC Convenor: 


\begin{tabular}{|c|c|c|}
\hline Breeding & $\begin{array}{l}\text { This card explores the practice of breeding } \\
\text { within dairy farming. Breeding is an } \\
\text { important part of dairy farming because } \\
\text { cows can only produce milk if they have } \\
\text { been pregnant. }\end{array}$ & $\begin{array}{l}\text { Can you tell me about your } \\
\text { understanding of how breeding works } \\
\text { in dairy farming? }\end{array}$ \\
\hline Working & $\begin{array}{l}\text { This card explores the work life of a dairy } \\
\text { cow. Dairy cows are valued for the milk } \\
\text { they produce. On most dairy farms, they } \\
\text { will get milked twice-a-day. }\end{array}$ & $\begin{array}{l}\text { What can you tell me about your } \\
\text { understanding of a cow's work life? }\end{array}$ \\
\hline Leisure & $\begin{array}{l}\text { This card explores the leisure life of a cow, } \\
\text { everything she is doing when she isn't } \\
\text { working. Cows are curious, social and } \\
\text { intelligent animals, and leisure time is } \\
\text { important for their mental wellbeing. }\end{array}$ & $\begin{array}{l}\text { What kinds of activities have you heard } \\
\text { a cow enjoys doing in their leisure time? }\end{array}$ \\
\hline Cow \& Calf & $\begin{array}{l}\text { This card explores the relationship between } \\
\text { and dairy cow and her calf. In the media, it } \\
\text { is reported that cow and calf separation is } \\
\text { causing concern. }\end{array}$ & $\begin{array}{l}\text { What does a typical cow and calf } \\
\text { relationship look like for you? }\end{array}$ \\
\hline Bobby calves & $\begin{array}{l}\text { This card explores the life of bobby calves. } \\
\text { Bobby calves are considered as a surplus } \\
\text { to the dairy industry, the way bobby calves } \\
\text { are managed causes concern. }\end{array}$ & $\begin{array}{l}\text { What can you tell me about your } \\
\text { understanding of bobby calves? }\end{array}$ \\
\hline $\begin{array}{l}\text { Cost of animal } \\
\text { welfare }\end{array}$ & $\begin{array}{l}\text { This card explores the cost of animal } \\
\text { welfare. There is an economic cost attached } \\
\text { to improving the welfare of dairy cows ... }\end{array}$ & $\begin{array}{l}\text { Who do you think currently covers the } \\
\text { cost of ensuring dairy cows live in a } \\
\text { safe environment and are cared for } \\
\text { physically and mentally? }\end{array}$ \\
\hline
\end{tabular}




\begin{tabular}{|c|c|c|}
\hline Cow Feed & $\begin{array}{l}\text { This card explores what cows eat. In New } \\
\text { Zealand, most cows graze on pastures but } \\
\text { when pasture growth is slow their feed will } \\
\text { sometimes be substituted with crops or } \\
\text { imported feed such as PKE. }\end{array}$ & $\begin{array}{l}\text { Can you tell me about your } \\
\text { understanding of a cow's diet? } \\
\text { Do you think it has an impact on the } \\
\text { environment? }\end{array}$ \\
\hline Soil & $\begin{array}{l}\text { This card explores soil. Soil health is a vital } \\
\text { part of dairy farming, but dairy farming } \\
\text { practices are known to cause it harm. }\end{array}$ & $\begin{array}{l}\text { How do you think dairy farming } \\
\text { currently impacts soil health? }\end{array}$ \\
\hline Air & $\begin{array}{l}\text { This card explores dairy farming and the } \\
\text { atmosphere. Agriculture makes up nearly } \\
\text { half of New Zealand's total GHG emissions, } \\
\text { and nearly a quarter of that is from dairy } \\
\text { farming. }\end{array}$ & $\begin{array}{l}\text { How do you think dairy farming } \\
\text { currently impacts the air quality? }\end{array}$ \\
\hline Water & $\begin{array}{l}\text { This card explores the water involved in } \\
\text { dairy farming; this includes waterways, } \\
\text { wetlands, and groundwater. In the } \\
\text { media, dairy farming is often criticised } \\
\text { for the impacts it has on New Zealand's } \\
\text { waterways. }\end{array}$ & $\begin{array}{l}\text { What is your understanding of } \\
\text { the impacts dairy farming has on } \\
\text { waterways? }\end{array}$ \\
\hline $\begin{array}{l}\text { Cost of } \\
\text { environmental } \\
\text { mitigation }\end{array}$ & $\begin{array}{l}\text { This card explores the cost of } \\
\text { environmental mitigation and who is } \\
\text { currently paying for it. Intensive dairy } \\
\text { farming has already had quite a significant } \\
\text { impact on, there is an economic cost to } \\
\text { repairing this damage and making sure it } \\
\text { doesn't continue to happen }\end{array}$ & $\begin{array}{l}\text { Who do you currently covers the cost of } \\
\text { environmental mitigation and repair? }\end{array}$ \\
\hline
\end{tabular}




\begin{tabular}{|c|c|c|}
\hline Farm workers & $\begin{array}{l}\text { This card explores farm workers. Having } \\
\text { reliable farm workers is important, so is } \\
\text { the relationships they form with others on } \\
\text { the farm. }\end{array}$ & $\begin{array}{l}\text { What do you think the most important } \\
\text { relationships are for farm workers? Is it } \\
\text { with other workers, management, the } \\
\text { animals, the environment? }\end{array}$ \\
\hline Non-farmer & $\begin{array}{l}\text { This card explores the non-farmers and } \\
\text { the relationship they have with farmers. } \\
\text { Typically, farmers and non-farmers are } \\
\text { quite disconnected from each other and } \\
\text { this can cause issues. }\end{array}$ & $\begin{array}{l}\text { How do you think farmers and non- } \\
\text { farmers currently communicate with } \\
\text { each other? }\end{array}$ \\
\hline Industry & $\begin{array}{l}\text { This card explores the dairy industry. The } \\
\text { dairy industry brings billions of dollars } \\
\text { into New Zealand's economy each year } \\
\text { by exporting dairy products, this level of } \\
\text { production puts pressure on farmers. }\end{array}$ & $\begin{array}{l}\text { How do you think the dairy industry } \\
\text { influences the way individual farms and } \\
\text { farmers operate? }\end{array}$ \\
\hline Farmer wellbeing & $\begin{array}{l}\text { This card explores farmer wellbeing both } \\
\text { on farm and off farm. Farmer wellbeing } \\
\text { is important, but it can often be neglected } \\
\text { which can impact a farmer's work life and } \\
\text { home life. }\end{array}$ & $\begin{array}{l}\text { What do you think farmer wellbeing } \\
\text { looks like? }\end{array}$ \\
\hline Farm ownership & $\begin{array}{l}\text { This card explores the different types of } \\
\text { farm ownership. As the dairy industry } \\
\text { grew, intensive, investor-owned dairy } \\
\text { farms become more prominent than } \\
\text { family-owned farms. }\end{array}$ & $\begin{array}{l}\text { What do you think are the differences } \\
\text { between family-owned and investor- } \\
\text { owned dairy farms? }\end{array}$ \\
\hline
\end{tabular}

\section{Future Prompts:}

Now that we've had a chat about the current

situation of dairy farming, I'm going to ask you to pick one card from the spread, maybe one that you find the most important, and think about what the future of that card should or could be.

- If you were to change at least one thing about ..., to improve animal/human/ environmental wellbeing what would it be?

- Do you have any ideas on how you might create this change? 